\title{
Cell Biology of Hyphal Growth
} GERO STEINBERG, ${ }^{1,2}$ MIGUEL A. PEÑALVA, ${ }^{3}$ MERITXELL RIQUELME,
HAN A. WÖSTEN, ${ }^{2}$ and STEVEN D. HARRIS ${ }^{5}$

${ }^{1}$ Department of Biosciences, College of Live and Environmental Sciences, University of Exeter, EX1 1TE Exeter, United Kingdom; ${ }^{2}$ Department of Biology, University of Utrecht, $3584 \mathrm{CH}$, Utrecht, The Netherlands; ${ }^{3}$ Department of Cellular and Molecular Biology, Centro de Investigaciones Biológicas CSIC, Madrid, 28040, Spain; ${ }^{4}$ Department of Microbiology, Center for Scientific Research and Higher Education of Ensenada, CICESE, Ensenada, Baja California C.P. 22860, Mexico; ${ }^{5}$ Center for Plant Science Innovation and Department of Plant Pathology, University of Nebraska, Lincoln, NE 68588-0660

\begin{abstract}
Filamentous fungi are a large and ancient clade of microorganisms that occupy a broad range of ecological niches. The success of filamentous fungi is largely due to their elongate hypha, a chain of cells, separated from each other by septa. Hyphae grow by polarized exocytosis at the apex, which allows the fungus to overcome long distances and invade many substrates, including soils and host tissues. Hyphal tip growth is initiated by establishment of a growth site and the subsequent maintenance of the growth axis, with transport of growth supplies, including membranes and proteins, delivered by motors along the cytoskeleton to the hyphal apex. Among the enzymes delivered are cell wall synthases that are exocytosed for local synthesis of the extracellular cell wall. Exocytosis is opposed by endocytic uptake of soluble and membrane-bound material into the cell. The first intracellular compartment in the endocytic pathway is the early endosomes, which emerge to perform essential additional functions as spatial organizers of the hyphal cell. Individual compartments within septated hyphae can communicate with each other via septal pores, which allow passage of cytoplasm or organelles to help differentiation within the mycelium. This article introduces the reader to more detailed aspects of hyphal growth in fungi.
\end{abstract}

\section{INTRODUCTION}

Filamentous fungi are a large and ancient clade of microorganisms that occupy a broad range of ecological niches $(\underline{1}, \underline{2})$. Fungi are recyclers, being major decomposers of plant debris ( $\underline{3})$; they form mycorrhizal symbiosis with $93 \%$ of all flowering plant families (4), and they serve in the industrial production of proteins $(\underline{5})$. However, fungi pose a threat to public health, the ecosystem, and our food security $(\underline{6}, \underline{7})$. The success of filamentous fungi is largely due to their elongate hypha, a chain of cells separated from each other by septa ( $\underline{8})$.
Hyphae grow rapidly by polarized exocytosis at the apex (9-11), which allows the fungus to extend over long distances and invade many substrates, including soils and host tissues. Hyphal tip growth is initiated by establishment of a growth site and the subsequent maintenance of the growth axis, with transport of growth supplies, including membranes and proteins, delivered by motors along the cytoskeleton to the hyphal apex (12). Among the enzymes delivered are cell wall synthases that are exocytosed for local synthesis of the extracellular cell wall (13). Exocytosis is opposed by endocytic uptake of soluble and membrane-bound material into the cell (14). The first intracellular compartment in the endocytic pathway is the early endosomes (EEs), which emerge to perform essential additional functions as spatial organizers of the hyphal cell (15). Individual compartments within septated hyphae can communicate with each other via septal pores, which allow passage of cytoplasm or organelles (16) to help differentiation within the mycelium (17). This article introduces the reader to more detailed aspects of hyphal growth in fungi.

Received: 28 November 2016, Accepted: 8 December 2016, Published: 21 April 2017

Editors: Joseph Heitman, Department of Molecular Genetics and Microbiology, Duke University Medical Center, Durham, NC 27710; Neil A. R. Gow, School of Medical Sciences, University of Aberdeen, Fosterhill, Aberdeen, AB25 2ZD, United Kingdom

Citation: Steinberg G, Peñalva MA, Riquelme M, Wösten HA, Harris SD. 2017. Cell biology of hyphal growth. Microbiol Spectrum 5(2): FUNK-0034-2016. doi:10.1128/microbiolspec.FUNK-0034-2016.

Correspondence: Gero Steinberg, gsteinberg@exeter.ac.uk (c) 2017 American Society for Microbiology. All rights reserved. 


\section{REGULATION OF HYPHAL MORPHOGENESIS}

Hyphal morphogenesis refers to the complex biological processes that directly contribute to the formation of highly polarized hyphae by filamentous fungi. The two fundamental processes that underlie hyphal morphogenesis are polarity establishment and polarity maintenance. The regulation of these processes over time and space presumably accounts for much of the variation in hyphal morphology and growth patterns observed in the filamentous fungi (18). Additional processes that contribute to the complexity of hyphal morphology in those filamentous fungi that belong to the Dikarya include septation and the formation of septal pores (19). The regulation of these processes must also play an important role in specifying the overall organization of hyphae in these fungi. Nevertheless, we are still at an early stage in understanding the temporal and spatial regulation of hyphal morphogenesis. Progress has been achieved in determining how hyphae maintain a polarity axis (20, 21), but we still know little about how polarization sites are initially established in germinating spores and during branch formation. In addition, much remains to be learned about when and where septa are made. The following sections will address these points, but before doing so, it is perhaps useful to focus on the broader regulatory issue of how morphogenesis is coordinated with hyphal growth.

Experimentally, we typically grow filamentous fungi and assess morphogenesis under conditions that are largely homogeneous and in which all needed nutrients are available. This is unlikely to be representative of conditions that hyphae would normally experience in their natural environment (though there are likely to be important exceptions). In reality, most hyphae propagate in a spatially heterogeneous environment that is characterized by a patchy distribution of nutrients. Accordingly, two possible strategies could conceivably be invoked to account for hyphal extension under variable conditions. First, hyphal growth could be a "bruteforce" mechanism by which a hypha harnesses the morphogenetic machinery (i.e., the cytoskeleton and vesicle trafficking machinery) and turgor pressure to plough ahead with colonization of the substrate. Extension rates and the frequency of branching may only be minimally adjusted to account for a changing environment. Alternatively, hyphae may fine-tune extension rates and morphogenesis to reflect the local environment at the tip and at incipient sites of branch formation. It seems reasonable to speculate that some combination of both strategies is deployed within a given mycelium. However, the latter strategy would seemingly rely more on the ability of hyphae to adjust the timing and location of polarization events, as well as to modulate the degree of polarity maintenance, in response to local environmental conditions. Insight into how this might occur comes from the model yeasts Saccharomyces cerevisiae and Schizosaccharomyces pombe. Both normally utilize an internal program to specify the position of localized cell surface expansion and cell wall deposition but are able to override the program in response to external signals such as mating pheromones (22). Accordingly, it is tempting to speculate that the signaling pathways that mediate growth and stress responses in filamentous fungi (e.g., TOR, PKA, HOG) likely interface with the mechanisms that temporally and spatially regulate hyphal morphogenesis. To date, little is known about how these pathways might impact hyphal morphogenesis, though there is growing evidence that they do mediate tropic responses that influence the directionality of hyphal extension (23). Characterization of the links between these pathways and the morphogenetic machinery would appear to be fertile territory for future investigation.

\section{Spatial Regulation of Hyphal Morphogenesis}

The key events underlying the spatial regulation of hyphal morphogenesis are the initial specification of a polarity axis (polarity establishment) and the subsequent stabilization of the axis (polarity maintenance). Two types of polarity establishment events are commonly observed in a typical hypha: spore polarization and branch formation (Fig. 1). In both cases, specification of a polarity axis occurs in a cell that is otherwise displaying isotropic or apolar growth (i.e., germinating spores or an existing hyphal compartment). Stabilization of the resulting axis requires the recruitment of the morphogenetic machinery to the specified site. As a result, cell surface expansion and cell wall deposition are subsequently confined to a discrete cortical site, which ultimately leads to the formation of a new hypha.

Detailed studies of $S$. cerevisiae and $S$. pombe have provided significant insight into the nature of the spatial landmarks that direct polarity establishment (22). $S$. cerevisiae utilizes a set of cortical landmark proteins (the Bud proteins) to specify new polarity axes (24), whereas $S$. pombe relies on microtubule-based delivery of a set of marker proteins (the Tea proteins) to position new growth sites $(\underline{25})$. By contrast, comparatively little is known about mechanisms that specify new polarity axes in filamentous fungi. The Tea proteins are reasonably well conserved (26) and play a fundamental role in regulating the directionality of hyphal extension (see below). A subset of the Bud proteins is also present in 


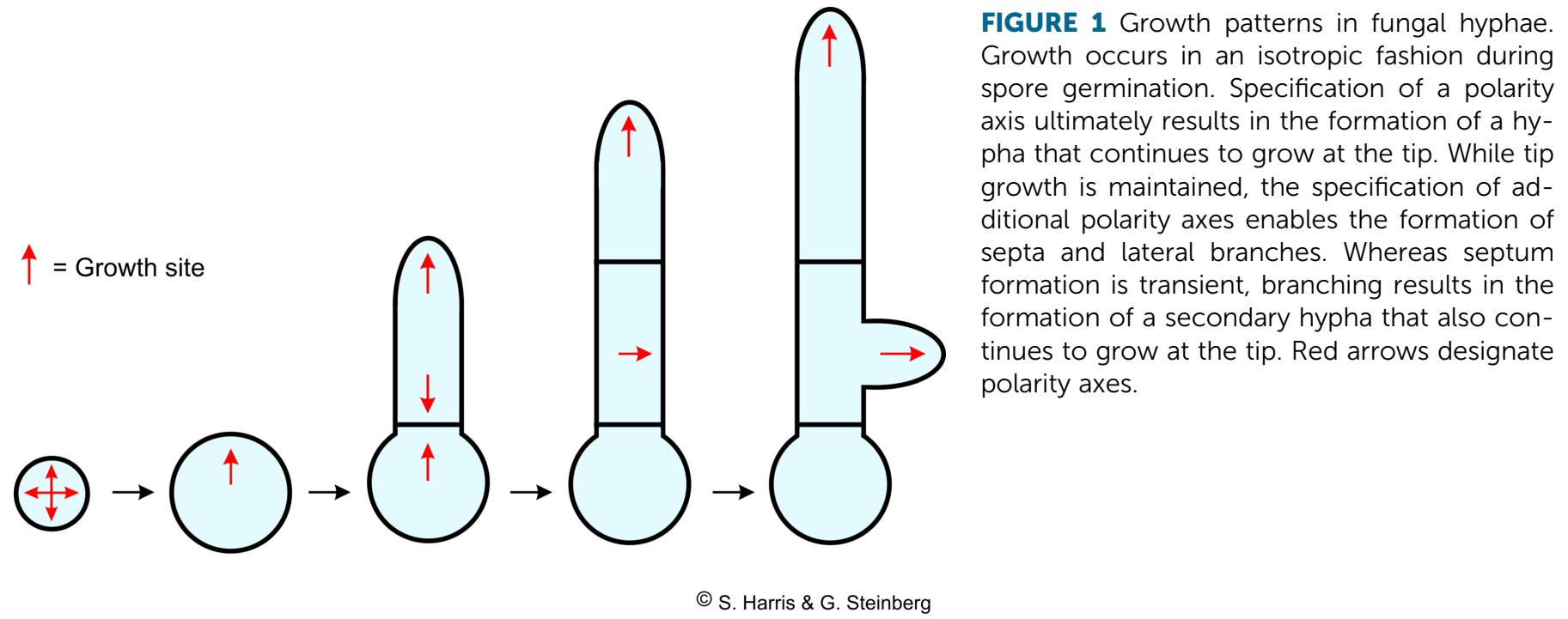

filamentous fungi $(\underline{27}, \underline{28})$, but instead they regulate septum formation (see below). Accordingly, at this time, the identities of any landmark/marker proteins that mediate polarity establishment in filamentous fungi remain a mystery. There is even some question as to whether a marking system is indeed necessary. Few examples of spatially biased spore polarization have been observed (e.g., reference 23), and when reported, it is in response to signals emanating from a potential plant host. Indeed, for those fungi whose spores are capable of producing multiple hyphae, it appears to be more important to ensure that the second polarity axis is opposite to the first. This type of bipolar spore polarization pattern is often observed and can be perturbed by disruption of the vesicle trafficking machinery, microtubules, and Tea marking system $(\underline{29}, \underline{30})$.

A unique feature of filamentous fungi that enables the formation of mycelia is the ability to simultaneously sustain multiple axes of hyphal polarity. These axes result in the formation of branches, either lateral branches that emerge from subapical compartments or apical branches that form by "splitting" of the hyphal tip (31). As with spore polarization, branch formation requires the initial specification of a polarity axis followed by its stabilization. To date, the extent to which branching occurs in a defined pattern has not been fully explored. Furthermore, relatively little is known about mechanisms potentially involved in spatial regulation of branch formation in filamentous fungi. Nevertheless, key clues have emerged from a limited number of studies. For example, in Aspergillus nidulans, the absence of the Cdc42 GTPase or the FadA heterotrimeric G protein complex largely abolishes the formation of lateral branches and suggests signaling pathways that might be required for the specification of branch sites (32) (S. Harris, unpublished results). More intriguingly, the well-characterized septins appear to play a critical role in the specification and/or stabilization of new polarity axes at lateral branch sites (33). Elegant work using Ashbya gossypii suggests that the pivotal function of septins at incipient branch sites is to recognize membrane curvature (34). Lastly, evidence suggests that some fungi (e.g., A. nidulans, Epichloe festucae) actively suppress lateral branch formation from regions adjacent to hyphal tips through the localized accumulation of reactive oxygen species mediated by NADPH oxidase complexes (35, 36). This presumably ensures that growth is directed toward the tip and facilitates migration away from depleted substrate when nutrients are scarce.

A key feature that distinguishes hyphae from yeast cells is their ability to sustain polarized growth over a considerable distance. This implies that the regulatory systems that stabilize polarity axes must be much more stringent in filamentous fungi to support the long-range vectorial delivery of secretory vesicles to the hyphal tip. Although several components of the morphogenetic machinery have been implicated in the maintenance of hyphal polarity $(\underline{20}, \underline{21})$, the nature and identity of any regulatory system that organizes the machinery and marks the hyphal tip remain elusive. It has been firmly established that spatially coupled exocytosis and endocytosis are essential for the stabilization of polarity axes $(\underline{37}, 38)$, and it has been suggested that this could reflect the need to recycle one or more cell surface markers 
that identify the hyphal tip $(39, \underline{40})$. It should also be added that a secondary role for the coupling of endocytosis with exocytosis might be to enable the spontaneous generation of local asymmetries that are then amplified to define a polarity axis if no functional marker is present. To date, the most compelling candidate for a hyphal tip marker is the A. nidulans TeaR protein (a homologue of the $S$. pombe mod5 cell end marker). TeaR is associated with exocytic vesicles that are transported on microtubules and delivered to the cell surface at the hyphal tip, where it mediates the local recruitment of the morphogenetic machinery (41). Recent evidence suggests that membrane-associated TeaR is rapidly dispersed at hyphal tips, only to be replenished again via microtubules (42). This result supports the existence of a dynamic feedback loop that continually establishes transient polarity axes at the hyphal tip that serve to maintain the overall direction of hyphal extension. The presence of lipid microdomains at hyphal tips and their importance in the formation of stable polarity axes raise the possibility that additional regulatory systems may operate in parallel with TeaR to mark the hyphal tip $(\underline{43}, \underline{44})$.

Filamentous fungi exhibit tropic responses to chemical, mechanical, electrical, and other environmental stimuli (see references $\underline{45}$ and $\underline{46}$ ). The dynamic nature of polarity maintenance provides a satisfying explanation for how the direction of hyphal extension can be rapidly reoriented in response to external signals. Moreover, it seems likely that the perception and transduction of external signals can override internally programmed polarity systems such as that mediated by TeaR. The demonstration that a chemotropic response is mediated by a cell surface pheromone receptor and a mitogenactivated protein kinase signaling pathway in the root colonizing fungus Fusarium oxysporum (23) provides some insight into how an existing polarity axis can be subverted by external signals.

\section{Temporal Regulation of Hyphal Morphogenesis}

In uninucleate fungal cells, the maintenance of nuclear content requires precise coordination of cellular morphogenesis with nuclear division. Mechanisms that couple these two processes have been described in some detail in $S$. cerevisiae and relatives. For example, in $S$. cerevisiae, regulatory mechanisms focused on the cyclin-dependent kinase (CDK) Cdc28 coordinate polarity transitions with nuclear division at multiple points in the cell cycle (47). Candida albicans is a polymorphic fungus that forms uninucleate hyphal cells, and here also, CDK plays a critical role in controlling the timing of polarity establishment, septum formation, and the transition from budding to hyphal growth (48). Key CDK targets include the septins and polarisome protein Spa2 $(49,50)$. The importance of CDK for the temporal coordination of morphogenesis with the cell cycle has also been documented in the plant pathogen Ustilago maydis (51).

In multinucleate fungal hyphae, the need to coordinate the timing of polarity establishment with nuclear division is not so apparent. Indeed, A. nidulans mutants incapable of nuclear division are able to form elongated hyphae (52), and mutants that fail to undergo spore polarization are able to complete multiple rounds of nuclear division (29). Despite this apparent lack of dependency, there is some evidence in Aspergillus species that polarity establishment and septum formation are under normal circumstances coordinated with nuclear division $(\underline{29}, \underline{53}, \underline{54})$. This presumably reflects the need to maintain a preferred ratio of cytoplasmic volume per nucleus in growing hyphae. The underlying process, which has been termed the duplication cycle (53), remains poorly characterized, and it is not even clear whether the phenomenon is broadly conserved. For example, hyphal compartments in Neurospora crassa and A. gossypii can possess $>100$ asynchronously dividing nuclei, and there is no apparent evidence that hyphal morphogenesis is temporally coupled to the division of these nuclei (e.g., reference 55). One final observation potentially refutes the notion that hyphal morphogenesis is not dependent on nuclear division in filamentous fungi. In particular, the temperature-sensitive A. nidulans $\operatorname{nim} L$, nimM, and $\operatorname{nim} N$ (never-in-mitosis) fail to undergo nuclear division and fail to establish polarity (unlike other nim mutants; references 29, 52, 56). These mutants are very sensitive to the DNA synthesis inhibitor hydroxyurea and share their polarization phenotype with wild-type conidia exposed to hydroxyurea (29). These observations suggest that completion of an as yet to be defined step in the $S$ phase of the cell cycle might be necessary for spore polarization to proceed.

\section{FUNGAL EXOCYTOSIS}

Hyphal growth occurs by apical extension. Cell wallmodifying enzymes, substrates, and the membrane required for cell expansion are delivered to the apex by exocytosis, which suggests that the filamentous habit of growth is strongly dependent on the secretory pathway. Such an apparently simple fact has major implications both in the fungal pathogenicity field (host invasion is 
dependent on apical extension) and in the field of biotechnology (filamentous fungi are major producers of industrial enzymes). The hyphal mode of growth and its dependence on exocytosis represent an experimental advantage, because mutations impairing exocytosis even to a minor extent often result in reduced colony growth, making them easily scorable (57). Moreover, mutations impairing exocytic regulators delay or preclude polarity establishment $(58,59)$ or, when inactivated by conditional mutations in rapidly growing hyphae, often result in a tip swelling (60), which can be used as a cellautonomous indicator of exocytic deficit.

\section{The Golgi and Its Regulation}

Although an increasing body of evidence supports the contention that unconventional protein secretion pathways do exist in fungi (61), these are relatively poorly understood. Therefore, this article will focus on the Golgi as the central hub in the conventional secretory pathway that sorts protein cargoes to their final destination, be it the extracellular milieu, the plasma membrane, or the endovacuolar system. Several recent reports testify to the interest that the mechanistic understanding of biosynthetic traffic is spawning. For brevity we will consider here reports using the genetic models A. nidulans and N. crassa. Pioneering work on motors that move carriers toward their destinations, carried out with $U$. maydis, will be considered below.

As in $S$. cerevisiae, in the filamentous ascomycetes A. nidulans and N. crassa the Golgi consists of isolated membrane-bound structures that do not pile up to form the characteristic stacks of mammalian cells $(\underline{62}, \underline{63})$. Even though these isolated membranous structures were initially denoted Golgi "equivalents," they are bona fide Golgi "cisternae," equivalent to those in other eukaryotes. Their nonstacked organization represents a major experimental advantage for live microscopy studies because cisternae can be resolved by diffraction-limited optical microscopy (64-66). When imaged with fluorescent proteins, the extensively studied Golgi of $A$. nidulans is seen as a dynamic network of ring-shaped and fenestrated cisternae, often interconnected by tubular structures $(64,67,68)$. This morphology is consistent with electron microscopy studies (summarized in reference 63).

The Golgi is an intrinsically transient and compositionally heterogeneous membranous entity that is constantly fed by anterograde coat protein complex II (COPII) carriers budding from transitional endoplasmic reticulum (ER) domains/ER exit sites (Fig. 2). An unanswered question in cell biology is how the protein cargo that exits the ER traffics across the Golgi apparatus and is sorted into plasma membrane- and endosome-bound carriers (69). It is widely accepted that this traffic occurs, at least in part, by cisternal maturation rather than by vesicle-mediated connections between stable cisternae. According to this view, early cisternae, which are formed by ER-derived traffic, progressively change their lipid and protein content, becoming not only gradually enriched in cargo but also, in the end, compositionally competent (see below) to break up into carrier vesicles destined for the plasma membrane and endosomes (Fig. 2). Cisternae at this final stage of maturation are denoted "late" or "TGN" cisternae (see below). The progressive attainment of late composition is thought to be mediated by retrograde COPI vesicle traffic retrieving to cisternae in earlier stages of maturation those components that do not belong to mature (i.e., later) stages (Fig. 2).

Strong support for the cisternal maturation model comes from ground-breaking studies of $S$. cerevisiae (70, 71) and from our own work in A. nidulans (Pantazopoulou and Peñalva, unpublished observations; see also below). However, readers should note that the maturation model very likely requires some modification to accommodate the involvement of tubular connections that are often observed between metazoan cisternae (and between fungal ones [68]). These connections could represent highways for certain types of cargo. The model also needs to accommodate the experimentally supported possibility that rapid partitioning mediated by domains of different lipid composition enables the budding of carriers at all levels (72; for overview see references 69,71 ). In a useful attempt to relate the compositional and morphological variety of the Golgi with specific roles, Glick and coworkers (3) have proposed that the Golgi consists of cisternae in three different functional stages (Fig. 2). We will use this scheme for further discussion.

In stage I, denoted "cisternal assembly," ER-derived COPII carriers coalesce to form cisternae (Fig. 2). During this stage, ER protein residents that escape to the Golgi incorporated into COPII carriers recycle to their normal destination using COPI-coated retrograde vesicles (74). This is the case, for example, for TM receptors such as A. nidulans RerA ${ }^{\text {Rer1 }}$, which sorts soluble cargo at the ER into anterograde COPII carriers, and for the syntaxin SedV $V^{\mathrm{Sed} 5}$, a key component of the SNARE machinery mediating membrane fusion at the Golgi (60, 64, 75). Membranes in stage I contain a network of peripheral proteins recruited to them by Golgi-specific GTPases that tether membranes, thereby facilitating fusion. Among them are A. nidulans $\mathrm{GrhA}^{\mathrm{Grh} 1}(\underline{68})$ and N. crassa USO-1 (65). As cisternae increase in size at the 


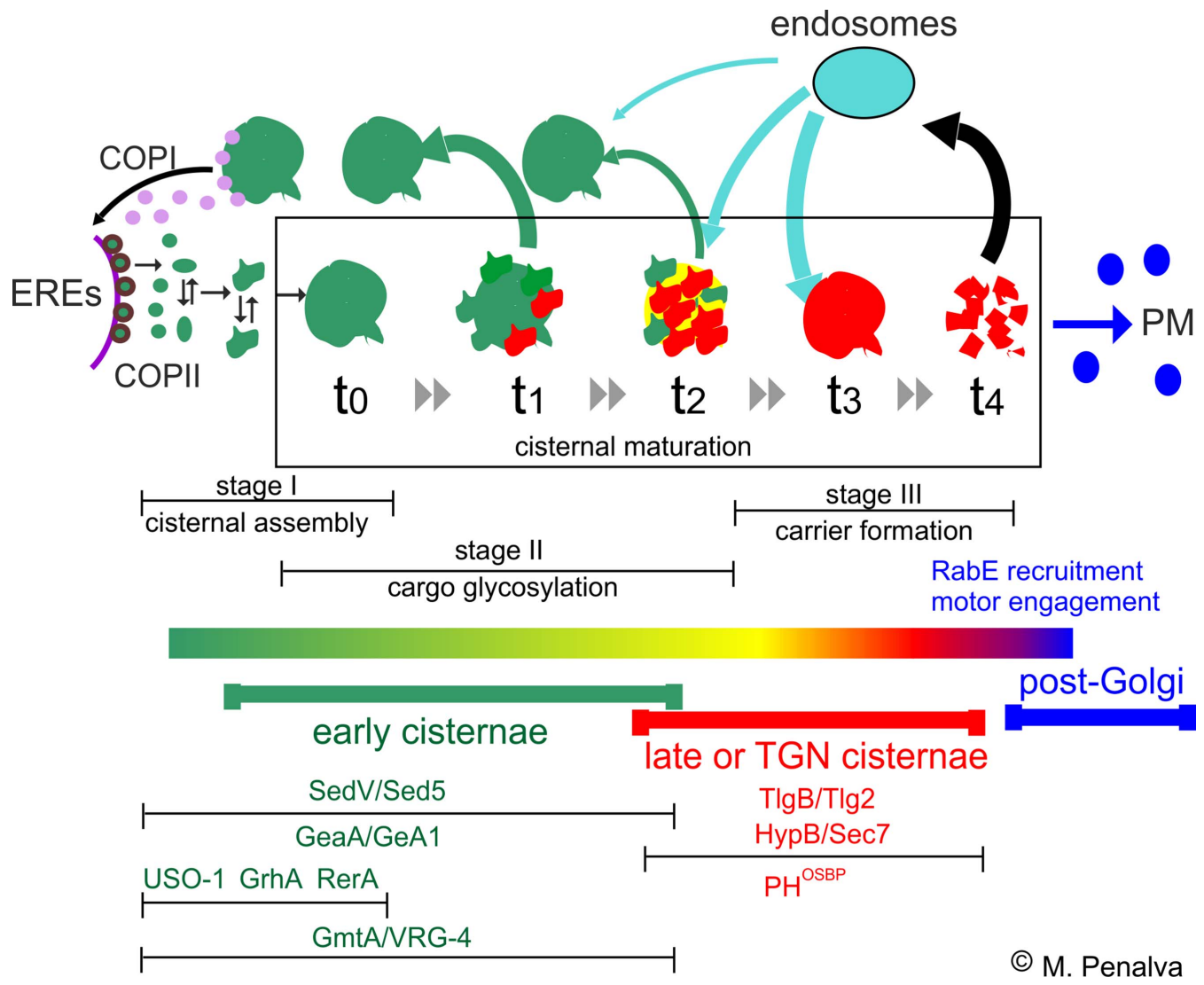

FIGURE 2 Highly schematic representation of the cisternal maturation process in the nonstacked fungal Golgi, with indication of the different functional stages. COPII-coated vesicles (green) bud off specialized domains of the ER denoted ER exit sites (ERES) or transitional ER (left). COPII vesicles coalesce to form an early Golgi cisterna, represented here as a green fenestrated structure that depicts actual Golgi structures often visible in EM micrographs. Retrograde COPI traffic (violet vesicles) retrieves back to the ER proteins such as cargo receptors that need to be recycled. Early cisternae are equipped with cargo glycosylation enzymes (t0). As time passes (double arrowheads) an early Golgi cisterna becomes progressively enriched in cargo and late Golgi components (represented in red) by delivering early Golgi ones (e.g., glycosylating enzymes) to cisternae in earlier stages of maturation, in a process which is likely mediated by COPI retrograde traffic (t1 and t2). Eventually, late Golgi components become predominate (TGN, t3) and the cargoenriched cisterna becomes competent to tear off into carriers destined for the plasma membrane (PM) and the endosomes (t4). TGN cisternae also receive traffic from the endosomal system (blue arrows). In the route (dark blue) connecting the cisternae with the PM, the transition between late Golgi and post-Golgi identity is dictated by the recruitment of RabE ${ }^{\text {RAB11 }}$ to the membranes, which is critically regulated by TRAPPII (see text). Proteins that have been shown by microscopy to localize to specific stages are indicated, with green lettering indicating early Golgi and red lettering indicating TGN. The image summarizes work performed with $A$. nidulans.

expense of heterotypic and homotypic fusion, they move on to functional stage II (Fig. 2).

Stage II is the glycosylation stage ( $\underline{73})$. Golgi cisternae at this stage, during which the definitive carbohydrate decoration of protein cargo is laid, are equipped with glycosidases and glycosyltransferases. Golgi glycosyl- transferases extend the $\mathrm{O}$-mannose core that is attached in the ER to a subset of cargoes, giving rise to the diverse species-specific $\mathrm{O}$-glycans decorating fungal secreted proteins. $\mathrm{N}$-glycosylated proteins are remodeled, after modification of core $\mathrm{N}$-glycan structures also added at the ER, by attachment of further polysaccharide chains 
of variable size and composition (76). These stage II cisternae are also armed with the transporters needed to import nucleotide diphosphate-activated monosaccharide precursors from the cytosol into the cisternal lumen. GDP-mannose transporters GmtA of A. nidulans (77) and VRG-4 of N. crassa (65), homologues of budding yeast $\operatorname{Vrg} 4 \mathrm{p}$ used in seminal studies on Golgi maturation (70), are useful to define this compartment. Cisternae at this stage no longer receive anterograde COPII carriers. However, stage II cisternae are also furnished with tethers and with the SedV ${ }^{\mathrm{Sed} 5}$ syntaxin to accept retrograde traffic (presumably COPI-mediated) that retrieves to them carbohydrate-modifying enzymes that escape to cisternae in a posterior stage (stage III) of maturation. The COG (conserved oligomeric Golgi) complex (78) also mediates the tethering of these intraGolgi carriers to stage II cisternae, such that deficient COG function results in glycosylation defects (79). The physiological importance of two A. nidulans Golgi COG components, PodB ${ }^{\operatorname{Cog} 2}$ and $\mathrm{SwoP}^{\mathrm{Cog} 4}$, has been demonstrated by showing that two classical ts alleles, podB1 (polarity defective) and swoP1 (swollen cell), cause polarization, cell wall, and protein glycosylation defects (80). The role of GmtA was established with the hyperbranching and hypomannosylating ts mutation calI11 (i.e., gmtA11), which results in calcofluor white sensitivity (77).

Cisternae that progress to stage III, denoted "carrier forming" (73), acquire a composition that enables them to generate anterograde carriers destined for the plasma membrane and the endosomes (Fig. 2) but that incapacitates them to generate retrograde COPI traffic destined for cisternae at earlier stages of maturation. Cisternae in this carrier-forming stage have been denoted the trans-Golgi network (TGN), by analogy to the most plasma membrane-proximal (trans) cisternae of the mammalian Golgi stacks. For all fungal purposes TGN is synonymous with "late Golgi." Traffic exiting the TGN toward endosomes is mediated by clathrincoated carriers that use AP-1, GGA (Golgi-localized, gamma adaptin ear-containing, ARF-binding), and epsin adaptors to sort appropriate cargo into the clathrin cage. In contrast, as discussed below, carriers connecting the TGN with the plasma membrane are atypical in that they do not appear to involve any protein coat. TGN membranes contain PtdIns4P and the late-Golgi Arf1 GEF (guanine nucleotide exchange factor) Sec7, which has been intensively studied in A. nidulans (60, 81- 14 ) and used as a prototypic TGN marker in both A. nidulans (68) and N. crassa (65). However, the most robust marker of the TGN is a fusion protein between
mRFP and the PH domain of the human oxysterol binding protein $\left(\mathrm{PH}^{\mathrm{OSBP}}\right)$. This chimera is recruited very efficiently and specifically to TGN cisternae by coincidence detection of active (i.e., GTP-loaded and membrane bound) Arf1 and PtdIns4P (ㅎ5).

The cisternal maturation model implies that TGN cisternae must dissipate as they break up into transport vesicles. A study of $A$. nidulans documented the process by which TGN cisternae give rise to post-Golgi carriers destined for the apical plasma membrane (82). During this process, cisternal membranes progressively lose Golgi identity (i.e., they lose $\mathrm{PH}^{\mathrm{OSBP}}$ [i.e., Arf1/PtdIns4P] and $\mathrm{HypB}^{\mathrm{Sec} 7}$ [the late Golgi Arf1 GEF]) as they become increasingly rich in $\mathrm{RabE}^{\mathrm{RAB} 11}$ (Ypt31/32p in budding yeast), the determinant of post-Golgi identity (2). By the time $\mathrm{RabE}^{\mathrm{RAB} 11}$ peaks at a maternal cisterna, the signal of $\operatorname{Sec} 7 / \mathrm{PH}^{\mathrm{OSBP}}$ has virtually disappeared. At this point, $\mathrm{RabE}^{\mathrm{RAB11}}$-rich membranes undergo rapid movement to the Spitzenkörper (SPK), using kinesin and myosin-5 motors that power their long-distance transport to the SPK (2), consistent with a model in which $\mathrm{RabE}^{\mathrm{RAB} 11}$ participates directly or indirectly in the recruitment of the motors (Fig. 2). The fact that cisternae that have acquired RabE $E^{\text {RAB11 }}$ and undergone movement toward the apex leave little signal of TGN markers behind strongly suggests that TGN cisternae largely dissipate into RabE ${ }^{\mathrm{RAB} 11}$ exocytic carriers, which represents strong evidence for a maturation-based mechanism determining the biogenesis of these carriers (82). The biogenesis of carriers destined for endosomes, which had been filmed in S. cerevisiae (6ㅡ), has been recently documented in A. nidulans (87).

Unlike early Golgi cisternae (stages I and II), TGN cisternae contain the t-SNARE $\mathrm{TlgB}^{\mathrm{Tlg} 2}$, which colocalizes with $\mathrm{PH}^{\mathrm{OSBP}}(\underline{60})$. $\mathrm{TlgB}^{\mathrm{Tlg} 2}$ is a $\mathrm{Qa}$ syntaxin that forms SNARE bundles with Vti1 as Qb-, TlgA ${ }^{\text {Tlg1 }}$ as Qc-, and SynA as R-SNARE (75). In all likelihood, this SNARE bundle mediates the fusion of retrograde traffic connecting the earliest endosomal compartment, to which SynA arrives by endocytosis, with the TGN. This is the pathway that is followed by proteins that, like SynA itself, are efficiently taken up by the subapical endocytic ring and pass through the TGN before returning by way of apex-directed exocytosis to the plasma membrane $(\underline{37}, \underline{64}, \underline{88})$. This earliest endosome, which for convenience is designated here as a "sorting endosome," should not be confused with the EEs, which are readily identifiable by their high motility on microtubule and the presence of the GTPase Rab5 (see below).

The SynA pathway is the one that must be responsible for the strong labeling of the SPK with the endocytic 
tracer FM4-64 (89). Another passenger of this pathway is the A. nidulans phospholipid flippase DnfA ${ }^{\text {Dnf1 }}$ (39). cis-acting mutations abolishing endocytosis of SynA (64) or DnfA ${ }^{\text {Dnf1 }}$ (39) result in a uniform rather than polarized distribution of the cargo, showing that rapid endocytic uptake/recycling combined with slow diffusion across the plane of the membrane generates polarity (90). In A. nidulans, traffic of cargoes between the sorting endosome and the TGN requires RAB6 $\left(\mathrm{RabC}^{\mathrm{RAB} 6}\right.$ ) (64) and its effector Vps52 (39). Another flippase, DnfB ${ }^{\text {Drs2 }}$, is a TGN resident that partially localizes, like DnfA ${ }^{\text {Dnf1 }}$, to the SPK. Remarkably, DnfA ${ }^{\text {Dnf1 }}$ and $\mathrm{DnfB}^{\text {Drs2 }}$ reside in different regions of the SPK (39). The role of flippases in exocytosis is not understood, but it may have major practical implications: ablation of the Magnaporthe grisea APT2 gene (homologue of $\mathrm{DnfB}^{\mathrm{Drs} 2}$ ) does not result in hyphal growth or sporulation defects but precludes the secretion of several extracellular enzymes and, importantly, prevents pathogenicity (91).

$\mathrm{Tlg} \mathrm{B}^{\mathrm{Tlg} 2}$ is notable in that its genetic ablation is inconsequential for growth and results in a minor effect on SynA localization (75). However, $\operatorname{tg} B \Delta$ is synthetically lethal when combined with a hypomorphic mutation in sed $V$, the gene encoding the early Golgi syntaxin (75). This indicates that the Golgi can be organized with only one syntaxin $\left(\mathrm{SedV}^{\mathrm{Sed} 5}\right)$, provided that this syntaxin is fully functional. A plausible explanation is that when $T \lg \mathrm{B}^{\mathrm{Tlg} 2}$ is absent, proteins can recycle from sorting endosomes to early Golgi cisternae in a SedV $V^{\mathrm{Sed} 5}$. dependent manner and then move forward to the TGN by cisternal maturation. This interpretation is supported by the observation that $\mathrm{SedV}^{\mathrm{Sed} 5}$, like $\mathrm{TlgB}^{\mathrm{Tlg} 2}$, can form SNARE bundles with SynA, Vti1, and TlgA ${ }^{T l g 1}(\underline{75})$. If this interpretation were correct, the only role of $\mathrm{TlgB}^{\mathrm{Tlg} 2}$ would be in the fusion of retrograde carriers derived from the endosomes with the TGN.

\section{The Master Regulators of the Golgi: RABs, Arf1, and Their Regulators}

The budding from the ER of COPII carriers that feed the Golgi, the different stages of Golgi maturation, and the exit of carriers from the TGN are governed by small GTPases of the ARF and RAB families. SarA ${ }^{\text {Sar1 }}$ is an ER-located ARF that plays a fundamental role in the budding of COPII carriers $(92,93)$. Temperature shift experiments with $A$. nidulans sar $A^{\text {ts }}$ mutations have been used to impair ER exit. As predicted by the cisternal maturation model, in cells shifted to the restrictive temperature, early Golgi residents such as SedV ${ }^{\mathrm{Sed} 5}$, which have access to COPI-mediated retrograde traffic, rapidly relocalize to the ER, consistent with their Golgi localization being determined by an equilibrium between anterograde and retrograde traffic. In contrast, the TGN (late Golgi) resident $\mathrm{TlgB}^{\mathrm{Tlg} 2}$ does not rapidly relocalize to the ER, relocalizing instead to a diffuse cytosolic haze (92). This different behavior of early and late Golgi membranes $\left(\mathrm{SedV}^{\mathrm{Sed} 5}\right.$ and $\mathrm{TlgB}^{\mathrm{Tlg} 2}$ are integral membrane proteins) is consistent with the cisternal maturation model. Notably, prolonged impairment of ER exit by $\operatorname{sar} A^{t s}$ mutations results in the formation of apical balloons surrounded by a thick wall of chitin. One possible explanation is that chitin biosynthetic enzymes are less dependent on SarA ${ }^{\text {Sar1 }}$ function than other cell wall biosynthetic activities (92).

ARF1 (ArfA in A. nidulans) is an essential regulator of the Golgi (94) that plays different roles at the levels of the early and late cisternae. Two essential ArfA GEFs, GeaA and $\mathrm{HypB}^{\mathrm{Sec} 7}$, localizing to the early and late Golgi membranes, respectively, ultimately mediate these roles (81). A major (and as yet unexplained) finding that illustrates the power of random classical genetic screens was that geaA1 resulting in a single Y1022C substitution within a conserved domain of GeaA makes vegetative growth independent of $\mathrm{HypB}^{\mathrm{Sec} 7}$ and thus of the TGN (81). Remarkably, besides the early Golgi, $\mathrm{GeaA}^{\mathrm{Y} 1022 \mathrm{C}}$ localizes to the apical plasma membrane, suggesting that under these conditions early Golgi membranes can undergo exocytosis.

Three RAB GTPases are needed to organize the Golgi: RAB1 (RabE ${ }^{\mathrm{RAB} 11}$, YPT-31), RAB6 (RabC ${ }^{\mathrm{RAB} 6}$ ), and RAB11 (RabE ${ }^{\mathrm{RAB} 11}$, YPT-31). RabO ${ }^{\mathrm{RAB} 1} / \mathrm{YPT}-1$ $(\underline{60}, \underline{65})$ and $\mathrm{RabC}^{\mathrm{Rab} 6}(\underline{64})$ are present in both the early and the late Golgi. Notably, the three Golgi RABs are present also in the SPK (see below).

In $A$. nidulans, $\mathrm{RabO}^{\mathrm{RAB} 1}$ and $\mathrm{RabE}^{\mathrm{RAB} 11}$ are essential $(60,82)$. The acute inactivation of $\mathrm{RabO}^{\mathrm{RAB} 1}$ rapidly disorganizes both the early and the late Golgi cisternae $(60)$. In addition to exocytosis, $A$. nidulans $\mathrm{RabO}^{\mathrm{RAB} 1}$ plays a crucial role in autophagy (4). The absence of $\mathrm{RabC}^{\mathrm{RAB} 6}$, albeit not lethal, is severely debilitating and leads to fragmented cisternae (64). It results in delocalization of the $\mathrm{Vps} \mathrm{T}^{\mathrm{VPS} 10}$ vacuolar hydrolase receptor, which recycles between the endosomes and the Golgi (64), an observation consistent with the role generally attributed to RAB6 homologues as key regulators of retrograde traffic in the secretory pathway.

RAB11 has been studied in detail in A. nidulans $(\underline{82}, \underline{83})$. As noted above, RabE ${ }^{\mathrm{RAB} 11}$ is not a Golgi resident, but it is instead recruited to TGN membranes to determine their acquisition of post-Golgi identity. This recruitment must be governed by its GEF, which 
is therefore crucial for exocytosis. A long-standing question in the literature concerned the identity of the $\mathrm{RabE}^{\mathrm{RAB} 11} / \mathrm{Ypt} 31$ GEF and the roles of the TRAPP (oligomeric complex transport protein particle) as a Golgi organizer. TRAPP has been isolated in three versions. TRAPPI (composed of Trs33, Ber3, Bet5, Trs23, Trs31, and Trs20 subunits) is a demonstrated GEF for Ypt1 (yeast RAB1), acting in the ER/early Golgi interphase. TRAPPIII is TRAPPI plus Trs85 and acts as GEF for Ypt1 in the preautophagosome. TRAPPII is TRAPPI plus three additional subunits: Trs120, Trs130, and Trs65. TRAPPII had been proposed to be the Ypt31 GEF acting in the TGN (95), but this role was disputed by others, who concluded that TRAPPII was the late Golgi version of the GEF that activates Ypt1 in early Golgi (96). hypA1 is a ts mutation in the gene encoding A. nidulans Trs120 (97). The characterization of extragenic suppressors of bypA1 combined with biochemical assays established that the physiological substrate of TRAPPII is RabE ${ }^{\mathrm{RAB} 11}$ (the Ypt31 orthologue). TRAPPII, as visualized with Trs120-GFP, peaks at TGN cisternae preceding their dissipation into carriers, thereby determining the Golgi to post-Golgi transition by governing $\mathrm{RabE}^{\mathrm{RAB} 11}$ recruitment (3). It remains to be established whether TRAPPII is assembled de novo in the TGN. Alternatively, TRAPPII might be assembled using as a scaffold the TRAPPI complex already present in the early cisternae that would arrive at the TGN by maturation. If this were the case, anterograde traffic across the Golgi might be mediated by a RAB1 to RAB11 cascade governed by maturation of TRAPPI into TRAPPII (95).

\section{The Fungal SPK and Delivery of Cell Wall-Building Enzymes}

The SPK is a conspicuous apical body observed at the growing apices of hyphae in fungal species belonging to the subkingdom Dikarya (Ascomycota and Basidiomycota). The SPK was first discovered in fixed cells of the basidiomycetes Coprinus sterquilinus and Coprinus narcoticus stained with iron-hematoxylin (10). It was later observed in live cells of Polystictus versicolor, where it was shown to be important for maintaining hyphal tip elongation, morphology, and growth direction $(98,99)$. The subsequent characterization of the SPK in diverse fungal species by phase-contrast and transmission electron microscopy identified up to nine SPK patterns $(\underline{100})$. Mating projections of $S$. cerevisiae, mating projections and invasive pseudohyphae of C. albicans, dikaryotic hyphae of $U$. maydis, and germ tubes of Uromyces phaseoli and Puccinia graminis dis- play an apical cluster referred to as an SPK-like structure thought to operate as the SPK in hyphae (101-103).

Among the non-Dikarya fungi, only Allomyces and Basidiobolus have been found to display an SPK (104, 105). Early studies reported the absence of an SPK in the Zygomycetes (106). More recently, several zygomycetous fungi were analyzed (Gilbertella persicaria, Phycomyces blakesleanus, Rhizopus oryzae, Coemansia reversa, Mucor indicus, Gigaspora spp., and Mortierella verticillata), and it was shown that they present instead an apical vesicle crescent $(13,107,108)$. The apical vesicle crescent corresponds mainly to an accumulation of apical vesicles of different sizes, as for the SPK. However, practically nothing is known about the composition or regulation of the apical vesicle crescent vesicles. In contrast, extensive studies conducted on ascomycetous species have made it possible to identify the main components of the SPK (see below).

Hyphal growth occurs at the apices (10). Autoradiographic analysis of $M$. indicus (formerly rouxii) showed accumulation of tritiated $\mathrm{N}$-acetyl-D-glucosamine (GlycNAc), a monomeric unit of chitin, preferentially at hyphal tips, indicating that apical growth was correlated to a polarized mechanism of cell wall assembly (9). Several authors proposed that this assembly of cell wall at the apex must include the participation of synthetic as well as lytic (plasticizing, softening) activities (109-111). By contrast, an alternative model not involving lytic activity proposed a plastic cell wall at the apex that would become rigid at the subapex, where remodeling glycosyltransferases would cross-link the cell wall material and rigidify it (11). Recent work with $N$. crassa has revealed two glycosyltransferases belonging to the CAZy family GH17 localized at the plasma membrane of the hyphal dome, excluding the foremost apical region immediately across from the SPK (112) (Fig. 3), in support of cell wall remodeling occurring at the subapex.

At the ultrastructural level the SPK corresponds to an aggregation of vesicles, actin microfilaments, and ribosomes and an amorphous unidentified material ( 113 , 114) (Fig. 3). A computer simulation exercise led to the formulation of the vesicle supply center model for fungal morphogenesis (115). This model proposed that the SPK behaves as a vesicle supply center, from which vesicles travel to and fuse with the apical plasma membrane, providing the enzymatic machinery needed for cell wall expansion. Once inserted in the plasma membrane, (i) chitin synthases take $\mathrm{N}$-acetyl glucosamine subunits (GlcNac) from the cytoplasmic side and incorporate them into a growing chain of chitin microfibrils ( $\beta-1,4-$ GlcNAc), and (ii) the glucan synthase takes glucose 


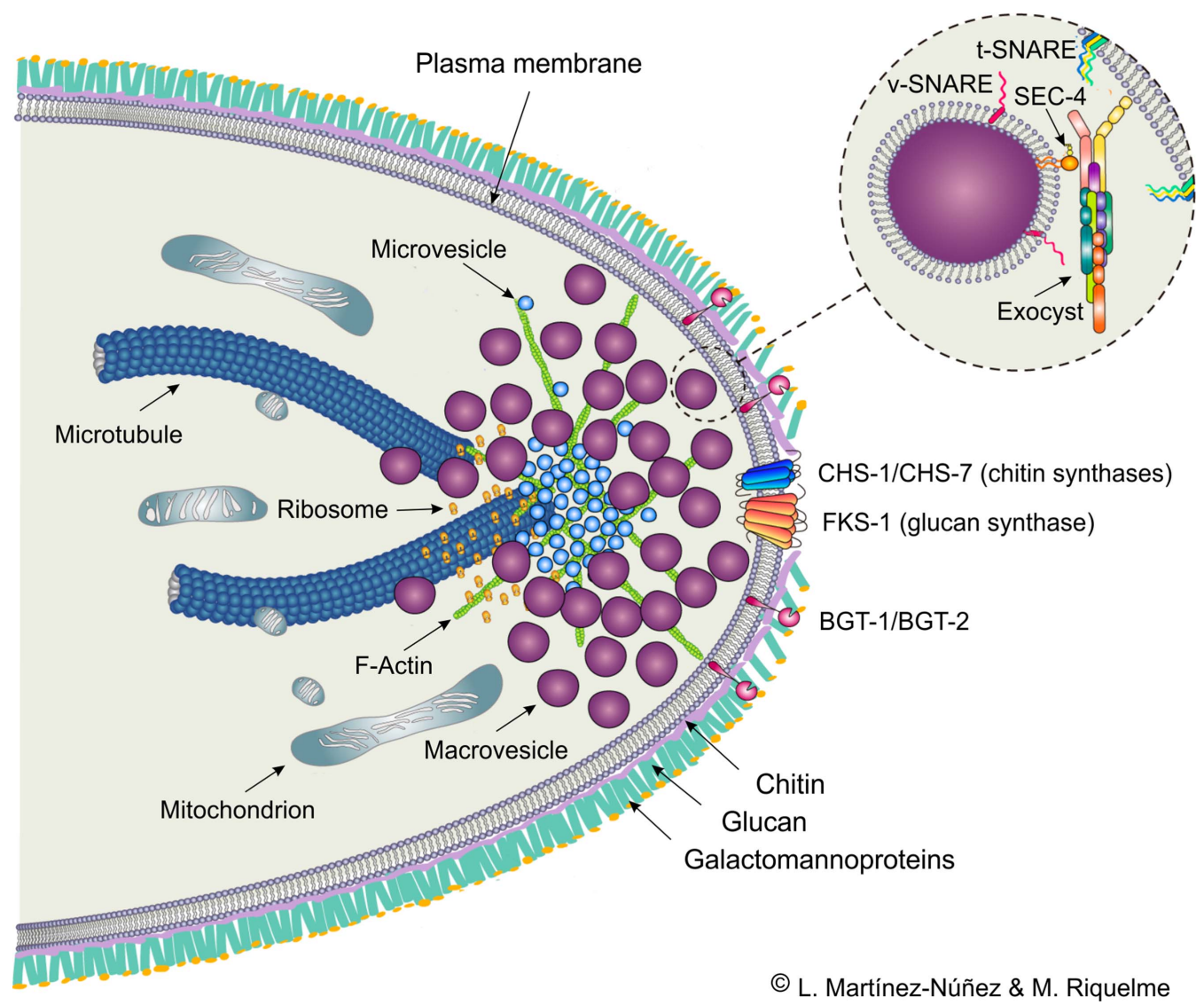

FIGURE 3 Illustration of a hyphal tip with the main organelles and subcellular components involved in apical cell wall growth. The diagram is based on work with $N$. crassa. (Art: Leonora Martínez-Núñez).

subunits (Glc) from the cytoplasmic side and incorporates them into an extending chain of $\beta-1,3$-glucan $(116,117)$. The sequencing of fungal genomes allowed the construction of translational fusions of specific genes with fluorescent proteins enlightening many components of the SPK.

The ultimate evidence for the suggested link between the SPK and cell wall assembly at tips was confirmed when cell wall biosynthetic enzymes such as chitin and glucan synthases were identified at the SPK in N. crassa $(118,119)$. Significantly, coexpression of differentially fluorescently tagged enzymes identified chitin synthases and components of the glucan synthase complex at the core and at the outer layer of the SPK, respectively, coinciding with the distribution of microvesicles (chitosomes) and macrovesicles reported at the transmission electron microscopy level (119, 120) (Fig. 3). Small GTPases YPT-1/RabO (Rab1) and YPT-31/RabC (Rab6) have been found occupying the inner and the peripheral layers of the SPK in N. crassa and A. nidulans, respectively $(\underline{64}, \underline{65})$. All the above suggests different popula- tions of vesicles containing different cell wall synthesizing activities and being regulated by different molecular switches. We are only starting to discern the lipid composition of membranes and its role in establishing membrane asymmetry and in vesicle traffic. In $A$. nidulans flippases DnfA (Dnf1) and DnfB (Drs2) also occupy distinct strata of the SPK, in support of existing different populations of vesicles $(\underline{39}, 121)$.

The SPK has been suggested to be a transfer station from cytoplasmic microtubules to actin microfilaments $(122,123)$. Cytoplasmic microtubules which extend through the cytoplasm and reach the SPK region are thought to participate in the long-distance traffic of vesicles to the SPK, whereas the actin cytoskeleton, found at the SPK core would mediate the flow of vesicles to and from the SPK $(\underline{124}, \underline{125})$ (Fig. 3). In A. nidulans the microtubular and actin cytoskeletons are connected at the hyphal tips by cell-end markers (26). TeaA is delivered by microtubules to the tip plasma membrane, where it interacts with TeaR and other components, subsequently leading to the recruitment of the formin SepA, 
which polymerizes actin cables (126). Interestingly, while cytoplasmic microtubules are important to maintain SPK stability, hyphal morphology, and fast growth rates, they seem dispensable for vesicles to reach the SPK (127, 128).

We lack information on the biogenesis of the vesicles that constitute the SPK. While several fungal organelles have been characterized, we lack information about the post-ER and/or post-Golgi processes relative to the formation and traffic of vesicles that concentrate at the SPK (see above). It has been shown that the exocyst complex has a role in determining the site at the plasma membrane for delivery of cell wall-synthesizing enzymes (129). In N. crassa the exocyst components were found at two locations within the hyphal tip: at the apical plasma membrane and at the frontal region of the SPK outer layer. It is well established that an intact SPK is needed to maintain hyphal morphology and growth directionality in ascomycete fungi (130). Recently, it was found that only the aggregation of macrovesicles (not of the microvesicles) at the SPK is dependent on an intact exocyst (120). Finally, it is worth noting that the lipophilic dye FM4-64 stains the SPK in living hyphae (89). FM4-64 is taken up by the cell via endocytosis at the plasma membrane (131) (for more details see below), suggesting a connection between the exo- and endocytosis.

\section{Myosin-Chitin Synthases in Apical Exocytosis}

Our knowledge concerning the delivery of vesicles and enzymes to the hyphal tip is largely based on intensive studies of $N$. crassa and A. nidulans. Both organisms belong to the phylum Ascomycota, which accounts for $\sim 64 \%$ of all fungi (2). The second major group is the basidiomycetes, which provide $34 \%$ of all described species (2). Despite the economic and ecological importance of this group, our understanding of secretion pathways in basidiomycetes is restricted to the plant pathogen $U$. maydis. In hyphae of $U$. maydis, microtubules are required to deliver chitin synthase-containing vesicles to the apical growth region (132). U. maydis does not contain a typical SPK, comprised of macro- and microvesicles, but similar to N. crassa and A. nidulans, vesicles accumulate near the hyphal tip in this fungus $(103)$. How this vesicle cluster is formed is not fully understood, but class $\mathrm{V}$ chitin synthases may participate in this process. Class $\mathrm{V}$ chitin synthases are fungal-specific cell wall-forming enzymes that carry an $\mathrm{N}$-terminal myosin motor domain. This domain is even found in ancient Cryptomycota (133), suggesting that it is a hallmark of the Fungi. It was shown that the myosin motor domain of the U. maydis class V chitin synthase (Mcs1) (134) is not involved in apical delivery of the enzyme. Instead, this is achieved by coordinated activity of the motor proteins kinesin-1 along microtubules and myosin-5 along filamentous actin (135); the myosin-motor domain of the class $\mathrm{V}$ chitin synthase tethers delivered vesicles to apical actin. The transient interaction of the motor and actin increases the pausing time of the vesicles at the hyphal apex, thereby supporting polar exocytosis (135).

Interestingly, Mcs1-tethered vesicles also carry a class VII chitin synthase and a $\beta$-glucan synthase (a homologue of glucan synthase Fks1 in N. crassa) (136). After exocytosis, these cell wall enzymes are immobilized by newly formed polysaccharide chains, suggesting that codelivery and coexocytosis help the coordination of enzymatic activity in building the complex fungal cell wall. Myosin-chitin synthases have also been described in numerous ascomycetes, including A. nidulans, (137), Aspergillus fumigatus (138, 139), F. oxysporum (140), Colletotrichum graminicola (141), Magnaporthe oryzae (142), and N. crassa (143). Ascomycete myosin-chitin synthases have been shown to be required for morphogenesis, development, and pathogenicity $(140,141, \underline{143}$, 144). As in $U$. maydis, kinesin-1 delivers A. nidulans myosin-chitin synthase along microtubules to the hyphal apex (145), where its myosin motor domain interacts with F-actin (146). However, whether ascomycete myosin-chitin synthases act as vesicle tethers at sites of apical exocytosis remains to be determined.

\section{FUNGAL ENDOCYTOSIS AND EE MOTILITY Fungal Endocytosis}

Hyphal tip growth has been described as being due to the tip-ward delivery and the apical release of Golgiderived vesicles $(11,122)$. In animal cells, this release (i.e., exocytosis) is balanced by the uptake of material into vesicles that form at the plasma membrane (i.e., endocytosis). These vesicles then fuse with early endosomes, and the contents can be recycled back to the surface or dispatched to the lysosome (i.e., the fungal vacuole) for degradation. For many years, endocytosis was thought to be absent in fungi (147). However, over the past 2 decades, fungal endocytosis has been recognized to be pivotal for cell function. The initial breakthrough came with the use of the lipophilic marker dye FM4-64 in the 1990s in the yeast S. cerevisiae (131) and then in the filamentous fungi Uromyces fabae (148) and U. maydis (149). This fluorescent dye inserts into the plasma membrane from where it is internalized by the formation of endocytic transport vesicles (131). Subse- 
quently, studies of M. grisea (150), A. nidulans (151), $N$. crassa, and six additional fungi (9) confirmed the endocytic uptake of FM4-64 into fungal cells. These results were complemented by live-cell imaging and mutants studies in numerous fungi, including U. maydis, A. oryzae, A. nidulans, C. albicans, A. gossypii, and N. crassa (37-39, 152-160). Collectively, these studies revealed a critical role for endocytosis and endocytic recycling in hyphal growth of filamentous fungi (for overview see references $\underline{15}, \underline{57}$ ).

\section{The Molecular Machinery for EE Motility}

Fungal EEs were first described in the dimorphic fungus $U$. maydis (160). In this fungus, shortly after internalization, the dye FM4-64 concentrates in small, rapidly moving vesicular organelles (160). A putative t-SNARE, Yup1, binds these organelles via a PHOX-domain (i.e., phosphoinositide binding domain) $(160,161)$ that interacts with the lipid PIP3, characteristic of EEs (reference 162). Consistent with this, the FM4-64-stained organelles carry the small GTPases Rab4 and Rab5 $(155,161)$, both shown to reside on EEs in mammalian cells $(163,164)$. Thus, there is little doubt that the rapidly moving FM4-64-positive vesicles are EEs. Rab5positive EEs were also described in A. nidulans (8), N. crassa (165), and Zymoseptoria tritici (166) but are not found in the yeast $S$. cerevisiae. Thus, motile EEs are a hallmark of filamentous fungi.

Microtubules are biopolymers of tubulin-dimers that support long-distance transport of organelles and vesicles in fungal cells $(12,167)$. They elongate at their plus end, while the minus end is usually embedded in a nucleation site, such as the fungal spindle pole body. Motility along microtubules is mediated by molecular motors, which use the polarity of microtubules to transport their cargo. In general, kinesins are known to move toward the plus end of a microtubule, while cytoplasmic dynein motors are minus end-directed. Both types of motors are "mechanoenzymes" that hydrolyze ATP to power a conformational change in the motor domain. Repeating cycles of ATP hydrolysis result in a sequence of $\sim 8$-nm steps along the microtubule $(168,169)$. In filamentous fungi, the first membrane trafficking motors identified were the cytoplasmic dyneins in N. crassa (170) and A. nidulans (171), which were recognized to play a role in nuclear migration. Shortly after, kinesin motors were identified in N. crassa (172), U. maydis (149), Nectria haematococca (173), and the zygomycete Syncephalastrum racemosum (174). Interestingly, all kinesins belong to the same subgroup of kinesin motors (kinesin-1), which is thought to support tip-ward transport of fungal secretory vesicles
(135) and to deliver dynein to microtubule plus ends $(175,176)$ (for more details on general motor function see references $\underline{12}, 167$ and 177). The first insight into the machinery of EE motility was provided by studies of U. maydis, where kinesin-3 was identified to be the motor for plus end-directed motility of EEs (178). A similar role of kinesin-3 in EE motility was discovered in A. nidulans $(179,180)$ and $N$. crassa $(\underline{165})$. Kinesin-3 motor proteins comprise 8 of the 45 kinesins in the human genome (181) but are absent from $S$. cerevisiae. This emphasizes the similarity of membrane trafficking in filamentous fungi and elongated mammalian cells such as neurons $(167,182)$.

Fungal EEs have been shown to move in a bidirectional fashion along microtubules (8ㅗ 175, 183), suggesting that plus end-directed kinesin-3 gets opposed by minus end-directed cytoplasmic dynein. Indeed, deletion of the gene for kinesin-3 resulted in the accumulation of EEs at microtubule minus ends (178), whereas inactivation of cytoplasmic dynein results in a cluster of EEs at microtubule plus ends in the hyphal apex (175, 179). Interestingly, the deletion of kinesin- 1 also led to EE clustering at the hyphal tip. This is due to a role of this motor in delivery of dynein to microtubule plus ends $(175,176)$ (Fig. 4). Dynein motors accumulate at the plus end to form a "dynein comet" $(175,184)$. Studies of $U$. maydis have shown that the apical dynein comets consist of $\sim 55$ dynein motors. Two mechanisms cooperate in the formation of the comet, namely binding of the dynein-associated complex dynactin to EB1-like proteins at microtubule plus ends and by a stochastic crowding effect (185). Dynein is released from the dynein comet and, while moving toward the subapical minus ends, can randomly pick up kinesin-3-delivered EEs (186) (Fig. 4). The large numbers of dyneins at plus ends increase the probability of such interaction. This ensures that EEs do not fall off the microtubule when they arrive at plus ends, but rather are transported back toward minus ends (185) (Fig. 4).

After dynein takes over, moving EEs still bind kinesin$3(179,186)$. Surprisingly, the amount of kinesin-3 on these organelles is $\sim 4$ times higher than that of dynein (186). This suggests that kinesin-3 activity is repressed upon dynein binding. While the exact mechanism underpinning this regulation is not known, the recent identification of an EE-located motor adapter complex provides the first insight into the complex interplay between kinesin-3 and dynein during bidirectional EE motility. The key protein in this EE adapter complex is a hook protein, which was identified in a genetic screen for mutants defective in EE motility in A. nidulans (187) and 


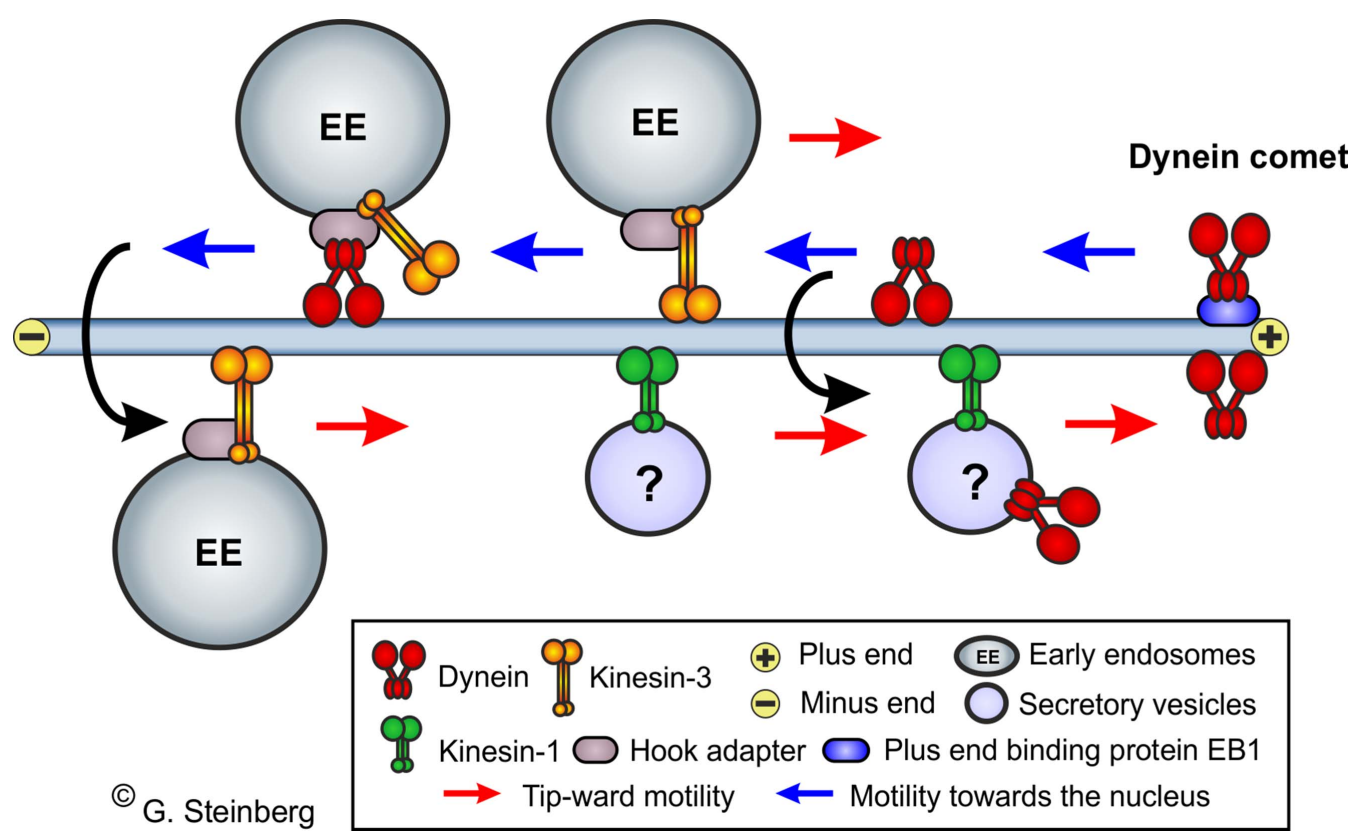

FIGURE 4 Diagram showing the cooperation of molecular motors in bidirectional EE motility. The illustration is based on results obtained from studies of $U$. maydis. See text for detailed description.

U. maydis (188). Hook forms a complex with two associated proteins, named FTS and FHIP (188), that help anchor the adapter complex to the EE membrane (189). Hook itself interacts with dynein $(187,188)$ and kinesin$3(188)$ and is therefore a good candidate for controlling the activity or the attachment of both motors during bidirectional EE motility (15). This notion is supported by the finding that some kinesin-3 is released from EEs shortly before dynein binds (188). It is likely, however, that more proteins participate in this regulation, because for example, the dynactin subunit p25 is needed for dynein-dependent EE motility (190). However, EE motility may also be regulated by proteins that are not part of the transport machinery or the EE adapter complex. This is illustrated by the vezatin-like protein VezA in A. nidulans (191). Mutants in vezA show defects in dynein-hook interaction and, consequently, are impaired in retrograde EE motility. Surprisingly, VezA is not located on EEs, and the mechanism by which it controls interaction of dynein and EEs is not fully understood. Furthermore, the microtubule tracks themselves could participate in regulation of EE motility. It was shown in N. crassa and A. nidulans that kinesin-3 moves cargo preferentially along a subset of modified and less dynamic microtubules $(\underline{165}, 180)$. However, such selective transport of kinesin-3 was not found in the basidiomycete $U$. maydis (192).

\section{Multiple Functions for Fungal EEs}

The discovery of kinesin-3 as the motor for plus enddirected motility of fungal EEs (178) allowed the generation of mutants where EE motility was inhibited. This opened new avenues to investigate the role of these organelles in filamentous fungi. Over the past 10 years, intensive studies of $U$. maydis and A. nidulans have revealed multiple roles of EEs in fungal growth and virulence (Fig. 5).

\section{The role of EEs in the endocytic pathway}

EEs are the first compartment that sorts incoming material for recycling back to the plasma membrane or for degradation to the vacuole. It was shown that endocytic recycling supports tip growth of hyphae in $A$. nidulans, A. oryzae, N. crassa, and A. gossypii (37, 38, 152, 153, $156,157)$. In addition, endocytic receptor recycling is essential during the early steps of pathogenicity in U. maydis (155). A role of EEs in recycling is also indicated by the fact that fungi contain the small GTPase Rab4 (155), which is involved in endocytic recycling at mammalian EEs (164). However, experimental evidence for such a role of Rab4 in filamentous fungi is missing. The second pathway from the EEs involves a maturation process, where Rab5 is replaced by Rab7, as shown in mammals (193), A. nidulans (194), and U. maydis (161). This maturation process from an EE to a late endosome 


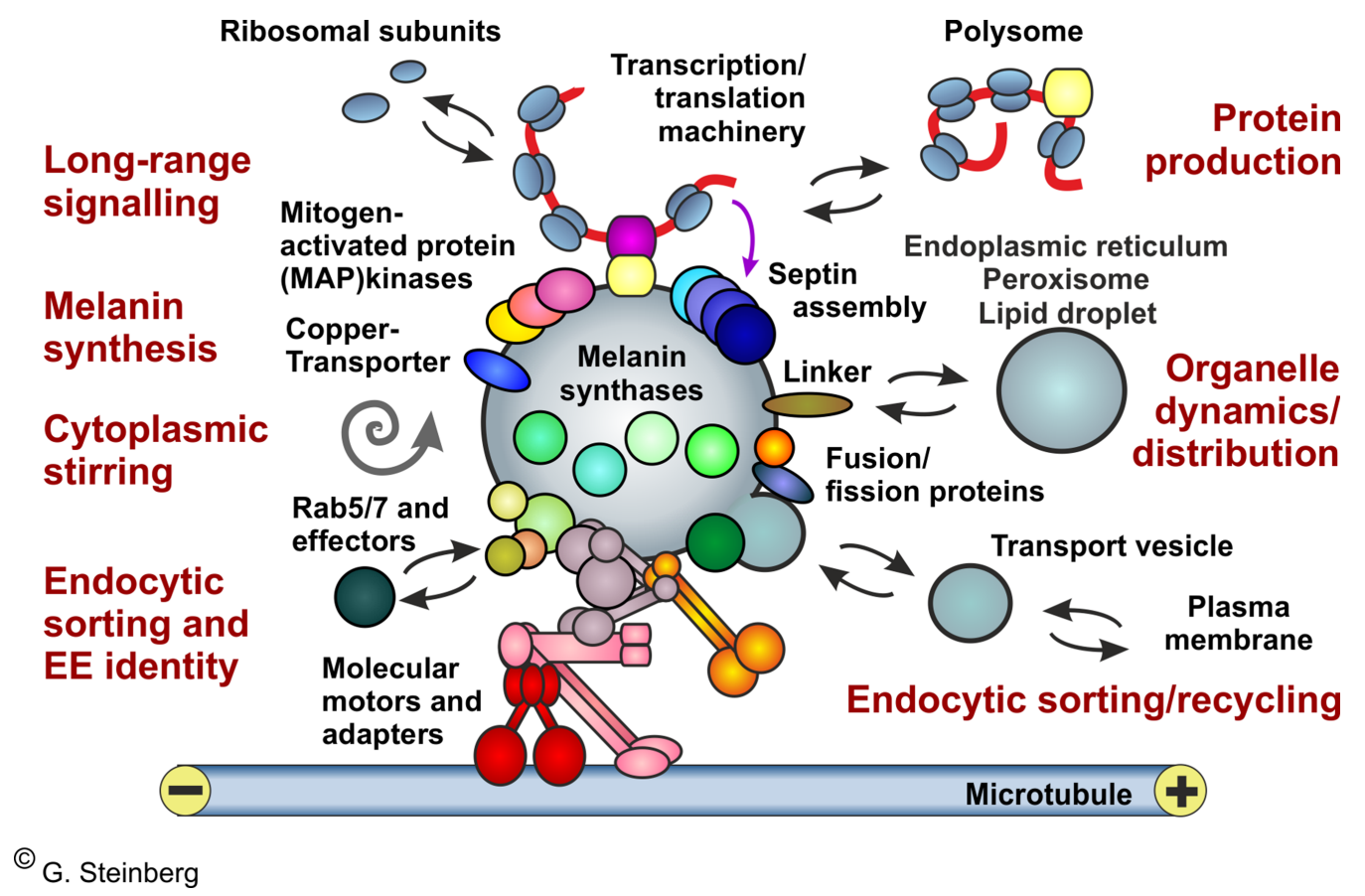

\begin{abstract}
FIGURE 5 EEs as multifunctional platforms. Proteins that associate with the organelles are shown as colored symbols and described in black; functions are indicated in dark red. The diagram is based on work with U. maydis, A. nidulans, and A. fumigatus. See text for detailed description.
\end{abstract}

and finally delivery to the vacuole involves EE motility $(161,194)$ and a complicated machinery of additional protein factors $(\underline{75}, 195)$. A. nidulans mutants defective in such factors (e.g., Vps33 or PepA ${ }^{\text {Pep12) }}(\underline{75})$ do not form normal colonies, which demonstrates that sorting to the vacuole is crucial for normal hyphal growth.

\section{Hitchhiking of the protein translation machinery and organelles on EEs}

Fungal EEs are constantly moving, and their motility is fueled by hydrolysis of ATP (15). The costs for the cell to maintain EE motility are best illustrated by a simple calculation, using parameters from $U$. maydis. Here, $\sim 100$ EEs are constantly moving (M. Schuster and G. Steinberg, unpublished results) at a rate of $\sim 2 \mu \mathrm{m} / \mathrm{s}$ (186). Considering a step size of $8 \mathrm{~nm}(\underline{168}, \underline{169})$ and consumption of one ATP per step (196), these 100 EEs consume 90 million ATPs per hour. While EE motility is required to sort endocytosed material to the lysosome (see above), this high energy cost suggests additional functions of EE motility. Indeed, recent studies in $U$. maydis and A. nidulans have shown that other cellular cargos can "hitchhike" on moving EEs. The first report of such a mechanism demonstrated that the U. maydis mRNA-binding protein Rrm4 travels on EEs (197). Rrm4 links various mRNAs to a FYVE-domain- containing protein, Upa1, which itself is expected to bind to PIP3 lipid $(198,199)$. While it was initially suggested that this hitchhiking mechanism delivers mRNAs to the ends of the hyphal tip cell (200), a more recent report shows that entire polysomes (ribosomes and mRNA) bind and unbind to EEs, which distributes the protein translation machinery in the cell (161). Thus, transient hitchhiking supports the spatial organization of the translational machinery in the fungal cell.

Interestingly, it was reported that this mechanism is also used to relay organelles. In U. maydis (201) and A. nidulans (202), peroxisomes also transiently hitchhike on moving EEs. Moreover, lipid droplets and, to lesser extent, ER are distributed by moving EEs (201). Interestingly, when EE motility was blocked, organelles clustered at the hyphal tip $(187,201,202)$. It was shown in $U$. maydis that this is due to a pole-ward drift of these organelles, probably powered by myosin 5-dependent delivery of secretory vesicles to the hyphal apex (203). Thus, hitchhiking on moving EEs maintains an even distribution of organelles and polysomes, which is vital for protein production and organelle function. It is worth noting that the process of hitchhiking is not restricted to filamentous fungi but may be a more general mechanism of cargo distribution in eukaryotic cells (204). 


\section{Local protein translation on moving EEs}

Recent studies of $U$. maydis revealed a novel aspect of mRNA hitchhiking on EEs. It was shown that polysomes, while bound to moving EEs, are translationally active $(161,205)$. Initially, it was thought that this mechanism may ensure binding of ribosomes to EEanchored mRNA for cellular distribution (161). However, recent results in U. maydis show that all core septin proteins (Cdc3, Cdc10, Cdc11, Cdc12) travel on EEs in an Rrm4-dependent way (206). This suggests that septin mRNA is traveling on EEs and subsequently being translated on the organelles to septin proteins, which assemble into a heteromeric septin building block. Thus, local translation on EEs may help to assemble and transport protein complexes in the hyphal cell.

\section{Mixing the cytoplasm to enhance organelle interactions}

EEs are constantly moving along microtubules (186). This raises the possibility that the EE trafficking stirs the fungal cytoplasm. Evidence for such a function was recently provided in $U$. maydis. Here, bidirectional EE motility increases the diffusion of peroxisomes and lipid droplets (203). This is most likely due to perturbation of the cytoplasm or direct collision between EEs and organelles. These unspecific interactions are further fostered by dynein-driven bending of microtubules (207, 208), which allow moving EEs to explore all regions of the cytoplasm within the hyphal cell tube. Mathematical modeling shows that these perturbations increase the local mobility of peroxisomes and lipid droplets, thus raising the chance of organelle-organelle interactions, which are essential for the cellular roles of both organelles (209). Interestingly, EEs in A. nidulans were shown to support the aggregation of proteins, which are formed in response to a heat shock (210). How EEs support protein aggregation is not known, but transient interactions between both were reported (210), suggesting that either hitchhiking (see above) or passive collisions support protein aggregate formation.

\section{Participation of EEs in melanin biosynthesis}

Melanin is a negatively charged hydrophobic polymer pigment. This polymer mechanically strengthens the fungal cell wall and protects microorganisms against microbicidal peptides, reactive oxygen species, and antifungal drugs. Consequently, melanin is associated with fungal virulence, in both human and plant pathogens (211-213). A genetic screen, designed to identify conidial pigmentation mutants in A. fumigatus (214), revealed a novel role for EEs in melanin biosynthesis.
In one of the mutants, all melanin synthesis genes were unaffected, but a conserved sorting nexin, Mvp1, was mutated (215). This protein contains a PHOX domain, known to bind to lipids enriched in EEs (162). Subsequent studies led to the discovery that early enzymes of the melanin biosynthesis pathway (Alb1, Arp1, Arp2, Ayg1) are recruited to EEs. This, and the role of the sortin nexin Mvp1 in conidia pigmentation, strongly suggest that fungal melanin biosynthesis is initiated in the endosomal system, from where melanin intermediates are secreted and further processed by late biosynthetic enzymes (Abr1, Abr2) in the cell wall. Thus, EEs may govern aspects of secondary metabolism in filamentous fungi.

\section{Endosomes in Long-Range Signaling}

Mammalian neurons and elongate fungal hyphae share a common challenge in long-range signaling from the cell pole to the nucleus. In $U$. maydis, the nucleus is located $\sim 50 \mu \mathrm{m}$ behind the growing tip (216), and perception of external cues by tip-located receptors requires signaling over this distance. In neurons, such retrograde signaling is supported by moving EEs (217), and it was speculated that fungal EEs also take part in long-range transmission of signals (218). Evidence for this hypothesis comes from work with U. maydis. When the fungus enters into its plant host, it secretes effector proteins to suppress plant defense system activation (219-222). But how does the fungal nucleus know that effector genes need to be transcribed? It was shown that retrograde EE motility bridges between the invading hyphal tip and the subapical nucleus and that this motility is required to increase effector gene transcription and subsequent effector protein secretion (219). This supports the notion that EE motility transmits the signal for effector production from the hyphal tip to the subapical nucleus. Neither the plant cues that trigger effector transcription nor the detailed mechanism underpinning signal relay is known. However, the mitogen-activated protein kinase Crk1, described in the control of morphogenesis in $U$. maydis (223), is located on EEs and participates in regulating effector transcription (219). While our understanding of long-range signaling in fungi is still very fragmentary, these findings demonstrate a role for moving EEs in signal transduction.

Since the discovery of EEs in 2000 in U. maydis (160), our knowledge of the molecular machinery and cellular role of EE motility has increased significantly. It has emerged that EEs are motile multipurpose platforms that are involved in various essential aspects of fungal biology (Fig. 5). Initially recognized as sorting organelles, 
involved in recycling and degradation of endocytosed cargo, EEs have now been shown to spatially organize the hyphal cell. They enable long-range signaling and serve as platforms for local protein translation. Thus, motile EEs are pivotal to the fungal cell.

\section{SEPTATION IN FUNGAL HYPHAE Septum Formation}

Fungal cells divide via the process of septation, whereby the localized synthesis of a cross-wall divides an existing cell into two distinct cells. In yeasts, dissolution of the septum physically separates the two cells. However, they remain attached in multicellular hyphae and often retain some degree of cytoplasmic continuity through septal pores. It is well established that the process of septum formation in fungal hyphae requires the presence of intact actin filaments, which assemble into a ring (i.e., the contractile actin ring [CAR]) (Fig. 6) that constricts in a process resembling cytokinesis in animal cells (224, 225). In yeasts, and presumably hyphae as well, the CAR guides deposition of the septal wall material $(\underline{224}, \underline{226})$. Much of our understanding of the mechanisms that underlie assembly and constriction of the CAR is based on the functional characterization of gene products identified on the basis of their homology to yeast proteins with well-defined roles in septation (e.g., references 226-228). In general, the roles of these gene products appear to be largely conserved in filamentous fungi (224). Additional studies have provided insight into the regulation of septum formation in fungal hyphae, and in some cases they have yielded unexpected surprises (229). These surprises to a large extent reflect novel features of septum formation in multicellular hyphae compared to yeasts. This includes, for example, the precise spacing of septa so that the appropriate compartment size is

FIGURE 6 Time course of the contraction of the CAR during septum formation in the wheat pathogen $Z$. tritici. The side view of the three-dimensional image stack shows that the CAR is closing with time. Time in minutes is shown in the upper-left corners. The CAR was labeled using an F-actin-specific GFP-LifeAct probe.
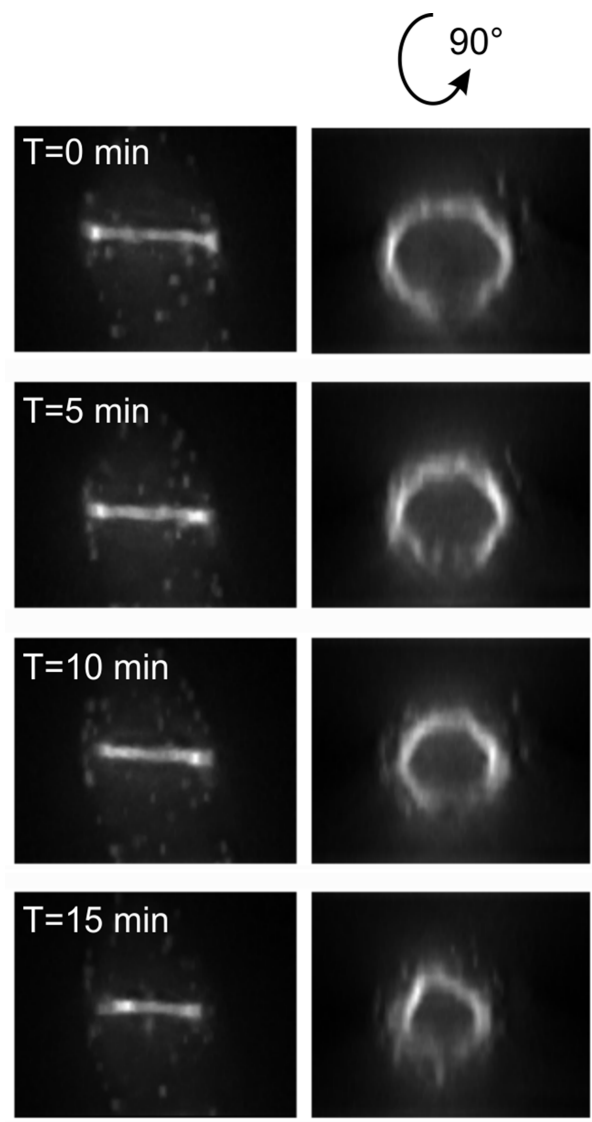
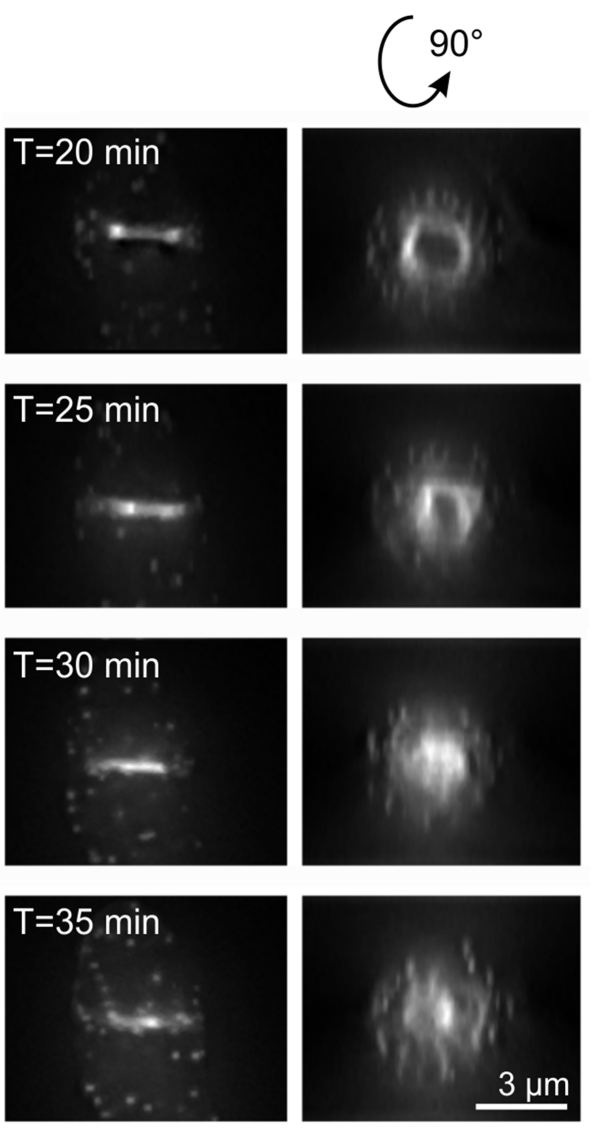

(C) M. Schuster \& G. Steinberg 
A

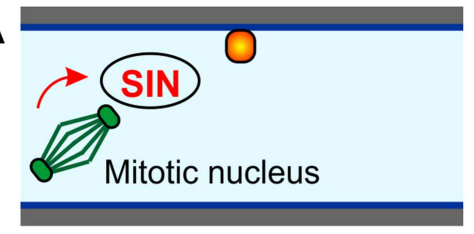

B

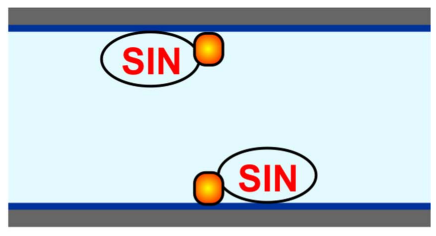

C

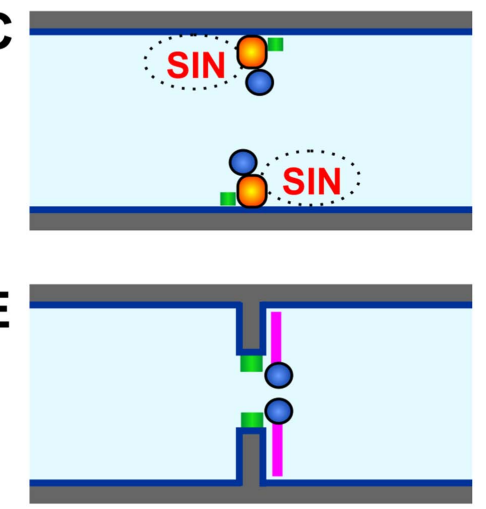

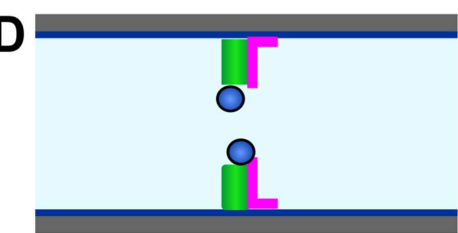

$\mathbf{F}$

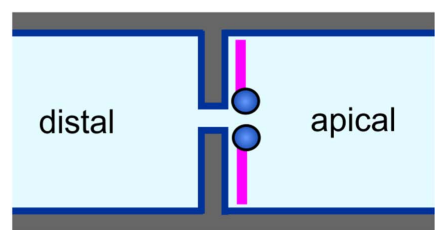

FIGURE 7 Model for septum formation. (A) A signal emanating from mitotic nuclei is relayed to the septation site via the septation initiation network (SIN). (B) Components needed for assembly of the contractile actin ring (CAR) (actin filaments, Bud4) are already associated with the septation site and operate in conjunction with the SIN to define the division plane. (C) Activation of the GTPase Rho4 at the septation site initiates organization of actin filaments into a CAR. (D) Constriction of the CAR is coincident with appearance of a septin ring. (E) Deposition of the septum is guided by the CAR. The septin ring disassembles once the final size of the septal pore is reached. (F) Several proteins, including calcineurin and Rho4, remain associated with the mature septal pore. The diagram was modified from Beck et al. (345).

\section{Bud4 Rho4 Contractil actin ring (CAR) I Septin filament SIN Septation Initiation Network}

(C) S. Harris \& G. Steinberg

maintained (230). Achieving a greater understanding of the mechanics and regulation of septum formation in fungal hyphae will go a long way toward revealing key functional features that underlie the unique organization of fungal hyphae.

\section{The CAR and deposition of the septum}

Like in animal cells, assembly and constriction of the CAR underlies septum formation in fungal hyphae $(224,225)$. The CAR initially appears at the incipient septation site as a tangle of actin filaments that is associated with myosin and tropomyosin. This structure subsequently consolidates into a thin "proto-CAR" that circumscribes the hypha. Constriction of the CAR coincides with ingrowth of the plasma membrane and the deposition of the new cell wall material that will become the septum. The CAR remains positioned at the advancing edge of the invaginating plasma membrane, which is also the active site of cell wall deposition that is mediated by the delivery of exocytic vesicles. During constriction, the appearance of actin patches that flank the CAR is consistent with localized endocytosis. Unlike cytokinesis in yeast cells, the CAR does not fully close, thereby retaining cytoplasmic continuity between adjacent hyphal cells through the resulting septal pore.
Other than tropomyosin and myosin, other components of the CAR include the anillin-like protein Bud4 $(\underline{27}, 224,231)$, formin $(224,232)$, the actin-nucleating protein Bud6 (233), alpha-actinin (234, 235), paxillin (A. Virag and S. D. Harris, unpublished), and chitin synthase (224, 236). Notably, Bud4 and chitin synthase appear just prior to the initiation of constriction (224) (Fig. 7). Depending on the specific fungus, the absence of any of these components completely abolishes septum formation or results in the formation of abnormal septa. In general, formins, Bud6, and alpha-actinin are directly needed to assemble microfilaments into a CAR (232, 233, 235). The role of Bud4 is particularly intriguing, because Bud4 homologues in S. cerevisiae and S. pombe associate with septins $(\underline{237}, \underline{238})$. In filamentous fungi such as A. nidulans, A. fumigatus, and N. crassa, septins also appear as rings at septation sites (e.g., references 239-241). In addition, fungal septins are subject to posttranslational modification such as phosphorylation (242), which likely plays a key role in determining their association with diverse partner proteins. Nevertheless, the relationship of septin localization and modifications to CARs and the timing of their appearance remain to be determined.

Studies using A. nidulans and N. crassa show that the monomeric GTPase Rho4 coordinates assembly of 
the CAR at septation sites $(\underline{28}, \underline{243})$. Strikingly, Rho4 orthologues are conserved in filamentous fungi and $S$. pombe, but not in $S$. cerevisiae (which possesses a different GTPase known as Rho4). Activated Rho4 appears to recruit formins to the septation site (28), which is presumably an early step in the formation of the proto-CAR. It is interesting to note that weak homologues of $S$. cerevisiae Bud3 serve as guanine nucleotide exchange factors that activate Rho4 $(27,28)$. Accordingly, rbo4 and bud3 mutants fail to recruit formins and thus do not assemble CARs or form septa. These results suggest that the Bud3-Bud4 module that provides a septin-associated spatial landmark for polarity establishment in budding yeast could conceivably have been co-opted from an ancestral function in directing CAR assembly at septation sites in filamentous fungi.

\section{Regulation of septum formation in fungal hyphae}

The formation of CARs at septation sites is subject to both spatial and temporal regulation (53). The existence of spatial regulation is supported by the uniform distribution of septa in fungal hyphae and their general exclusion from apical regions. Temporal regulation is likely based on the coordination of septum formation with mitosis at least in those filamentous fungi that exhibit parasynchronous nuclear division. Collectively, both forms of regulation presumably ensure that the compartment sizes in a hypha are appropriate for the extant growth conditions.

In $A$. nidulans, results from the use of mitotic inhibitors support the view that signals emanating from dividing nuclei (e.g., the mitosis spindle or spindle poles) trigger the local formation of CARs (225). A promising source for such a signal is the septation initiation network (SIN), which coordinates CAR assembly and constriction with mitosis in S. pombe (244) (Fig. 7). Elements of the SIN pathway are conserved in filamentous fungi and are needed for CAR formation and septation (e.g., references 245, 246). However, they appear to function in a manner that is different from $S$. pombe, because for example, prior association with spindle poles is not required for SIN recruitment to septation sites (247). Although these observations implicate the SIN in the temporal regulation of CAR assembly or maturation, the specific nature of the signal remains to be determined. The timing of septum formation is also subject to regulation by DNA damage and other forms of genotoxic stress (229, 248). For example, low levels of DNA damage permit nuclear division but block septation in A. nidulans and Fusarium graminearum. In $A$. nidulans, this effect is mediated by inhibition of the same CDK that regulates mitosis (229).

Even though signals emanating from mitotic nuclei are presumably capable of triggering CAR assembly or maturation, it is also evident that not all mitoses are capable of activating formation of a septum. Otherwise, hyphal cells would in principle contain only a single nucleus, which is not the case for many filamentous fungi. Indeed, the regular spacing of septa and the relatively uniform number of septa per hyphal compartment in these fungi imply that septum formation is spatially regulated. That is, the activation of CAR assembly by a given mitosis event seemingly precludes adjacent dividing nuclei from also triggering septation. This could be simply due to titration of one or more key components needed for CAR assembly, but it might also reflect the active repression of septum formation at sites flanking a new CAR even if mitotic nuclei are nearby. How this might occur remains a puzzle, though it is tempting to speculate that cortical landmarks might specify "preseptation" sites that must be activated by an adjacent mitosis event to enable CAR formation or they are otherwise disassembled.

\section{Communication and Differentiation of Hyphal Compartments}

In basidiomycetes and ascomycetes, septa divide the hypha into compartments. These septa contain pores of 50 to $500 \mathrm{~nm}(249-252)$ that allow intra- and interhyphal translocation of metabolites, proteins, RNA, and even organelles. The rate of mass flow of cytoplasm in the mycelium of the basidiomycetes Armillaria mellea and Serpula lacrimans is in the range of 3 to $70 \mu \mathrm{m} \mathrm{s}^{-1}(\underline{253})$, while a rate of $\sim 5 \mu \mathrm{m} \mathrm{s}^{-1}$ was observed in $N$. crassa (254). These rates underpin the potential for fast mixing of cytoplasm through the mycelium, implying that the mycelium of ascomycete and basidiomycete fungi is continuous like that of lower fungi. This paradigm is, however, changing. Studies have shown that fungal septa with growing hyphae can be closed, thus preventing cytoplasmic exchange between compartments (see "The Mechanism of Septal Pore Closure," below), which allows heterogeneity of hyphal cells within the fungal mycelium.

\section{Hyphal heterogeneity}

Zones within fungal mycelia show heterogeneous gene expression patterns and heterogeneity in growth and secretion (255-260; overview in reference 17). For instance, growth is mainly limited to the periphery of 
colonies of Aspergillus niger (255), while protein secretion occurs throughout the colony, with the exception of an intermediate zone, that is primed to sporulate under particular environmental conditions (260). There is differential gene expression across these zones (256, 259), and different proteins are secreted at the periphery and central zones of these colonies (259). Even hyphae within a given mycelial zone are heterogeneous with respect to cytosolic composition (17, 255, 257, 258, 261-265). For instance, part of the hyphae at the outer zone of $A$. niger colonies have high transcriptional and translational activity, which is accompanied by secretion of proteins that are involved in substrate degradation (255, 263-265).

Hyphae show highly polarized apical tip growth. They have at least four regions. The most apical region of hyphae (i.e., the first 1 to $5 \mu \mathrm{m}$ ) contains the Spitzenkörper, some mitochondria, and some smooth endoplasmic reticulum $(266,267)$. The tip region is also rich in actin filaments but sparse in ribosomes $(262,268)$. The second region is 2 to 4 times as large and contains mitochondria and some ER cisternae (104). The third region, which ends at the first septum, contains the complete collection of organelles. The fourth and following regions make up the second and following compartments. They contain all organelles, but their structure and abundance are often different from those in the third region. For instance, vacuoles are more abundant in subapical compartments, while $18 \mathrm{~S}$ rRNA is less abundant, at least in the basidiomycete Schizophyllum commune (262).

\section{Mechanisms of cytoplasmic flow}

Cytoplasmic streaming depends on the architecture of the mycelium and is the result of turgor pressure gradients, diffusion, and/or turbulence due to movement of organelles along the cytoskeleton. Hyphal fusion plays an important role in long-distance translocation of nutrients in N. crassa (269). This is evident from the finding that transport of nutrients is highly affected in a soft mutant $(\Delta s o)$, which is a mutant strain that lacks the ability to undergo hyphal fusion. Even a $50 \%$ reduction in hyphal fusion frequency, as occurs in the $\Delta p r m-1$ mutant, results in decreased nutrient translocation rates from the center toward the periphery of the colony (269).

Turgor pressure-mediated translocation has been proposed as a mechanism of cytoplasmic streaming in several fungi $(\underline{253}, \underline{269-271)})$. For instance, long-distance translocation of the nonmetabolizable glucose analogue 3-O-[ $\left[{ }^{14} \mathrm{C}\right]$ methyl glucose through the mycelium of Morchella esculenta would depend on this mechanism.
Translocation of 3-O-methyl glucose depends on the formation of sclerotia. A mutant unable to form these survival structures does not transport this glucose analogue through the mycelium (270). To explain these results, it was postulated that nutrients and solutes lower the water potential of the cytosol in the vegetative hyphae, resulting in water uptake from the medium. This uptake generates a higher turgor pressure in the hyphae. However, it is insufficiently high to create a flow through the mycelium. For this to occur, solutes are converted into high-molecular-weight polymers upon their arrival at the sclerotia or are released as exudate into the medium. These processes decrease the turgor within the sclerotia and thus act as a sink by attracting water (i.e., cytosol) from the vegetative hyphae. Addition of the metabolic inhibitor azide strongly reduces translocation of 3-O-methyl glucose, showing that metabolic activity is a prerequisite for turgor pressure gradient-mediated translocation to occur.

Mass transport driven by pressure gradients also dominates intrahyphal transport toward the hyphal tips of $N$. crassa (272). The pressure gradient required for this flow is very low $\left(10^{2}\right.$ to $\left.10^{4} \mathrm{~Pa} \mathrm{~cm}^{-1}\right)$ compared with the 4 to $510^{5} \mathrm{~Pa}$ turgor pressure within these hyphae (273). This low required value of the gradient is caused by the micrometer-range width of the hyphae. Pressure differences in micro-channels in the range of $10^{2}$ to $10^{3} \mathrm{~Pa}$ result in translocation rates of 50 to $500 \mu \mathrm{m} \mathrm{s}^{-1}$, with mixing of the fluid dominated by diffusion (274). This velocity agrees with the maximal rate of bulk flow in $N$. crassa hyphae of $60 \mu \mathrm{m} \mathrm{s}^{-1}$, although average flow rates are only $\sim 5 \mu \mathrm{m} \mathrm{s}^{-1}$ (254). The intrahyphal osmotic gradients required for mass flow in $N$. crassa are likely to result from ion transport, as indicated by experiments using extracellular osmotic gradients. The high concentration of organelles in the cytosol of $N$. crassa hyphae impedes bulk flow of the cytoplasm, causing a so-called partial plug flow (272).

Cytoplasmic streaming in N. crassa occurs at $\sim 5 \mu \mathrm{m}$ $\mathrm{s}^{-1}$ (254). In contrast, the N. crassa kinesin motor Nkin transports its cargo at 2.1 to $3.8 \mu \mathrm{m} \mathrm{s}^{-1}$ (275). Thus, it is very unlikely that fast cytoplasmic streaming is a direct consequence of motor activity. Indeed, movement of nuclei toward the outer part of the colony was still observed in strains with mutations in microtubule-related motors (dynein and kinesin) and after treatment of wildtype strains with molecules disrupting the cytoskeleton (276). However, motor proteins move organelles in hyphal cells (overview in references 12, 167, 277, 278). Such motor-driven motility of organelles was recently shown to mix the cytoplasm and increase diffusion 
within the cytoplasm (203), which could support the exchange between adjacent hyphal cells. This notion is supported by findings in A. niger, in which depolymerization of actin and tubulin with cytochalasin $\mathrm{A}$ and nocodazole, respectively, reduced the rate of cytoplasmic streaming by about $25 \%$ (279). While cytoplasmic streaming was shown to support apical translocation of organelles $(272,280)$, it may also result in an uneven distribution of organelles, as was shown in N. crassa (281). Cytoplasm streams toward the apex in this fungus. The stream narrows in the septal pores, resulting in microfluidic eddies on the upstream side of the septum, where nuclei can be trapped. The presence of septa in hyphae thus creates subcellular domains within N. crassa hyphae.

It is currently not known if the mechanism underlying cytoplasmic streaming in N. crassa applies to all its hyphae or to other fungi. Most of the work on streaming in $N$. crassa has been done with so-called trunk hyphae. These hyphae are wider than the majority of hyphae in the mycelium. Such trunk hyphae have also been observed in other fungi such as A. niger (282), where they also represent the minority; cytoplasmic streaming in A. niger hyphae has a rate 2,000 times lower than that observed in $N$. crassa, while its growth rate is about 10 -fold lower (279). The cytoplasm of fungal cells is able to contract, which was shown in A. niger, N. crassa, and Trichoderma atroviride $(283,284)$. Thus, motordriven contractions of the cytoskeleton may contribute to cytoplasmic streaming in filamentous fungi.

\section{Selective transport across closed septa}

Fungi have the ability to close their septa, which limits exchange between hyphal compartments (see "Communication and Differentiation of Hyphal Compartments," above). In A. niger it was shown that the newly formed compartments are in exchange with neighbor- ing compartments, while older parts of the mycelium are closed off by plugging of the septal pore, with $\sim 90 \%$ of the 4th to 8th subapical septa closed, followed by complete sealing of the 9th and 10th septa (279). Closure of these septa is mainly caused by a peroxisomelike organelle, the Woronin body (see "Closing Pores by Woronin Bodies," below). Due to the closure of old septa in the center of the colony, transport of nutrients through the cytoplasm cannot occur. Indeed, measurement of a fluorescent glucose analogue provided no evidence for glucose transport from the periphery to the colony center (282). Surprisingly, however, glucose was found to be transported from the center to the periphery of the mycelium. Because the fluorescent glucose analogue accumulated in the cross-walls of the septa, it was concluded that glucose is efficiently transported across the plasma membrane lining the septal cross-walls (282). This could be mediated by transporters that allow the passive passage of sugars down a concentration gradient. Indeed, a hexose transporter, $m s t E$, localizes to septa in A. nidulans (285). Such a septal pore-independent and selective transport mechanism would operate independently of septal pore plugging (Fig. 8). Indeed, transport of glucose between different zones of the colony of $A$. niger was not increased in mutants that were devoid of Woronin bodies (282).

\section{The Mechanism of Septal Pore Closure}

Filamentous fungi grow by apical tip growth of their hyphae. In ascomycete and basidiomycete fungi and a few subgroups of the zygomycetes, septa partition the hypha into subcompartments. Communication between these compartments is mediated by septal pores, which range in size from $25 \mathrm{~nm}$ in C. albicans (286) to $360 \mathrm{~nm}$ in N. crassa (287). The width of the septal pore allows exchange of cytoplasm, including small molecules, ribosomes, and proteins, but also entire organelles such as "older" part of hypha_ Growing tip

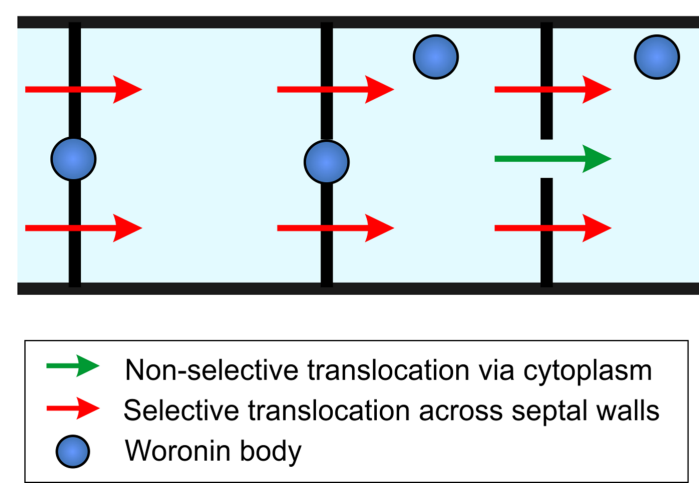

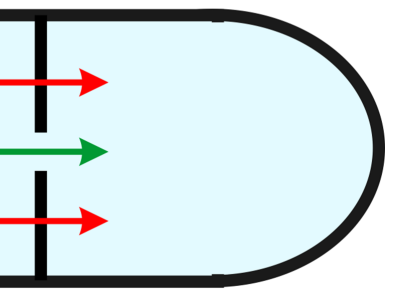

○ H. Wösten \& G. Steinberg
FIGURE 8 Model for tip-ward translocation in A. niger. Newly formed hyphal compartments are in cytoplasmic contact with neighboring cells. The Woronin body is not plugging the septal pore, and cytoplasmic streaming, as well as diffusion through the septal pore, is possible (green arrow). Older septa are plugged by Woronin bodies, which prevents exchange of cytoplasm. However, selective transport of molecules such as glucose toward the growth region is still possible (red arrows). This may involve septum-associated transporters. 
mitochondria and nuclei $(252,254,288)$. However, it is essential for the hyphal cell to keep this exchange under tight control and thus be able to close the septal pore upon stress or cell injury or during particular developmental stages and differentiation. To this end, fungi have developed various ways to plug the septal pore (289). In most cases, insight into the process of pore closure is based on ultrastructural studies, which show closure by organelles, small crystalline bodies, or electron-dense proteinaceous material (289). However, recent research has begun to shed light on the molecular mechanisms underpinning pore closure in filamentous fungi.

\section{Closing pores by proteinaceous material}

Plugging of the septal pore by a deposit occurs independently of hyphal injury and is based on de novo deposition of proteinaceous material (289). Basidiomycete fungi contain a complex septal pore, the dolipore (252), which was shown in S. commune to be plugged by electron-dense proteinaceous material in response to environmental stress (e.g., osmotic shock) or hyphal wounding $(290,291)$. Such deposition appears to be the only mechanism for pore plugging in basidiomycetes (subphyllum Agaricomycotina). Not much is known about the nature of this electron-dense material. However, it has been suggested that the septal pore cap (i.e., parenthesomes; Fig. 9) (252) of the basidiomycete dolipore provides a reservoir from which plugging proteins are released (289). The septal pore cap is derived from the endoplasmic reticulum and flanks both sides of the pore channel. Septal pore caps are usually perforated and were suggested to act as sieves that limit passage of organelles through the dolipore (292); passage of nuclei through dolipores requires its degradation and conversion to a simple pore (293). Support for an additional role of the septal pore cap in pore plugging comes from the recent identification of protein SPC18 in Rhizoctonia solani (294). SPC18 localizes to septal pore caps but was also found in the pore channels, suggesting that the septal pore cap provides the material for plugging the dolipore. This notion is further supported by a mutant in a septal pore cap protein SPC33 in S. commune (295). This mutant lacks septal pore caps and is unable to close the dolipore channel upon wounding. Interestingly, this results in defects in growth and fruiting body formation, indicating that the ability to close the septal pore is a prerequisite for differentiation and development in basidiomycetes.

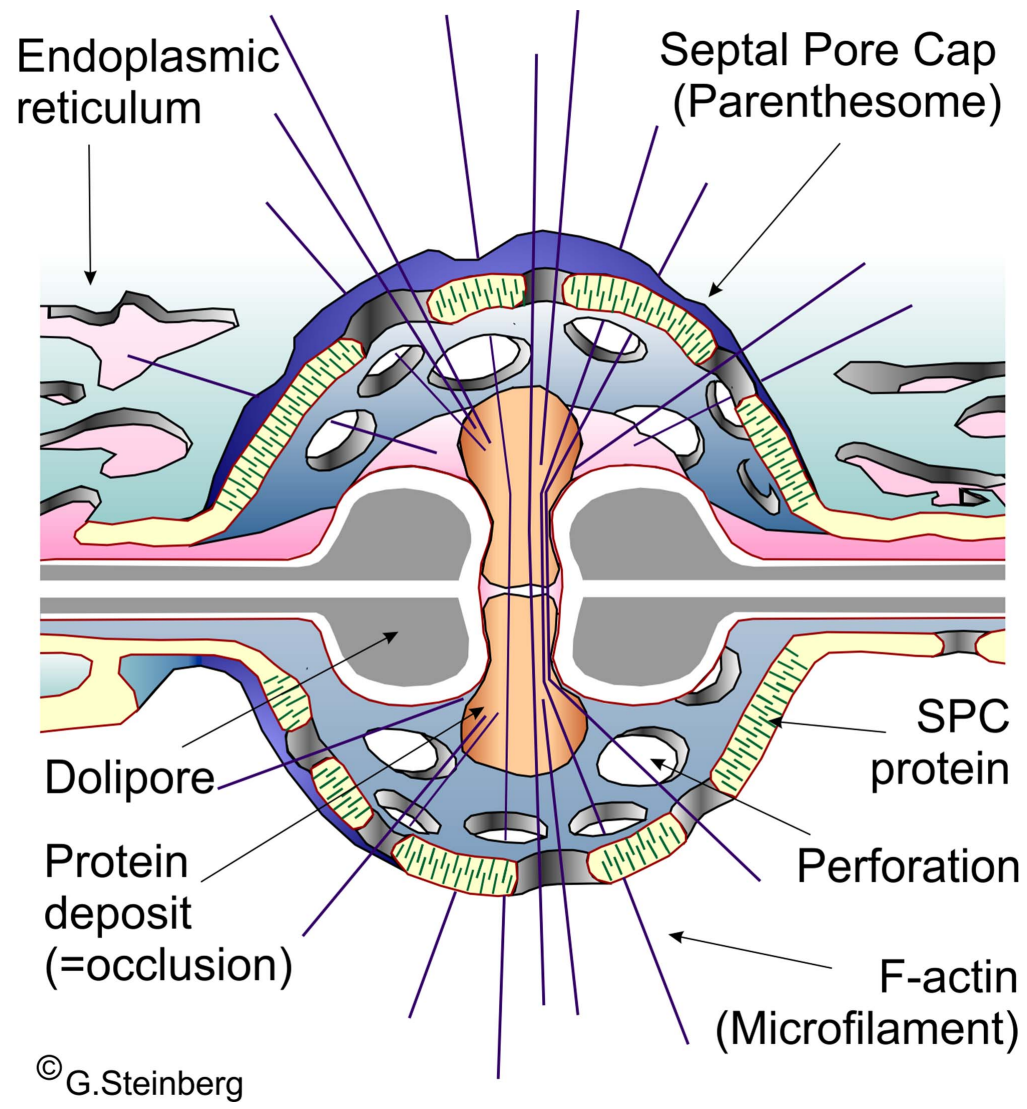

FIGURE 9 Schematic drawing of a dolipore in the basidiomycete Polyporus biennis. The image was redrawn from a reconstruction of electron micrographs, first published in reference $\underline{346}$. 
In older parts of hyphae in the ascomycete fungus N. crassa, septal pores contain accumulations of electron-dense material (287), suggesting that protein deposition limits flow between hyphal compartments. Work in N. crassa, Sordaria macrospora, and Aspergillus oryzae revealed a role for the SOFT/PRO40/SO1 protein (hereafter named $\mathrm{SO}$ ) in plugging septal pores (296-298). SO is a cytoplasmic protein that, upon cell injury or environmental stress, relocates to the septal pore. Mutants lacking SO show slower plugging after cell injury (297) or are significantly impaired in septal closure (298). This suggests that deposition of SO proteins participates in sealing septa. Interestingly, only the C-terminal half of $\mathrm{SO}$ is involved in plugging septal pores in A. orzyae, whereas the N-terminal half appears to serve a septum-independent role in cell-cell fusion (299). This functional diversity may explain the broad phenotypic variation in SO mutants, which show defects in cell-cell fusion, aerial hyphae formation, and conidiation (298, 300).

Whether SO protein represents the electron-dense material in septal pores of ascomycetes (e.g., references 287, 301) is not known. In A. nidulans, the NIMA kinase locates at the septum and the septal pore is open (302). Upon entry into mitosis, NIMA leaves the septum to control early steps in mitosis (303). Upon this relocation of NIMA, the septal pore closes, and this isolates the mitotic cell from neighboring interphase cells (302). Thus, NIMA appears to orchestrate septal pore opening during interphase. Surprisingly, this NIMA-controlled plugging occurs independently of SO and of Woronin bodies (see below), suggesting that additional mechanisms exist which close a septal pore. Indeed, the recent identification of 17 additional septal pore-associated (SPA) proteins (304) suggests that various proteins cooperate in pore closure. A subset of these SPA proteins localize to the lumen of the septal pore channel (SPA type II: SPA3, SPA5, SPA6). Thus, these proteins may participate in controlling communication and exchange between hyphal compartments. Such a role in pore plugging is further supported by biochemical data that show that recombinant SPA5 self-assembles into gel-like aggregates (304). However, the precise cellular role of most SPA proteins needs to be elucidated.

\section{Closing pores by Woronin bodies (WBs)}

Filamentous ascomycetes (subphylum Pezizomycotina) and imperfect fungi (Deuteromycota) have developed an additional mechanism for septal pore plugging. This is based on a fungus-specific organelle, the WB. WBs were named by A. H. Reginald Buller (305) after the Russian botanist Mikhail Strepanovich Woronin, who first described kleine Körnchen (small granules) adjacent to septa in Ascobolus pulcherrimus (306). Woronin's observations were confirmed in various fungi, where these highly refractive particles were found to move within the cytoplasm (see reference $\underline{305}$ for references). Subsequent electron microscopy studies revealed that WBs are spherical membrane-bound organelles of 100 to $750 \mathrm{~nm}$ in diameter (289). Fungal cells contain usually 3 to $6 \mathrm{WBs}$ adjacent to their septa (305, 307), but a large number of additional WBs are found in the cytoplasm of $A$. nidulans and A. fumigatus (302, 308, 309). Septum-associated WBs are nonmobile and anchored at the septal pore $(301,308,310)$. In Neurospora and Sordaria, WBs are larger and are anchored at the cell periphery, which is thought to be an adaptation to the prominent and rapid cytoplasmic streaming seen in these fungi (311).

The main purpose of WB-based septal pore closure is to prevent catastrophic loss of cytoplasm after hyphal injury (289). The first insight into such a function in septal pore plugging was provided by ultrastructural studies that showed WBs sealing septa in wounded hyphae (312-314). A breakthrough came with the identification of the protein Hex1 in WBs of N. crassa (315, 316), which was subsequently reported in M. grisea (317), Trichoderma reesei (318), A. oryzae (301), and A. fumigatus (308). Hex1 is the main component of the crystalline matrix of WBs $(319,320)$, and deletion of hex genes results in the absence of WBs $(301,308, \underline{315}$, 316). Strikingly, these null mutants are impaired in sealing their septa after injury, which strongly indicates a role of WBs in septal pore plugging. However, WBs also seal 5 to $13 \%$ of septal pores in unwounded hyphae (321). This suggests that WBs have additional roles in restricting flow through septal pores in healthy hyphae, and this may generate heterogeneity within the mycelium (261).

Ultrastructural studies of F. oxysporum suggested that WBs originate from microbodies (i.e., peroxisomes and glyoxysomes; reference 322 ). This conclusion gained support by the finding that antibodies against the peroxisomal targeting signal recognize WBs (323). Hex1 from $N$. crassa contains a peroxisomal targeting signal, and live-cell imaging confirmed that Hex1 crystals are formed at peroxisomes (324), where a Woronin sorting complex (WSC) supports assembly of Hex1 and formation of WBs, as well as cortical anchorage of the organelle (325). A role for the WSC in WB formation was confirmed in A. fumigatus, although WSC was not involved in anchorage of WBs near the septum (326). 
Finally, it was shown that mutants deleted in peroxisomal pex-genes (pex6, pex14, pex11), required for proliferation or biogenesis of peroxisomes in M. grisea, N. crassa, and A. oryzae, lack WBs (327-329). Taken together, these studies provide compelling evidence for the conclusion that WBs derive from peroxisomes.

It was recognized early that WBs, once in position, are stationary and even resist fast cytoplasmic streaming $(301,305,308,324, \underline{325})$. Interestingly, when WBs were misplaced by an optical laser trap in N. haematococca, they snapped back to their original position at the septum (330). This simple experiment strongly suggests the existence of a physical tether that holds WBs in position. Indeed, ultrastructural studies suggested a fibrous connection between WBs and the septal pore (309). Again, it was work with $N$. crassa that moved the field forward and revealed the molecular nature of this tether. A genetic screen for mutants defective in WB segregation identified the leashin (lab) locus, which is involved in WB tethering (331). This locus encodes two proteins, LAH-1 and LAH-2. While LAH-1 tethers WBs to the cell cortex, LAH-2 is located at the hyphal apex and the septal pore, where it performs unknown functions. In most other ascomycetes, only LAH-2 homologues, consisting of 6,000 to 7,500 amino acids, are found that have been shown to tether WBs to the septum. In A. oryzae and A. fumigatus mutants that lack Lah proteins, WBs are no longer tethered to the septum and hyphae fail to plug their septal pores after wounding (326, 332). Most strikingly, a shorter version of Lah reduces the distance of WBs to the septal pore (from 99 to $50 \mathrm{~nm}$ ) (332), which adds further evidence for a role of Lah in tethering WBs to septal pores. The molecular details of how Lah proteins tether the WB proteins may differ between fungi, because Lah was shown to interact with WSC in N. crassa (331), whereas Lah was reported to bind directly to HexA in A. fumigatus (326). How the cytoplasmic tether interacts with the WB core protein HexA is not understood.

The mechanism by which WBs move into the septal pore during plugging remains elusive. A tempting hypothesis is that hyphal injury results in high pressure in the adjacent cells, and bulk flow of cytoplasm moves WBs into the pore channel $(310,313)$. Indeed, sealing of septal pores takes several seconds, and hyphal cells often show some cytoplasmic bleeding before the pore is plugged $(261,297)$. However, such a passive mechanism does not explain why only one WB seals the septal pore while the others remain unaffected (307). Alternatively, it was suggested that an active, maybe cytoskeletondependent or contractile mechanism could draw WBs toward the septum $(307,310)$. The nature of such a mechanism is not known, but it may involve the tether protein Lah. Indeed, Lah shares short sequence motifs with the muscle protein titin $(331,332)$, which were shown to respond to changes in intracellular calcium, thereby changing the elasticity of the protein (333). Hyphal wounding increases calcium levels at the septal pore (304), which supports the idea that Lah could act as an elastic molecular spring that drags WBs into the septal pore.

In $A$. nidulans and $A$. oryzae the vast majority of the WBs are not associated with the septum $(302,308)$, but rather move rapidly along the cytoskeleton at a speed of $\sim 1.4 \mu \mathrm{m} / \mathrm{s}(302)$. Similar behavior was described by early light microscopists $(\underline{305}$ and references therein), suggesting that WB motility is a common feature. Currently, neither the molecular machinery for this motility nor the biological role of these moving WBs is understood. One possibility is that immature WBs are motile until they settle at the septum. Alternatively, WBs may have additional and septum-independent functions in the fungal cell. Assessing this question is further complicated by the fact that contradictory conclusions were drawn from hex1 mutants in various fungi. While Hex1, and therefore WBs, in A. oryzae was found to be essential for conidiaton (301), N. crassa mutants deleted in HEX-1 either showed no defect in conidiation (315) or exhibited poor conidiation (316). Moreover, in the plant pathogen M. grisea, the Hex1 homologue MVP1 was reported to be dispensable for virulence (317), whereas another study concluded that Hex1 in this fungus is highly important for its full virulence (334). The reason for such phenotypic variation is currently not known.

\section{Consolidation}

The final step after plugging the pore by protein deposit and/or WBs is the development of a permanent seal of the pore. This process, called consolidation, is found in asco- and basidiomycetes (289, 335). It involves synthesis and deposition of electron-lucent cell wall material at the septum and occurs within $30 \mathrm{~min}$ to $3 \mathrm{~h}$ after hyphal wounding (290, 307, 314). Cell wall formation requires delivery of secretory vesicles, which carry cell wall synthases along the cytoskeleton $(135,136$, 336, 337). Indeed, large numbers of vesicles (314), as well as actin filaments and associated myosin- 5 motors, concentrate at the septal pore of injured hyphae (304). Thus, consolidation results in permanent sealing, which follows the rapid emergency plugging of septal pores in response to hyphal cell injury. 


\section{CONCLUDING REMARKS AND FUTURE DIRECTIONS}

In this article, we have summarized our current knowledge of important processes underlying hyphal growth in filamentous fungi. We have shown that hyphal morphogenesis and septum formation are distinct morphogenetic processes that rely on the cytoskeleton and vesicle trafficking machinery to direct localized cell wall deposition to a precise location. Vesicle trafficking also characterizes the conventional secretory pathway in fungi. We have summarized our understanding of the processing of secretory cargo across the Golgi, coatindependent secretory vesicle budding from the transGolgi network, and the composition of the Spitzenkörper. Recent identification of nonclassical pathways and the role of fungal-specific myosin-chitin synthases in exocytosis add to the complexity of the secretory pathway in filamentous fungi. In addition, it has emerged that EEs are not only involved in the endocytic pathway; they are also crucial for the spatial organization of the hyphal cell and perform specialized roles in long-range signaling, melanin biosynthesis, septin filament assembly and organizing protein translation in the cell. Finally, we have summarized our current knowledge of the mechanism of septum plugging and its role in controlling communication between hyphal cells.

While our understanding of various proteins and structures involved in these critical processes is growing rapidly, little is known about the regulatory mechanisms that orchestrate them. Current research is focused on a few model fungi; this limits comparative studies. However, comparative genomics among fungal species belonging to different taxa will allow identification of conserved key core determinants of hyphal tip growth. Furthermore, establishing molecular tools for cytological studies in nonmodel fungi, such as the wheat pathogen Z. tritici $(166,338-343)$ or the grass pathogen species Ustilago bromivora and Brachypodium spp. (344), will enable more detailed comparison of the cytology of hyphal growth and fungal pathogenicity.

\section{REFERENCES}

1. Berbee ML, Taylor JW. 2010. Dating the molecular clock in fungi: how close are we? Fungal Biol Rev 24:1-16. http://dx.doi.org/10.1016/j.fbr .2010 .03 .001

2. Stajich JE, Berbee ML, Blackwell M, Hibbett DS, James TY, Spatafora JW, Taylor JW. 2009. The fungi. Curr Biol 19:R840-R845. http://dx.doi .org/10.1016/j.cub.2009.07.004

3. Evans CS, Hedger JN. 2001. Degradation of plant cell wall polymers, p 1-26. In Gadd GM (ed), Fungi in Bioremediation. Cambridge University Press, Cambridge, United Kingdom. http://dx.doi.org/10.1017/СВO9780 511541780.002

4. Brundrett MC. 2009. Mycorrhizal associations and other means of nutrition of vascular plants: understanding the global diversity of host plants by resolving conflicting information and developing reliable means of diagnosis. Plant Soil 320:37-77. http://dx.doi.org/10.1007/s11104-008 -9877-9

5. Iwashita K. 2002. Recent studies of protein secretion by filamentous fungi. J Biosci Bioeng 94:530-535. http://dx.doi.org/10.1016/S1389 $-1723(02) 80191-8$

6. Brown GD, Denning DW, Gow NA, Levitz SM, Netea MG, White TC. 2012. Hidden killers: human fungal infections. Sci Transl Med 4:165rv13. http://dx.doi.org/10.1126/scitranslmed.3004404

7. Fisher MC, Henk DA, Briggs CJ, Brownstein JS, Madoff LC, McCraw SL, Gurr SJ. 2012. Emerging fungal threats to animal, plant and ecosystem health. Nature 484:186-194. http://dx.doi.org/10.1038/nature10947

8. Harris SD. 2001. Septum formation in Aspergillus nidulans. Curr Opin Microbiol 4:736-739. http://dx.doi.org/10.1016/S1369-5274(01) 00276-4

9. Bartnicki-Garcia S, Lippman E. 1969. Fungal morphogenesis: cell wall construction in Mucor rouxii. Science 165:302-304. http://dx.doi.org /10.1126/science.165.3890.302

10. Reinhardt MO. 1892. Das Wachstum von Pilzhyphen. Jahrb Wiss Bot 23:479-566.

11. Wessels JGH. 1988. A steady-state model for apical wall growth in fungi. Acta Bot Neerl 37:3-16. http://dx.doi.org/10.1111/j.1438-8677 1988.tb01576.x

12. Steinberg G. 2007. Hyphal growth: a tale of motors, lipids, and the Spitzenkörper. Eukaryot Cell 6:351-360. http://dx.doi.org/10.1128/EC $.00381-06$

13. Riquelme M, Roberson RW, Sánchez-León E. 2016. Hyphal tip growth in filamentous fungi, p 47-66. In Wendland J (ed), Growth, Differentiation and Sexuality, vol. I, 3rd ed. Springer International Publishing, Cham, Switzerland.

14. Peñalva MA. 2010. Endocytosis in filamentous fungi: Cinderella gets her reward. Curr Opin Microbiol 13:684-692. http://dx.doi.org/10.1016 lj.mib.2010.09.005

15. Steinberg G. 2014. Endocytosis and early endosome motility in filamentous fungi. Curr Opin Microbiol 20:10-18. http://dx.doi.org/10.1016 /j.mib.2014.04.001

16. Jedd G, Pieuchot L. 2012. Multiple modes for gatekeeping at fungal cell-to-cell channels. Mol Microbiol 86:1291-1294. http://dx.doi.org /10.1111/mmi.12074

17. Wösten HA, van Veluw GJ, de Bekker C, Krijgsheld P. 2013. Heterogeneity in the mycelium: implications for the use of fungi as cell factories. Biotechnol Lett 35:1155-1164. http://dx.doi.org/10.1007/s10529 $-013-1210-\mathrm{x}$

18. Harris SD. 2011. Hyphal morphogenesis: an evolutionary perspective. Fungal Biol 115:475-484. http://dx.doi.org/10.1016/j.funbio.2011.02 .002

19. Celio GJ, Padamsee M, Dentinger BT, Bauer R, McLaughlin DJ. 2006. Assembling the fungal tree of life: constructing the structural and biochemical database. Mycologia 98:850-859. http://dx.doi.org/10.3852 Imycologia.98.6.850

20. Harris SD. 2010. Hyphal growth and polarity, p 238-259. In Borkovich KA, Ebbole DJ (ed), Cellular and Molecular Biology of Filamentous Fungi. ASM Press, Washington, DC.

21. Riquelme M. 2013. Tip growth in filamentous fungi: a road trip to the apex. Annu Rev Microbiol 67:587-609. http://dx.doi.org/10.1146 lannurev-micro-092412-155652

22. Chang F, Peter M. 2003. Yeasts make their mark. Nat Cell Biol 5:294299. http://dx.doi.org/10.1038/ncb0403-294

23. Turrà D, El Ghalid M, Rossi F, Di Pietro A. 2015. Fungal pathogen uses sex pheromone receptor for chemotropic sensing of host plant signals. Nature 527:521-524. http://dx.doi.org/10.1038/nature15516

24. Chant J. 1999. Cell polarity in yeast. Annu Rev Cell Dev Biol 15:365391. http://dx.doi.org/10.1146/annurev.cellbio.15.1.365 
25. Chang F, Martin SG. 2009. Shaping fission yeast with microtubules. Cold Spring Harb Perspect Biol 1:a001347. http://dx.doi.org/10.1101 /cshperspect.a001347

26. Fischer R, Zekert N, Takeshita N. 2008. Polarized growth in fungi: interplay between the cytoskeleton, positional markers and membrane domains. Mol Microbiol 68:813-826. http://dx.doi.org/10.1111/j.1365 $\underline{-2958.2008 .06193 . x}$

27. Justa-Schuch D, Heilig Y, Richthammer C, Seiler S. 2010. Septum formation is regulated by the RHO4-specific exchange factors BUD3 and RGF3 and by the landmark protein BUD4 in Neurospora crassa. Mol Microbiol 76:220-235. http://dx.doi.org/10.1111/j.1365-2958.2010 $.07093 . \mathrm{x}$

28. Si H, Justa-Schuch D, Seiler S, Harris SD. 2010. Regulation of septum formation by the Bud3-Rho4 GTPase module in Aspergillus nidulans. Genetics 185:165-176. http://dx.doi.org/10.1534/genetics.110.114165

29. Harris SD. 1999. Morphogenesis is coordinated with nuclear division in germinating Aspergillus nidulans conidiospores. Microbiology 145: 2747-2756. http://dx.doi.org/10.1099/00221287-145-10-2747

30. Konzack S, Rischitor PE, Enke C, Fischer R. 2005. The role of the kinesin motor KipA in microtubule organization and polarized growth of Aspergillus nidulans. Mol Biol Cell 16:497-506. http://dx.doi.org $\underline{110.1091 / \mathrm{mbc} . \mathrm{E} 04-02-0083}$

31. Harris SD. 2008. Branching of fungal hyphae: regulation, mechanisms and comparison with other branching systems. Mycologia 100:823-832. http://dx.doi.org/10.3852/08-177

32. Si H, Rittenour WR, Harris SD. 2016. Roles of Aspergillus nidulans Cdc42/Rho GTPase regulators in hyphal morphogenesis and development. Mycologia 108:543-555. http://dx.doi.org/10.3852/15-232

33. DeMay BS, Meseroll RA, Occhipinti P, Gladfelter AS. 2009. Regulation of distinct septin rings in a single cell by Elm1p and Gin $4 p$ kinases. Mol Biol Cell 20:2311-2326. http://dx.doi.org/10.1091/mbc.E08-12-1169

34. Bridges AA, Jentzsch MS, Oakes PW, Occhipinti P, Gladfelter AS. 2016. Micron-scale plasma membrane curvature is recognized by the septin cytoskeleton. J Cell Biol 213:23-32. http://dx.doi.org/10.1083/jcb .201512029

35. Semighini CP, Harris SD. 2008. Regulation of apical dominance in Aspergillus nidulans hyphae by reactive oxygen species. Genetics 179: 1919-1932. http://dx.doi.org/10.1534/genetics.108.089318

36. Takemoto D, Tanaka A, Scott B. 2006. A p67Phox-like regulator is recruited to control hyphal branching in a fungal-grass mutualistic symbiosis. Plant Cell 18:2807-2821. http://dx.doi.org/10.1105/tpc.106.046169 37. Taheri-Talesh N, Horio T, Araujo-Bazán L, Dou X, Espeso EA, Peñalva MA, Osmani SA, Oakley BR. 2008. The tip growth apparatus of Aspergillus nidulans. Mol Biol Cell 19:1439-1449. http://dx.doi.org /10.1091/mbc.E07-05-0464

38. Upadhyay S, Shaw BD. 2008. The role of actin, fimbrin and endocytosis in growth of hyphae in Aspergillus nidulans. Mol Microbiol 68: 690-705. http://dx.doi.org/10.1111/j.1365-2958.2008.06178.x

39. Schultzhaus Z, Yan H, Shaw BD. 2015. Aspergillus nidulans flippase DnfA is cargo of the endocytic collar and plays complementary roles in growth and phosphatidylserine asymmetry with another flippase, DnfB. Mol Microbiol 97:18-32. http://dx.doi.org/10.1111/mmi.13019

40. Shaw BD, Chung DW, Wang CL, Quintanilla LA, Upadhyay S. 2011. A role for endocytic recycling in hyphal growth. Fungal Biol 115:541546. http://dx.doi.org/10.1016/j.funbio.2011.02.010

41. Takeshita N, Higashitsuji Y, Konzack S, Fischer R. 2008. Apical sterol-rich membranes are essential for localizing cell end markers that determine growth directionality in the filamentous fungus Aspergillus nidulans. Mol Biol Cell 19:339-351. http://dx.doi.org/10.1091/mbc.E07 $\underline{-06-0523}$

42. Ishitsuka Y, Savage N, Li Y, Bergs A, Grün N, Kohler D, Donnelly R, Nienhaus GU, Fischer R, Takeshita N. 2015. Superresolution microscopy reveals a dynamic picture of cell polarity maintenance during directional growth. Sci Adv 1:e1500947. http://dx.doi.org/10.1126/sciadv.1500947
43. Pearson CL, Xu K, Sharpless KE, Harris SD. 2004. MesA, a novel fungal protein required for the stabilization of polarity axes in Aspergillus nidulans. Mol Biol Cell 15:3658-3672. http://dx.doi.org/10.1091/mbc .E03-11-0803

44. Takeshita N, Diallinas G, Fischer R. 2012. The role of flotillin FloA and stomatin StoA in the maintenance of apical sterol-rich membrane domains and polarity in the filamentous fungus Aspergillus nidulans. Mol Microbiol 83:1136-1152. http://dx.doi.org/10.1111/j.1365-2958.2012 $.07996 . \mathrm{x}$

45. Chang F, Minc N. 2014. Electrochemical control of cell and tissue polarity. Annu Rev Cell Dev Biol 30:317-336. http://dx.doi.org/10.1146 lannurev-cellbio-100913-013357

46. Thomson DD, Wehmeier S, Byfield FJ, Janmey PA, Caballero-Lima D, Crossley A, Brand AC. 2015. Contact-induced apical asymmetry drives the thigmotropic responses of Candida albicans hyphae. Cell Microbiol 17:342-354. http://dx.doi.org/10.1111/cmi.12369

47. Lew DJ, Reed SI. 1995. Cell cycle control of morphogenesis in budding yeast. Curr Opin Genet Dev 5:17-23. http://dx.doi.org/10.1016/S0959 -437X(95)90048-9

48. Wang Y. 2009. CDKs and the yeast-hyphal decision. Curr Opin Microbiol 12:644-649. http://dx.doi.org/10.1016/j.mib.2009.09.002

49. Li CR, Au Yong JY, Wang YM, Wang Y. 2012. CDK regulates septin organization through cell-cycle-dependent phosphorylation of the Nim1related kinase Gin4. J Cell Sci 125:2533-2543. http://dx.doi.org/10.1242 lics.104497

50. Wang H, Huang ZX, Au Yong JY, Zou H, Zeng G, Gao J, Wang Y, Wong AH, Wang Y. 2016. CDK phosphorylates the polarisome scaffold Spa2 to maintain its localization at the site of cell growth. Mol Microbiol 101:250-264. http://dx.doi.org/10.1111/mmi.13386

51. Sgarlata C, Pérez-Martín J. 2005. Inhibitory phosphorylation of a mitotic cyclin-dependent kinase regulates the morphogenesis, cell size and virulence of the smut fungus Ustilago maydis. J Cell Sci 118:3607-3622. http://dx.doi.org/10.1242/jcs.02499

52. Morris NR. 1975. Mitotic mutants of Aspergillus nidulans. Genet Res 26:237-254. http://dx.doi.org/10.1017/S0016672300016049

53. Fiddy C, Trinci AP. 1976. Mitosis, septation, branching and the duplication cycle in Aspergillus nidulans. J Gen Microbiol 97:169-184. http://dx.doi.org/10.1099/00221287-97-2-169

54. Momany M, Taylor I. 2000. Landmarks in the early duplication cycles of Aspergillus fumigatus and Aspergillus nidulans: polarity, germ tube emergence and septation. Microbiology 146:3279-3284. http://dx.doi.org /10.1099/00221287-146-12-3279

55. Gladfelter AS, Hungerbuehler AK, Philippsen P. 2006. Asynchronous nuclear division cycles in multinucleated cells. J Cell Biol 172:347-362. http://dx.doi.org/10.1083/jcb.200507003

56. Bergen LG, Upshall A, Morris NR. 1984. S-phase, G2, and nuclear division mutants of Aspergillus nidulans. J Bacteriol 159:114119.

57. Peñalva MA, Galindo A, Abenza JF, Pinar M, Calcagno-Pizarelli AM, Arst HN, Pantazopoulou A. 2012. Searching for gold beyond mitosis: mining intracellular membrane traffic in Aspergillus nidulans. Cell Logist 2:2-14. http://dx.doi.org/10.4161/cl.19304

58. Harris SD, Hofmann AF, Tedford HW, Lee MP. 1999. Identification and characterization of genes required for hyphal morphogenesis in the filamentous fungus Aspergillus nidulans. Genetics 151:10151025 .

59. Momany M, Westfall PJ, Abramowsky G. 1999. Aspergillus nidulans swo mutants show defects in polarity establishment, polarity maintenance and hyphal morphogenesis. Genetics 151:557-567.

60. Pinar M, Pantazopoulou A, Arst HN Jr, Peñalva MA. 2013. Acute inactivation of the Aspergillus nidulans Golgi membrane fusion machinery: correlation of apical extension arrest and tip swelling with cisternal disorganization. Mol Microbiol 89:228-248. http://dx.doi.org/10.1111 $\underline{\underline{m m i} .12280}$ 
61. Malhotra V. 2013. Unconventional protein secretion: an evolving mechanism. EMBO J 32:1660-1664. http://dx.doi.org/10.1038/emboj .2013 .104

62. Klumperman J. 2011. Architecture of the mammalian Golgi. Cold Spring Harb Perspect Biol 3:a005181. http://dx.doi.org/10.1101 /cshperspect.a005181

63. Pantazopoulou A. 2016. The Golgi apparatus: insights from filamentous fungi. Mycologia 108:603-622. http://dx.doi.org/10.3852/15-309

64. Pantazopoulou A, Peñalva MA. 2011. Characterization of Aspergillus nidulans RabC/Rab6. Traffic 12:386-406. http://dx.doi.org/10.1111/j.1600 -0854.2011.01164.x

65. Sánchez-León E, Bowman B, Seidel C, Fischer R, Novick P, Riquelme M. 2015. The Rab GTPase YPT-1 associates with Golgi cisternae and Spitzenkörper microvesicles in Neurospora crassa. Mol Microbiol 95: 472-490. http://dx.doi.org/10.1111/mmi.12878

66. Wooding S, Pelham HRB. 1998. The dynamics of Golgi protein traffic visualized in living yeast cells. Mol Biol Cell 9:2667-2680. http://dx.doi .org/10.1091/mbc.9.9.2667

67. Breakspear A, Langford KJ, Momany M, Assinder SJ. 2007. CopA: GFP localizes to putative Golgi equivalents in Aspergillus nidulans. FEMS Microbiol Lett 277:90-97. http://dx.doi.org/10.1111/j.1574-6968.2007 $.00945 . \mathrm{x}$

68. Pantazopoulou A, Peñalva MA. 2009. Organization and dynamics of the Aspergillus nidulans Golgi during apical extension and mitosis. Mol Biol Cell 20:4335-4347. http://dx.doi.org/10.1091/mbc.E09-03-0254

69. Glick BS, Luini A. 2011. Models for Golgi traffic: a critical assessment. Cold Spring Harb Perspect Biol 3:a005215. http://dx.doi.org/10.1101 /cshperspect.a005215

70. Losev E, Reinke CA, Jellen J, Strongin DE, Bevis BJ, Glick BS. 2006. Golgi maturation visualized in living yeast. Nature 441:1002-1006. http://dx.doi.org/10.1038/nature04717

71. Matsuura-Tokita K, Takeuchi M, Ichihara A, Mikuriya K, Nakano A. 2006. Live imaging of yeast Golgi cisternal maturation. Nature 441:10071010. http://dx.doi.org/10.1038/nature04737

72. Patterson GH, Hirschberg K, Polishchuk RS, Gerlich D, Phair RD, Lippincott-Schwartz J. 2008. Transport through the Golgi apparatus by rapid partitioning within a two-phase membrane system. Cell 133:10551067. http://dx.doi.org/10.1016/j.cell.2008.04.044

73. Papanikou E, Glick BS. 2014. Golgi compartmentation and identity. Curr Opin Cell Biol 29:74-81. http://dx.doi.org/10.1016/j.ceb.2014.04 .010

74. Bonifacino JS, Glick BS. 2004. The mechanisms of vesicle budding and fusion. Cell 116:153-166. http://dx.doi.org/10.1016/S0092-8674(03) $\underline{01079-1}$

75. López-Berges MS, Pinar M, Abenza JF, Arst HN Jr, Peñalva MA. 2016. The Aspergillus nidulans syntaxin PepA(Pep12) is regulated by two Sec1/Munc-18 proteins to mediate fusion events at early endosomes, late endosomes and vacuoles. Mol Microbiol 99:199-216. http://dx.doi.org /10.1111/mmi.13226

76. Stanley P. 2011. Golgi glycosylation. Cold Spring Harb Perspect Biol 3:a005199. http://dx.doi.org/10.1101/cshperspect.a005199

77. Jackson-Hayes L, Hill TW, Loprete DM, Fay LM, Gordon BS, Nkashama SA, Patel RK, Sartain CV. 2008. Two GDP-mannose transporters contribute to hyphal form and cell wall integrity in Aspergillus nidulans. Microbiology 154:2037-2047. http://dx.doi.org/10.1099/mic.0 $.2008 / 017483-0$

78. Whyte JR, Munro S. 2001. The Sec34/35 Golgi transport complex is related to the exocyst, defining a family of complexes involved in multiple steps of membrane traffic. Dev Cell 1:527-537. http://dx.doi.org/10.1016 /S1534-5807(01)00063-6

79. Ungar D, Oka T, Krieger M, Hughson FM. 2006. Retrograde transport on the COG railway. Trends Cell Biol 16:113-120. http://dx.doi.org $\underline{10.1016 / j . t c b .2005 .12 .004}$
80. Gremillion SK, Harris SD, Jackson-Hayes L, Kaminskyj SG, Loprete DM, Gauthier AC, Mercer S, Ravita AJ, Hill TW. 2014. Mutations in proteins of the conserved oligomeric golgi complex affect polarity, cell wall structure, and glycosylation in the filamentous fungus Aspergillus nidulans. Fungal Genet Biol 73:69-82. http://dx.doi.org/10.1016/j.fgb .2014 .10 .005

81. Arst HN Jr, Hernández-González M, Peñalva MA, Pantazopoulou A. 2014. GBF/Gea mutant with a single substitution sustains fungal growth in the absence of BIG/Sec7. FEBS Lett 588:4799-4806. http://dx.doi.org /10.1016/j.febslet.2014.11.014

82. Pantazopoulou A, Pinar M, Xiang X, Peñalva MA. 2014. Maturation of late Golgi cisternae into RabE $\mathrm{RAB11}^{\mathrm{R}}$ exocytic post-Golgi carriers visualized in vivo. Mol Biol Cell 25:2428-2443. http://dx.doi.org/10.1091 /mbc.E14-02-0710

83. Pinar M, Arst HN Jr, Pantazopoulou A, Tagua VG, de los Ríos V, Rodríguez-Salarichs J, Díaz JF, Peñalva MA. 2015. TRAPPII regulates exocytic Golgi exit by mediating nucleotide exchange on the Ypt31 ortholog RabERAB11. Proc Natl Acad Sci USA 112:4346-4351. http://dx.doi.org /10.1073/pnas.1419168112

84. Pinar M, Pantazopoulou A, Peñalva MA. 2013. Live-cell imaging of Aspergillus nidulans autophagy: RAB1 dependence, Golgi independence and ER involvement. Autophagy 9:1024-1043. http://dx.doi.org/10.4161 lauto. 24483

85. Levine TP, Munro S. 2002. Targeting of Golgi-specific pleckstrin homology domains involves both PtdIns 4-kinase-dependent and -independent components. Curr Biol 12:695-704. http://dx.doi.org /10.1016/S0960-9822(02)00779-0

86. Daboussi L, Costaguta G, Payne GS. 2012. Phosphoinositidemediated clathrin adaptor progression at the trans-Golgi network. Nat Cell Biol 14:239-248. http://dx.doi.org/10.1038/ncb2427

87. Schultzhaus Z, Johnson TB, Shaw BD. 2017. Clathrin localization and dynamics in Aspergillus nidulans. Mol Microbiol 103:299-318. http://dx.doi.org/10.1111/mmi.13557

88. Abenza JF, Pantazopoulou A, Rodríguez JM, Galindo A, Peñalva MA. 2009. Long-distance movement of Aspergillus nidulans early endosomes on microtubule tracks. Traffic 10:57-75. http://dx.doi.org/10.1111/j.1600 $\underline{-0854.2008 .00848 . x}$

89. Fischer-Parton S, Parton RM, Hickey PC, Dijksterhuis J, Atkinson HA, Read ND. 2000. Confocal microscopy of FM4-64 as a tool for analysing endocytosis and vesicle trafficking in living fungal hyphae. J Microsc 198:246-259. http://dx.doi.org/10.1046/j.1365-2818.2000.00708.x

90. Valdez-Taubas J, Pelham HR. 2003. Slow diffusion of proteins in the yeast plasma membrane allows polarity to be maintained by endocytic cycling. Curr Biol 13:1636-1640. http://dx.doi.org/10.1016/j.cub.2003 .09 .001

91. Gilbert MJ, Thornton CR, Wakley GE, Talbot NJ. 2006. A P-type ATPase required for rice blast disease and induction of host resistance. Nature 440:535-539. http://dx.doi.org/10.1038/nature04567

92. Hernández-González M, Peñalva MA, Pantazopoulou A. 2015. Conditional inactivation of Aspergillus nidulans sarA(SAR1) uncovers the morphogenetic potential of regulating endoplasmic reticulum (ER) exit. Mol Microbiol 95:491-508. http://dx.doi.org/10.1111/mmi.12880

93. Veldhuisen G, Saloheimo M, Fiers MA, Punt PJ, Contreras R, Penttilä M, van den Hondel CA. 1997. Isolation and analysis of functional homologues of the secretion-related SAR1 gene of Saccharomyces cerevisiae from Aspergillus niger and Trichoderma reesei. Mol Gen Genet 256:446-455.

94. Lee SC, Shaw BD. 2008. Localization and function of ADP ribosylation factor A in Aspergillus nidulans. FEMS Microbiol Lett 283:216222. http://dx.doi.org/10.1111/j.1574-6968.2008.01174.x

95. Morozova N, Liang Y, Tokarev AA, Chen SH, Cox R, Andrejic J, Lipatova Z, Sciorra VA, Emr SD, Segev N. 2006. TRAPPII subunits are required for the specificity switch of a Ypt-Rab GEF. Nat Cell Biol 8:1263-1269. http://dx.doi.org/10.1038/ncb1489 
96. Cai Y, Chin HF, Lazarova D, Menon S, Fu C, Cai H, Sclafani A, Rodgers DW, De La Cruz EM, Ferro-Novick S, Reinisch KM. 2008. The structural basis for activation of the Rab Ypt1p by the TRAPP membranetethering complexes. Cell 133:1202-1213. http://dx.doi.org/10.1016/j.cell 2008.04.049

97. Yang Y, El-Ganiny AM, Bray GE, Sanders DAR, Kaminskyj SGW. 2008. Aspergillus nidulans hypB encodes a Sec7-domain protein important for hyphal morphogenesis. Fungal Genet Biol 45:749-759. http://dx .doi.org/10.1016/j.fgb.2007.11.005

98. Girbardt M. 1957. Der Spitzenkörper von Polystictus versicolor. Planta 50:47-59. http://dx.doi.org/10.1007/BF01912343

99. Girbardt M. 1969. Die Ultrastruktur der Apikalregion von Pilzhyphen. Protoplasma 67:413-441. http://dx.doi.org/10.1007/BF01254905

100. López-Franco R, Bracker CE. 1996. Diversity and dynamics of the Spitzenkörper in growing hyphal tips of higher fungi. Protoplasma 195: 90-111. http://dx.doi.org/10.1007/BF01279189

101. Chapa-y-Lazo B, Lee S, Regan H, Sudbery P. 2011. The mating projections of Saccharomyces cerevisiae and Candida albicans show key characteristics of hyphal growth. Fungal Biol 115:547-556. http://dx.doi .org/10.1016/i.funbio.2011.02.001

102. Hoch HC, Staples RC. 1983. Ultrastructural organization of the nondifferentiated uredospore germling of Uromyces phaseoli variety typica. Mycologia 75:795-824. http://dx.doi.org/10.2307/3792772

103. Lehmler C, Steinberg G, Snetselaar KM, Schliwa M, Kahmann R, Bölker M. 1997. Identification of a motor protein required for filamentous growth in Ustilago maydis. EMBO J 16:3464-3473. http://dx.doi.org 110.1093/emboj/16.12.3464

104. Roberson RW, Saucedo E, Maclean D, Propster J, Unger B, Oneil TA, Parvanehgohar K, Cavanaugh C, Lowry D. 2011. The hyphal tip structure of Basidiobolus sp.: a zygomycete fungus of uncertain phylogeny. Fungal Biol 115:485-492. http://dx.doi.org/10.1016/j.funbio.2011.02.012

105. Vargas M, Aronson JM, Roberson RW. 1993. The cytoplasmic organization of hyphal tip cells in the fungus Allomyces macrogynus. Protoplasma 176:43-52. http://dx.doi.org/10.1007/BF01378938

106. McClure WK, Park D, Robinson PM. 1968. Apical organization in the somatic hyphae of fungi. J Gen Microbiol 50:177-182. http://dx.doi .org/10.1099/00221287-50-2-177

107. Fisher KE, Roberson RW. 2016. Fungal hyphal growth: Spitzenkörper versus apical vesicle crescent. Fungal Genom Biol 6:136.

108. Fisher KE, Roberson RW. 2016. Hyphal tip cytoplasmic organization in four zygomycetous fungi. Mycologia 108:533-542. http://dx.doi .org/10.3852/15-226

109. Bartnicki-Garcia S. 1973. Fundamental aspects of hyphal morphogenesis, p 245-267. In Ashworth JM, Smith E (ed), Microbial Differentiation. Cambridge University Press, Cambridge, United Kingdom.

110. Green PB. 1969. Cell morphogenesis. Annu Rev Plant Pathol 20: 365-394. http://dx.doi.org/10.1146/annurev.pp.20.060169.002053

111. Robertson NF. 1965. Presidential address: the fungal hypha. Trans Br Mycol Soc 48:1-8. http://dx.doi.org/10.1016/S0007-1536(65)80001-8 112. Martínez-Núnez L, Riquelme M. 2015. Role of BGT-1 and BGT-2, two predicted GPI-anchored glycoside hydrolases/glycosyltransferases, in cell wall remodeling in Neurospora crassa. Fungal Genet Biol 85:5870. http://dx.doi.org/10.1016/j.fgb.2015.11.001

113. Bourett TM, Howard RJ. 1991. Ultrastructural immunolocalization of actin in a fungus. Protoplasma 163:199-202. http://dx.doi.org /10.1007/BF01323344

114. Grove SN, Bracker CE. 1970. Protoplasmic organization of hyphal tips among fungi: vesicles and Spitzenkörper. J Bacteriol 104:989-1009.

115. Bartnicki-Garcia S, Hergert F, Gierz G. 1989. Computer simulation of fungal morphogenesis and the mathematical basis for hyphal tip growth. Protoplasma 153:46-57. http://dx.doi.org/10.1007/BF01322464 116. Latgé JP, Calderone R. 2006. The fungal cell wall, p 73-104. In Kues U, Fischer R (ed), The Mycota, vol. 1, Springer-Verlag, Berlin, Germany.
117. Sietsma JH, Wessels JGH. 2006. Apical wall biogenesis, p 53-72. In Kues U, Fischer R (ed), The Mycota, Vol. 1. Springer-Verlag, Berlin, Germany.

118. Riquelme M, Bartnicki-García S, González-Prieto JM, Sánchez-León E, Verdín-Ramos JA, Beltrán-Aguilar A, Freitag M. 2007. Spitzenkorper localization and intracellular traffic of green fluorescent protein-labeled CHS-3 and CHS-6 chitin synthases in living hyphae of Neurospora crassa. Eukaryot Cell 6:1853-1864. http://dx.doi.org/10.1128/EC.00088-07

119. Verdín J, Bartnicki-Garcia S, Riquelme M. 2009. Functional stratification of the Spitzenkörper of Neurospora crassa. Mol Microbiol 74:1044-1053. http://dx.doi.org/10.1111/j.1365-2958.2009.06917.x

120. Riquelme M, Bredeweg EL, Callejas-Negrete O, Roberson RW, Ludwig S, Beltrán-Aguilar A, Seiler S, Novick P, Freitag M. 2014. The Neurospora crassa exocyst complex tethers Spitzenkörper vesicles to the apical plasma membrane during polarized growth. Mol Biol Cell 25: 1312-1326. http://dx.doi.org/10.1091/mbc.E13-06-0299

121. Peñalva MA. 2015. A lipid-managing program maintains a stout Spitzenkörper. Mol Microbiol 97:1-6. http://dx.doi.org/10.1111/mmi .13044

122. Bartnicki-Garcia S. 2002. Hyphal tip growth: outstanding questions, p 29-58. In Osiewacz HD, Molecular Biology of Fungal Development. Marcel Dekker, New York, NY.

123. Harris SD, Read ND, Roberson RW, Shaw B, Seiler S, Plamann M, Momany M. 2005. Polarisome meets Spitzenkörper: microscopy, genetics, and genomics converge. Eukaryot Cell 4:225-229. http://dx.doi.org /10.1128/EC.4.2.225-229.2005

124. Berepiki A, Lichius A, Shoji JY, Tilsner J, Read ND. 2010. F-actin dynamics in Neurospora crassa. Eukaryot Cell 9:547-557. http://dx.doi .org/10.1128/EC.00253-09

125. Delgado-Álvarez DL, Callejas-Negrete OA, Gómez N, Freitag M, Roberson RW, Smith LG, Mouriño-Pérez RR. 2010. Visualization of Factin localization and dynamics with live cell markers in Neurospora crassa. Fungal Genet Biol 47:573-586. http://dx.doi.org/10.1016/j.fgb .2010 .03 .004

126. Takeshita N, Mania D, Herrero S, Ishitsuka Y, Nienhaus GU, Podolski M, Howard J, Fischer R. 2013. The cell-end marker TeaA and the microtubule polymerase AlpA contribute to microtubule guidance at the hyphal tip cortex of Aspergillus nidulans to provide polarity maintenance. J Cell Sci 126:5400-5411. http://dx.doi.org/10.1242/jcs.129841

127. Horio T, Oakley BR. 2005. The role of microtubules in rapid hyphal tip growth of Aspergillus nidulans. Mol Biol Cell 16:918-926. http://dx .doi.org/10.1091/mbc.E04-09-0798

128. Riquelme M, Gierz G, Bartnicki-García S. 2000. Dynein and dynactin deficiencies affect the formation and function of the Spitzenkörper and distort hyphal morphogenesis of Neurospora crassa. Microbiology 146: 1743-1752. http://dx.doi.org/10.1099/00221287-146-7-1743

129. Caballero-Lima D, Kaneva IN, Watton SP, Sudbery PE, Craven CJ. 2013. The spatial distribution of the exocyst and actin cortical patches is sufficient to organize hyphal tip growth. Eukaryot Cell 12:998-1008. http://dx.doi.org/10.1128/EC.00085-13

130. Riquelme M, Reynaga-Peña CG, Gierz G, Bartnicki-García S. 1998. What determines growth direction in fungal hyphae? Fungal Genet Biol 24:101-109. http://dx.doi.org/10.1006/fgbi.1998.1074

131. Vida TA, Emr SD. 1995. A new vital stain for visualizing vacuolar membrane dynamics and endocytosis in yeast. J Cell Biol 128:779-792. http://dx.doi.org/10.1083/jcb.128.5.779

132. Treitschke S, Doehlemann G, Schuster M, Steinberg G. 2010. The myosin motor domain of fungal chitin synthase $\mathrm{V}$ is dispensable for vesicle motility but required for virulence of the maize pathogen Ustilago maydis. Plant Cell 22:2476-2494. http://dx.doi.org/10.1105/tpc.110.075028

133. James TY, Pelin A, Bonen L, Ahrendt S, Sain D, Corradi N, Stajich JE. 2013. Shared signatures of parasitism and phylogenomics unite Cryptomycota and Microsporidia. Curr Biol 23:1548-1553. http://dx .doi.org/10.1016/j.cub.2013.06.057 
134. Weber I, Assmann D, Thines E, Steinberg G. 2006. Polar localizing class $\mathrm{V}$ myosin chitin synthases are essential during early plant infection in the plant pathogenic fungus Ustilago maydis. Plant Cell 18:225-242. http://dx.doi.org/10.1105/tpc.105.037341

135. Schuster M, Treitschke S, Kilaru S, Molloy J, Harmer NJ, Steinberg G. 2012. Myosin-5, kinesin-1 and myosin-17 cooperate in secretion of fungal chitin synthase. EMBO J 31:214-227. http://dx.doi.org/10.1038 lemboj.2011.361

136. Schuster M, Martin-Urdiroz M, Higuchi Y, Hacker C, Kilaru S, Gurr SJ, Steinberg G. 2016. Co-delivery of cell-wall-forming enzymes in the same vesicle for coordinated fungal cell wall formation. Nat Microbiol 1:16149. http://dx.doi.org/10.1038/nmicrobiol.2016.149

137. Fujiwara M, Horiuchi H, Ohta A, Takagi M. 1997. A novel fungal gene encoding chitin synthase with a myosin motor-like domain. Biochem Biophys Res Commun 236:75-78. http://dx.doi.org/10.1006/bbrc.1997.6907

138. Aufauvre-Brown A, Mellado E, Gow NA, Holden DW. 1997. Aspergillus fumigatus chsE: a gene related to CHS3 of Saccharomyces cerevisiae and important for hyphal growth and conidiophore development but not pathogenicity. Fungal Genet Biol 21:141-152. http://dx.doi .org/10.1006/fgbi.1997.0959

139. Jiménez-Ortigosa C, Aimanianda V, Muszkieta L, Mouyna I, Alsteens D, Pire S, Beau R, Krappmann S, Beauvais A, Dufrêne YF, Roncero C, Latgé JP. 2012. Chitin synthases with a myosin motor-like domain control the resistance of Aspergillus fumigatus to echinocandins. Antimicrob Agents Chemother 56:6121-6131. http://dx.doi.org/10.1128 /AAC.00752-12

140. Madrid MP, Di Pietro A, Roncero MI. 2003. Class V chitin synthase determines pathogenesis in the vascular wilt fungus Fusarium oxysporum and mediates resistance to plant defence compounds. Mol Microbiol 47:257-266. http://dx.doi.org/10.1046/j.1365-2958.2003.03299.x

141. Werner S, Sugui JA, Steinberg G, Deising HB. 2007. A chitin synthase with a myosin-like motor domain is essential for hyphal growth, appressorium differentiation, and pathogenicity of the maize anthracnose fungus Colletotrichum graminicola. Mol Plant Microbe Interact 20:15551567. http://dx.doi.org/10.1094/MPMI-20-12-1555

142. Kong LA, Yang J, Li GT, Qi LL, Zhang YJ, Wang CF, Zhao WS, Xu JR, Peng YL. 2012. Different chitin synthase genes are required for various developmental and plant infection processes in the rice blast fungus Magnaporth eoryzae. PLoS Pathog 8:e1002526. http://dx.doi.org /10.1371/journal.ppat.1002526

143. Fajardo-Somera RA, Jöhnk B, Bayram Ö, Valerius O, Braus GH, Riquelme M. 2015. Dissecting the function of the different chitin synthases in vegetative growth and sexual development in Neurospora crassa. Fungal Genet Biol 75:30-45. http://dx.doi.org/10.1016/j.fgb .2015 .01 .002

144. Horiuchi H, Fujiwara M, Yamashita S, Ohta A, Takagi M. 1999. Proliferation of intrahyphal hyphae caused by disruption of csmA, which encodes a class $\mathrm{V}$ chitin synthase with a myosin motor-like domain in Aspergillus nidulans. J Bacteriol 181:3721-3729.

145. Takeshita N, Wernet V, Tsuizaki M, Grün N, Hoshi HO, Ohta A, Fischer R, Horiuchi H. 2015. Transportation of Aspergillus nidulans class III and V chitin synthases to the hyphal tips depends on conventional kinesin. PLoS One 10:e125937. http://dx.doi.org/10.1371/journal.pone .0125937

146. Takeshita N, Ohta A, Horiuchi H. 2005. CsmA, a class V chitin synthase with a myosin motor-like domain, is localized through direct interaction with the actin cytoskeleton in Aspergillus nidulans. Mol Biol Cell 16:1961-1970. http://dx.doi.org/10.1091/mbc.E04-09-0761

147. Read ND, Kalkman ER. 2003. Does endocytosis occur in fungal hyphae? Fungal Genet Biol 39:199-203. http://dx.doi.org/10.1016/S1087 -1845(03)00045-8

148. Hoffmann J, Mendgen K. 1998. Endocytosis and membrane turnover in the germ tube of Uromyces fabae. Fungal Genet Biol 24:77-85. http://dx.doi.org/10.1006/fgbi.1998.1059
149. Steinberg G, Schliwa M, Lehmler C, Bölker M, Kahmann R, McIntosh JR. 1998. Kinesin from the plant pathogenic fungus Ustilago maydis is involved in vacuole formation and cytoplasmic migration. J Cell Sci 111:2235-2246.

150. Atkinson HA, Daniels A, Read ND. 2002. Live-cell imaging of endocytosis during conidial germination in the rice blast fungus, Magnaporthe grisea. Fungal Genet Biol 37:233-244. http://dx.doi.org/10.1016 /S1087-1845(02)00535-2

151. Peñalva MA. 2005. Tracing the endocytic pathway of Aspergillus nidulans with FM4-64. Fungal Genet Biol 42:963-975. http://dx.doi.org /10.1016/j.fgb.2005.09.004

152. Araujo-Bazán L, Peñalva MA, Espeso EA. 2008. Preferential localization of the endocytic internalization machinery to hyphal tips underlies polarization of the actin cytoskeleton in Aspergillus nidulans. Mol Microbiol 67:891-905. http://dx.doi.org/10.1111/j.1365-2958.2007.06102.x

153. Echauri-Espinosa RO, Callejas-Negrete OA, Roberson RW, Bartnicki-García S, Mouriño-Pérez RR. 2012. Coronin is a component of the endocytic collar of hyphae of Neurospora crassa and is necessary for normal growth and morphogenesis. PLoS One 7:e38237. http://dx.doi .org/10.1371/journal.pone.0038237

154. Epp E, Nazarova E, Regan H, Douglas LM, Konopka JB, Vogel J, Whiteway M. 2013. Clathrin- and Arp2/3-independent endocytosis in the fungal pathogen Candida albicans. MBio 4:e00476-13. http://dx.doi.org /10.1128/mBio.00476-13

155. Fuchs U, Hause G, Schuchardt I, Steinberg G. 2006. Endocytosis is essential for pathogenic development in the corn smut fungus Ustilago maydis. Plant Cell 18:2066-2081. http://dx.doi.org/10.1105/tpc.105.039388 156. Higuchi Y, Shoji JY, Arioka M, Kitamoto K. 2009. Endocytosis is crucial for cell polarity and apical membrane recycling in the filamentous fungus Aspergillus oryzae. Eukaryot Cell 8:37-46. http://dx.doi.org /10.1128/EC.00207-08

157. Jorde S, Walther A, Wendland J. 2011. The Ashbya gossypii fimbrin SAC6 is required for fast polarized hyphal tip growth and endocytosis. Microbiol Res 166:137-145. http://dx.doi.org/10.1016/j.micres.2010.09 .003

158. Martin R, Hellwig D, Schaub Y, Bauer J, Walther A, Wendland J. 2007. Functional analysis of Candida albicans genes whose Saccharomyces cerevisiae homologues are involved in endocytosis. Yeast 24:511522. http://dx.doi.org/10.1002/yea.1489

159. Matsuo K, Higuchi Y, Kikuma T, Arioka M, Kitamoto K. 2013. Functional analysis of Abp1p-interacting proteins involved in endocytosis of the MCC component in Aspergillus oryzae. Fungal Genet Biol 56:125134. http://dx.doi.org/10.1016/j.fgb.2013.03.007

160. Wedlich-Söldner R, Bölker M, Kahmann R, Steinberg G. 2000. A putative endosomal t-SNARE links exo- and endocytosis in the phytopathogenic fungus Ustilago maydis. EMBO J 19:1974-1986. http://dx .doi.org/10.1093/emboj/19.9.1974

161. Higuchi Y, Ashwin P, Roger Y, Steinberg G. 2014. Early endosome motility spatially organizes polysome distribution. J Cell Biol 204:343357. http://dx.doi.org/10.1083/jcb.201307164

162. Lemmon MA. 2003. Phosphoinositide recognition domains. Traffic 4:201-213. http://dx.doi.org/10.1034/j.1600-0854.2004.00071.x

163. Chavrier P, Parton RG, Hauri HP, Simons K, Zerial M. 1990. Localization of low molecular weight GTP binding proteins to exocytic and endocytic compartments. Cell 62:317-329. http://dx.doi.org/10.1016/ 0092-8674(90)90369-P

164. van der Sluijs P, Hull M, Webster P, Mâle P, Goud B, Mellman I. 1992. The small GTP-binding protein rab4 controls an early sorting event on the endocytic pathway. Cell 70:729-740. http://dx.doi.org/10.1016 10092-8674(92)90307-X

165. Seidel C, Moreno-Velásquez SD, Riquelme M, Fischer R. 2013. Neurospora crassa NKIN2, a kinesin-3 motor, transports early endosomes and is required for polarized growth. Eukaryot Cell 12:1020-1032. http://dx.doi.org/10.1128/EC.00081-13 
166. Kilaru S, Schuster M, Latz M, Guo M, Steinberg G. 2015. Fluorescent markers of the endocytic pathway in Zymoseptoria tritici. Fungal Genet Biol 79:150-157. http://dx.doi.org/10.1016/j.fgb.2015.03 .019

167. Egan MJ, McClintock MA, Reck-Peterson SL. 2012. Microtubulebased transport in filamentous fungi. Curr Opin Microbiol 15:637-645. http://dx.doi.org/10.1016/j.mib.2012.10.003

168. Svoboda K, Schmidt CF, Schnapp BJ, Block SM. 1993. Direct observation of kinesin stepping by optical trapping interferometry. Nature 365:721-727. http://dx.doi.org/10.1038/365721a0

169. Toba S, Watanabe TM, Yamaguchi-Okimoto L, Toyoshima YY, Higuchi H. 2006. Overlapping hand-over-hand mechanism of single molecular motility of cytoplasmic dynein. Proc Natl Acad Sci USA 103: 5741-5745. http://dx.doi.org/10.1073/pnas.0508511103

170. Plamann M, Minke PF, Tinsley JH, Bruno KS. 1994. Cytoplasmic dynein and actin-related protein Arp1 are required for normal nuclear distribution in filamentous fungi. J Cell Biol 127:139-149. http://dx.doi .org/10.1083/jcb.127.1.139

171. Xiang X, Beckwith SM, Morris NR. 1994. Cytoplasmic dynein is involved in nuclear migration in Aspergillus nidulans. Proc Natl Acad Sci USA 91:2100-2104. http://dx.doi.org/10.1073/pnas.91.6.2100

172. Steinberg G, Schliwa M. 1995. The Neurospora organelle motor: a distant relative of conventional kinesin with unconventional properties. Mol Biol Cell 6:1605-1618. http://dx.doi.org/10.1091/mbc.6.11 $\underline{.1605}$

173. Wu Q, Sandrock TM, Turgeon BG, Yoder OC, Wirsel SG, Aist JR. 1998. A fungal kinesin required for organelle motility, hyphal growth, and morphogenesis. Mol Biol Cell 9:89-101. http://dx.doi.org/10.1091 Imbc.9.1.89

174. Steinberg G. 1997. A kinesin-like mechanoenzyme from the zygomycete Syncephalastrum racemosum shares biochemical similarities with conventional kinesin from Neurospora crassa. Eur J Cell Biol 73: 124-131.

175. Lenz JH, Schuchardt I, Straube A, Steinberg G. 2006. A dynein loading zone for retrograde endosome motility at microtubule plus-ends. EMBO J 25:2275-2286. http://dx.doi.org/10.1038/sj.emboj.7601119

176. Zhang J, Li S, Fischer R, Xiang X. 2003. Accumulation of cytoplasmic dynein and dynactin at microtubule plus ends in Aspergillus nidulans is kinesin dependent. Mol Biol Cell 14:1479-1488. http://dx.doi .org/10.1091/mbc.E02-08-0516

177. Steinberg G. 2011. Motors in fungal morphogenesis: cooperation versus competition. Curr Opin Microbiol 14:660-667. http://dx.doi.org $\underline{\text { /10.1016/j.mib.2011.09.013 }}$

178. Wedlich-Söldner R, Straube A, Friedrich MW, Steinberg G. 2002. A balance of KIF1A-like kinesin and dynein organizes early endosomes in the fungus Ustilago maydis. EMBO J 21:2946-2957. http://dx.doi.org 110.1093/emboj/cdf296

179. Egan MJ, Tan K, Reck-Peterson SL. 2012. Lis1 is an initiation factor for dynein-driven organelle transport. J Cell Biol 197:971-982. http://dx .doi.org/10.1083/jcb.201112101

180. Zekert N, Fischer R. 2009. The Aspergillus nidulans kinesin-3 UncA motor moves vesicles along a subpopulation of microtubules. Mol Biol Cell 20:673-684. http://dx.doi.org/10.1091/mbc.E08-07-0685

181. Miki H, Setou M, Kaneshiro K, Hirokawa N. 2001. All kinesin superfamily protein, KIF, genes in mouse and human. Proc Natl Acad Sci USA 98:7004-7011. http://dx.doi.org/10.1073/pnas.111145398

182. Steinberg G, Perez-Martin J. 2008. Ustilago maydis, a new fungal model system for cell biology. Trends Cell Biol 18:61-67. http://dx.doi . org/10.1016/j.tcb.2007.11.008

183. Higuchi Y, Nakahama T, Shoji JY, Arioka M, Kitamoto K. 2006. Visualization of the endocytic pathway in the filamentous fungus Aspergillus oryzae using an EGFP-fused plasma membrane protein. Biochem Biophys Res Commun 340:784-791. http://dx.doi.org/10.1016/j.bbrc $\underline{.2005 .12 .077}$
184. Han G, Liu B, Zhang J, Zuo W, Morris NR, Xiang X. 2001. The Aspergillus cytoplasmic dynein heavy chain and NUDF localize to microtubule ends and affect microtubule dynamics. Curr Biol 11:719-724. http://dx.doi.org/10.1016/S0960-9822(01)00200-7

185. Schuster M, Kilaru S, Ashwin P, Lin C, Severs NJ, Steinberg G. 2011. Controlled and stochastic retention concentrates dynein at microtubule ends to keep endosomes on track. EMBO J 30:652-664. http://dx .doi.org/10.1038/emboj.2010.360

186. Schuster M, Lipowsky R, Assmann MA, Lenz P, Steinberg G. 2011. Transient binding of dynein controls bidirectional long-range motility of early endosomes. Proc Natl Acad Sci USA 108:3618-3623. http://dx.doi.org/10.1073/pnas.1015839108

187. Zhang J, Qiu R, Arst HN Jr, Peñalva MA, Xiang X. 2014. HookA is a novel dynein-early endosome linker critical for cargo movement in vivo. J Cell Biol 204:1009-1026. http://dx.doi.org/10.1083/jcb.201308009

188. Bielska E, Schuster M, Roger Y, Berepiki A, Soanes DM, Talbot NJ, Steinberg G. 2014. Hook is an adapter that coordinates kinesin-3 and dynein cargo attachment on early endosomes. J Cell Biol 204:989-1007. http://dx.doi.org/10.1083/jcb.201309022

189. Yao X, Wang X, Xiang X. 2014. FHIP and FTS proteins are critical for dynein-mediated transport of early endosomes in Aspergillus. Mol Biol Cell 25:2181-2189. http://dx.doi.org/10.1091/mbc.E14-04-0873

190. Zhang J, Yao X, Fischer L, Abenza JF, Peñalva MA, Xiang X. 2011. The p25 subunit of the dynactin complex is required for dyneinearly endosome interaction. J Cell Biol 193:1245-1255. http://dx.doi.org /10.1083/jcb.201011022

191. Yao X, Arst HN Jr, Wang X, Xiang X. 2015. Discovery of a vezatinlike protein for dynein-mediated early endosome transport. Mol Biol Cell 26:3816-3827. http://dx.doi.org/10.1091/mbc.E15-08-0602

192. Steinberg G. 2015. Kinesin-3 in the basidiomycete Ustilago maydis transports organelles along the entire microtubule array. Fungal Genet Biol 74:59-61. http://dx.doi.org/10.1016/j.fgb.2014.10.010

193. Rink J, Ghigo E, Kalaidzidis Y, Zerial M. 2005. Rab conversion as a mechanism of progression from early to late endosomes. Cell 122:735749. http://dx.doi.org/10.1016/j.cell.2005.06.043

194. Abenza JF, Galindo A, Pinar M, Pantazopoulou A, de los Ríos V, Peñalva MA. 2012. Endosomal maturation by Rab conversion in Aspergillus nidulans is coupled to dynein-mediated basipetal movement. Mol Biol Cell 23:1889-1901. http://dx.doi.org/10.1091/mbc.E11-11-0925

195. Abenza JF, Galindo A, Pantazopoulou A, Gil C, de los Ríos V, Peñalva MA. 2010. Aspergillus RabB Rab5 integrates acquisition of degradative identity with the long distance movement of early endosomes. Mol Biol Cell 21:2756-2769. http://dx.doi.org/10.1091/mbc.E10-02 $\underline{-0119}$

196. Schnitzer MJ, Block SM. 1997. Kinesin hydrolyses one ATP per 8-nm step. Nature 388:386-390. http://dx.doi.org/10.1038/41111

197. Baumann S, Pohlmann T, Jungbluth M, Brachmann A, Feldbrügge M. 2012. Kinesin-3 and dynein mediate microtubule-dependent cotransport of mRNPs and endosomes. J Cell Sci 125:2740-2752. http://dx .doi.org/10.1242/jcs.101212

198. König J, Baumann S, Koepke J, Pohlmann T, Zarnack K, Feldbrügge M. 2009. The fungal RNA-binding protein Rrm4 mediates long-distance transport of $u b i 1$ and rho3 mRNAs. EMBO J 28:1855-1866. http://dx .doi.org/10.1038/emboj.2009.145

199. Pohlmann T, Baumann S, Haag C, Albrecht M, Feldbrügge M. 2015. A FYVE zinc finger domain protein specifically links mRNA transport to endosome trafficking. eL ife 4:e06041. http://dx.doi.org/10.7554/eLife.06041 200. Vollmeister E, Schipper K, Feldbrügge M. 2012. Microtubuledependent mRNA transport in the model microorganism Ustilago maydis. RNA Biol 9:261-268. http://dx.doi.org/10.4161/rna.19432

201. Guimaraes SC, Schuster M, Bielska E, Dagdas G, Kilaru S, Meadows BR, Schrader M, Steinberg G. 2015. Peroxisomes, lipid droplets, and endoplasmic reticulum "hitchhike" on motile early endosomes. J Cell Biol 211:945-954. http://dx.doi.org/10.1083/jcb.201505086 
202. Salogiannis J, Egan MJ, Reck-Peterson SL. 2016. Peroxisomes move by hitchhiking on early endosomes using the novel linker protein PxdA. J Cell Biol 212:289-296. http://dx.doi.org/10.1083/jcb.201512020 203. Lin C, Schuster M, Guimaraes SC, Ashwin P, Schrader M, Metz J, Hacker C, Gurr SJ, Steinberg G. 2016. Active diffusion and microtubulebased transport oppose myosin forces to position organelles in cells. Nat Commun 7:11814. http://dx.doi.org/10.1038/ncomms11814

204. Salogiannis J, Reck-Peterson SL. 2017. Hitchhiking: a non-canonical mode of microtubule-based transport. Trends Cell Biol 27:141-150. http://dx.doi.org/10.1016/j.tcb.2016.09.005

205. Baumann S, König J, Koepke J, Feldbrügge M. 2014. Endosomal transport of septin mRNA and protein indicates local translation on endosomes and is required for correct septin filamentation. EMBO Rep 15:94-102. http://dx.doi.org/10.1002/embr.201338037

206. Zander S, Baumann S, Weidtkamp-Peters S, Feldbrügge $M$. 2016. Endosomal assembly and transport of heteromeric septin complexes promote septin cytoskeleton formation. J Cell Sci 129:2778-2792. http://dx.doi.org/10.1242/jcs.182824

207. Fink G, Steinberg G. 2006. Dynein-dependent motility of microtubules and nucleation sites supports polarization of the tubulin array in the fungus Ustilago maydis. Mol Biol Cell 17:3242-3253. http://dx.doi .org/10.1091/mbc.E05-12-1118

208. Steinberg G, Wedlich-Söldner R, Brill M, Schulz I. 2001. Microtubules in the fungal pathogen Ustilago maydis are highly dynamic and determine cell polarity. J Cell Sci 114:609-622.

209. Schrader M, Godinho LF, Costello JL, Islinger M. 2015. The different facets of organelle interplay: an overview of organelle interactions. Front Cell Dev Biol 3:56. http://dx.doi.org/10.3389/fcell.2015.00056

210. Egan MJ, McClintock MA, Hollyer IH, Elliott HL, Reck-Peterson SL. 2015. Cytoplasmic dynein is required for the spatial organization of protein aggregates in filamentous fungi. Cell Reports 11:201-209. http://dx.doi.org/10.1016/j.celrep.2015.03.028

211. Chumley FG, Valent B. 1990. Genetic analysis of melanin deficient, nonpathogenic mutants of Magnaporthe grisea. Mol Plant Microbe Interact 3:135-143. http://dx.doi.org/10.1094/MPMI-3-135

212. Gómez BL, Nosanchuk JD. 2003. Melanin and fungi. Curr Opin Infect Dis 16:91-96. http://dx.doi.org/10.1097/00001432-200304000-00005

213. Nosanchuk JD, Casadevall A. 2006. Impact of melanin on microbial virulence and clinical resistance to antimicrobial compounds. Antimicrob Agents Chemother 50:3519-3528. http://dx.doi.org/10.1128/AAC.00545 $\underline{-06}$

214. Jackson JC, Higgins LA, Lin X. 2009. Conidiation color mutants of Aspergillus fumigatus are highly pathogenic to the heterologous insect host Galleria mellonella. PLoS One 4:e4224. http://dx.doi.org/10.1371 ljournal.pone.0004224

215. Upadhyay S, Xu X, Lowry D, Jackson JC, Roberson RW, Lin X. 2016. Subcellular compartmentalization and trafficking of the biosynthetic machinery for fungal melanin. Cell Rep 14:2511-2518. http://dx .doi.org/10.1016/j.celrep.2016.02.059

216. Fuchs U, Manns I, Steinberg G. 2005. Microtubules are dispensable for the initial pathogenic development but required for long-distance hyphal growth in the corn smut fungus Ustilago maydis. Mol Biol Cell 16:2746-2758. http://dx.doi.org/10.1091/mbc.E05-03-0176

217. Miaczynska M, Pelkmans L, Zerial M. 2004. Not just a sink: endosomes in control of signal transduction. Curr Opin Cell Biol 16:400406. http://dx.doi.org/10.1016/j.ceb.2004.06.005

218. Steinberg G. 2007. On the move: endosomes in fungal growth and pathogenicity. Nat Rev Microbiol 5:309-316. http://dx.doi.org/10.1038 Inrmicro1618

219. Bielska E, Higuchi Y, Schuster M, Steinberg N, Kilaru S, Talbot NJ, Steinberg G. 2014. Long-distance endosome trafficking drives fungal effector production during plant infection. Nat Commun 5:5097. http://dx.doi.org/10.1038/ncomms6097
220. Djamei A, Schipper K, Rabe F, Ghosh A, Vincon V, Kahnt J, Osorio S, Tohge T, Fernie AR, Feussner I, Feussner K, Meinicke P, Stierhof YD, Schwarz H, Macek B, Mann M, Kahmann R. 2011. Metabolic priming by a secreted fungal effector. Nature 478:395-398. http://dx.doi.org /10.1038/nature10454

221. Doehlemann G, van der Linde K, Assmann D, Schwammbach D, Hof A, Mohanty A, Jackson D, Kahmann R. 2009. Pep1, a secreted effector protein of Ustilago maydis, is required for successful invasion of plant cells. PLoS Pathog 5:e1000290. http://dx.doi.org/10.1371/journal.ppat .1000290

222. Hemetsberger C, Herrberger C, Zechmann B, Hillmer M, Doehlemann G. 2012. The Ustilago maydis effector Pep1 suppresses plant immunity by inhibition of host peroxidase activity. PLoS Pathog 8: e1002684. http://dx.doi.org/10.1371/journal.ppat.1002684

223. Garrido E, Pérez-Martín J. 2003. The crk1 gene encodes an Ime2related protein that is required for morphogenesis in the plant pathogen Ustilago maydis. Mol Microbiol 47:729-743. http://dx.doi.org/10.1046 /j.1365-2958.2003.03323.x

224. Delgado-Álvarez DL, Bartnicki-García S, Seiler S, Mouriño-Pérez RR. 2014. Septum development in Neurospora crassa: the septal actomyosin tangle. PLoS One 9:e96744. http://dx.doi.org/10.1371/journal .pone.0096744

225. Momany M, Hamer JE. 1997. Relationship of actin, microtubules, and crosswall synthesis during septation in Aspergillus nidulans. Cell Motil Cytoskeleton 38:373-384. http://dx.doi.org/10.1002/(SICI)1097 -0169(1997)38:4<373::AID-CM7>3.0.CO;2-4

226. García Cortés JC, Ramos M, Osumi M, Pérez P, Ribas JC. 2016. The cell biology of fission yeast septation. Microbiol Mol Biol Rev 80:779_ 791. http://dx.doi.org/10.1128/MMBR.00013-16

227. Seiler S, Justa-Schuch D. 2010. Conserved components, but distinct mechanisms for the placement and assembly of the cell division machinery in unicellular and filamentous ascomycetes. Mol Microbiol 78:10581076. http://dx.doi.org/10.1111/j.1365-2958.2010.07392.x

228. Willet AH, McDonald NA, Gould KL. 2015. Regulation of contractile ring formation and septation in Schizosaccharomyces pombe. Curr Opin Microbiol 28:46-52. http://dx.doi.org/10.1016/j.mib.2015.08.001 229. Harris SD, Kraus PR. 1998. Regulation of septum formation in Aspergillus nidulans by a DNA damage checkpoint pathway. Genetics 148:1055-1067.

230. Wolkow TD, Harris SD, Hamer JE. 1996. Cytokinesis in Aspergillus nidulans is controlled by cell size, nuclear positioning and mitosis. J Cell Sci 109:2179-2188.

231. Si H, Rittenour WR, Xu K, Nicksarlian M, Calvo AM, Harris SD. 2012. Morphogenetic and developmental functions of the Aspergillus nidulans homologues of the yeast bud site selection proteins Bud4 and Axl2. Mol Microbiol 85:252-270. http://dx.doi.org/10.1111/j.1365-2958 $.2012 .08108 . \mathrm{x}$

232. Sharpless KE, Harris SD. 2002. Functional characterization and localization of the Aspergillus nidulans formin SEPA. Mol Biol Cell 13:469479. http://dx.doi.org/10.1091/mbc.01-07-0356

233. Virag A, Harris SD. 2006. Functional characterization of Aspergillus nidulans homologues of Saccharomyces cerevisiae Spa2 and Bud6. Eukaryot Cell 5:881-895. http://dx.doi.org/10.1128/EC.00036-06

234. Cotado-Sampayo M, Ortega Pérez R, Ojha M, Seum C, Barja F. 2011. Characterization of Neurospora crassa $\alpha$-actinin. Curr Microbiol 63:100-105. http://dx.doi.org/10.1007/s00284-011-9954-9

235. Wang J, Hu H, Wang S, Shi J, Chen S, Wei H, Xu X, Lu L. 2009. The important role of actinin-like protein (AcnA) in cytokinesis and apical dominance of hyphal cells in Aspergillus nidulans. Microbiology 155: 2714-2725. http://dx.doi.org/10.1099/mic.0.029215-0

236. Ichinomiya M, Yamada E, Yamashita S, Ohta A, Horiuchi H. 2005. Class I and class II chitin synthases are involved in septum formation in the filamentous fungus Aspergillus nidulans. Eukaryot Cell 4:1125-1136. http://dx.doi.org/10.1128/EC.4.6.1125-1136.2005 
237. Berlin A, Paoletti A, Chang F. 2003. Mid2p stabilizes septin rings during cytokinesis in fission yeast. J Cell Biol 160:1083-1092. http://dx .doi.org/10.1083/jcb.200212016

238. Kang PJ, Hood-DeGrenier JK, Park HO. 2013. Coupling of septins to the axial landmark by Bud4 in budding yeast. J Cell Sci 126:12181226. http://dx.doi.org/10.1242/jcs.118521

239. Berepiki A, Read ND. 2013. Septins are important for cell polarity, septation and asexual spore formation in Neurospora crassa and show different patterns of localisation at germ tube tips. PLoS One 8:e63843. http://dx.doi.org/10.1371/journal.pone.0063843

240. Juvvadi PR, Fortwendel JR, Rogg LE, Steinbach WJ. 2011. Differential localization patterns of septins during growth of the human fungal pathogen Aspergillus fumigatus reveal novel functions. Biochem Biophys Res Commun 405:238-243. http://dx.doi.org/10.1016/j.bbrc.2011.01 .017

241. Lindsey R, Cowden S, Hernández-Rodríguez Y, Momany M. 2010. Septins AspA and AspC are important for normal development and limit the emergence of new growth foci in the multicellular fungus Aspergillus nidulans. Eukaryot Cell 9:155-163. http://dx.doi.org/10.1128 /EC.00269-09

242. Vargas-Muñiz JM, Renshaw H, Richards AD, Waitt G, Soderblom EJ, Moseley MA, Asfaw Y, Juvvadi PR, Steinbach WJ. 2016. Dephosphorylation of the core septin, AspB, in a protein phosphatase 2Adependent manner impacts its localization and function in the fungal pathogen Aspergillus fumigatus. Front Microbiol 7:997. http://dx.doi.org $\underline{\text { /10.3389/fmicb.2016.00997 }}$

243. Rasmussen CG, Glass NL. 2005. A Rho-type GTPase, rho-4, is required for septation in Neurospora crassa. Eukaryot Cell 4:1913-1925. http://dx.doi.org/10.1128/EC.4.11.1913-1925.2005

244. Simanis V. 2015. Pombe's thirteen: control of fission yeast cell division by the septation initiation network. J Cell Sci 128:1465-1474. http://dx.doi.org/10.1242/jcs.094821

245. Bruno KS, Morrell JL, Hamer JE, Staiger CJ. 2001. SEPH, a Cdc7p orthologue from Aspergillus nidulans, functions upstream of actin ring formation during cytokinesis. Mol Microbiol 42:3-12. http://dx.doi.org $\underline{\text { /10.1046/j.1365-2958.2001.02605.x }}$

246. Kim JM, Lu L, Shao R, Chin J, Liu B. 2006. Isolation of mutations that bypass the requirement of the septation initiation network for septum formation and conidiation in Aspergillus nidulans. Genetics 173:685696. http://dx.doi.org/10.1534/genetics.105.054304

247. Kim JM, Zeng CJ, Nayak T, Shao R, Huang AC, Oakley BR, Liu B. 2009. Timely septation requires SNAD-dependent spindle pole body localization of the septation initiation network components in the filamentous fungus Aspergillus nidulans. Mol Biol Cell 20:2874-2884. http://dx.doi.org/10.1091/mbc.E08-12-1177

248. Min K, Son H, Lim JY, Choi GJ, Kim JC, Harris SD, Lee YW. 2014. Transcription factor RFX1 is crucial for maintenance of genome integrity in Fusarium graminearum. Eukaryot Cell 13:427-436. http://dx.doi.org /10.1128/EC.00293-13

249. Bracker CE, Butler EE. 1963. The ultrastructure and development of septa in hyphae of Rhizoctonia solani. Mycologia 55:35-58. http://dx .doi.org/10.2307/3756380

250. Bracker CE, Butler EE. 1964. Function of the septal pore apparatus in Rhizoctonia solani during protoplasmic streaming. J Cell Biol 21:152157. http://dx.doi.org/10.1083/jcb.21.1.152

251. Gull K. 1978. Form and function of septa in filamentous fungi, p 7893. In Smith JE (ed), The Filamentous Fungi: Developmental Mycology, vol 3. Edward Arnold, London, United Kingdom.

252. Moore RT, McAlear JH. 1962. Fine structure of mycota. 7. Observations on septa of ascomycetes and basidiomycetes. Am J Bot 49:86-94. http://dx.doi.org/10.2307/2439393

253. Jennings DH. 1987. Translocation of solutes in fungi. Biol Rev Camb Philos Soc 62:215-243. http://dx.doi.org/10.1111/j.1469-185X.1987. $\underline{\text { tb00664.x }}$
254. Lew RR. 2005. Mass flow and pressure-driven hyphal extension in Neurospora crassa. Microbiology 151:2685-2692. http://dx.doi.org /10.1099/mic.0.27947-0

255. Wösten HA, Moukha SM, Sietsma JH, Wessels JG. 1991. Localization of growth and secretion of proteins in Aspergillus niger. J Gen Microbiol 137:2017-2023. http://dx.doi.org/10.1099/00221287-137-8-2017

256. Levin AM, de Vries RP, Conesa A, de Bekker C, Talon M, Menke HH, van Peij NN, Wösten HA. 2007. Spatial differentiation in the vegetative mycelium of Aspergillus niger. Eukaryot Cell 6:2311-2322. http:// dx.doi.org/10.1128/EC.00244-07

257. de Bekker C, Bruning O, Jonker MJ, Breit TM, Wösten HA. 2011. Single cell transcriptomics of neighboring hyphae of Aspergillus niger. Genome Biol 12:R71. http://dx.doi.org/10.1186/gb-2011-12-8-r71

258. de Bekker C, van Veluw GJ, Vinck A, Wiebenga LA, Wösten HA. 2011. Heterogeneity of Aspergillus niger microcolonies in liquid shaken cultures. Appl Environ Microbiol 77:1263-1267. http://dx.doi.org/10.1128 /AEM.02134-10

259. Krijgsheld P, Altelaar AF, Post H, Ringrose JH, Müller WH, Heck AJ, Wösten HA. 2012. Spatially resolving the secretome within the mycelium of the cell factory Aspergillus niger. J Proteome Res 11:2807-2818. http://dx.doi.org/10.1021/pr201157b

260. Krijgsheld P, Nitsche BM, Post H, Levin AM, Müller WH, Heck AJ, Ram AF, Altelaar AF, Wösten HA. 2013. Deletion of flbA results in increased secretome complexity and reduced secretion heterogeneity in colonies of Aspergillus niger. J Proteome Res 12:1808-1819. http://dx .doi.org/10.1021/pr301154w

261. Bleichrodt RJ, van Veluw GJ, Recter B, Maruyama J, Kitamoto K, Wösten HA. 2012. Hyphal heterogeneity in Aspergillus oryzae is the result of dynamic closure of septa by Woronin bodies. Mol Microbiol 86:13341344. http://dx.doi.org/10.1111/mmi.12077

262. Teertstra WR, Lugones LG, Wösten HA. 2004. In situ hybridisation in filamentous fungi using peptide nucleic acid probes. Fungal Genet Biol 41:1099-1103. http://dx.doi.org/10.1016/j.fgb.2004.08.010

263. van Veluw GJ, Teertstra WR, de Bekker C, Vinck A, van Beek N, Muller WH, Arentshorst M, van der Mei HC, Ram AF, Dijksterhuis J, Wösten HA. 2013. Heterogeneity in liquid shaken cultures of Aspergillus niger inoculated with melanised conidia or conidia of pigmentation mutants. Stud Mycol 74:47-57. http://dx.doi.org/10.3114/sim0008

264. Vinck A, de Bekker C, Ossin A, Ohm RA, de Vries RP, Wösten HA. 2011. Heterogenic expression of genes encoding secreted proteins at the periphery of Aspergillus niger colonies. Environ Microbiol 13:216-225. http://dx.doi.org/10.1111/j.1462-2920.2010.02322.x

265. Vinck A, Terlou M, Pestman WR, Martens EP, Ram AF, van den Hondel CA, Wösten HA. 2005. Hyphal differentiation in the exploring mycelium of Aspergillus niger. Mol Microbiol 58:693-699. http://dx.doi .org/10.1111/j.1365-2958.2005.04869.x

266. Riquelme M, Yarden O, Bartnicki-Garcia S, Bowman B, CastroLongoria E, Free SJ, Fleissner A, Freitag M, Lew RR, Mouriño-Pérez R, Plamann M, Rasmussen C, Richthammer C, Roberson RW, SanchezLeon E, Seiler S, Watters MK. 2011. Architecture and development of the Neurospora crassa hypha:- a model cell for polarized growth. Fungal Biol 115:446-474. http://dx.doi.org/10.1016/i.funbio.2011.02.008

267. Roberson RW, Abril M, Blackwell M, Letcher P, McLaughlin D, Mourino-Perez RR, Riquelme M, Uchida M. 2010. Hyphal structure, in cellular and molecular biology of filamentous fungi, p 8-24. In Borkovich K, Ebbole DJ (ed), Cellular and Molecular Biology of Filamentous Fungi. ASM Press, Washington, DC.

268. Heath IB. 1994. The cytoskeleton in hyphal growth, organelle movements, and mitosis, p 43-65. In Wessels JGH, Meinhardt F (ed), The Mycota I: Growth, Differentiation and Sexuality. Springer Verlag, Berlin, Germany. http://dx.doi.org/10.1007/978-3-662-11908-2_3

269. Simonin A, Palma-Guerrero J, Fricker M, Glass NL. 2012. Physiological significance of network organization in fungi. Eukaryot Cell 11: 1345-1352. http://dx.doi.org/10.1128/EC.00213-12 
270. Amir R, Steudle E, Levanon D, Hadar Y, Chet I. 1995. Turgor changes in Morchella esculenta during translocation and sclerotial formation. Exp Mycol 19:129-136. http://dx.doi.org/10.1006/emyc.1995.1015 271. Brownlee C, Jennings DH. 1982. The pathway of translocation in Serpula lacrimans. Trans Br Mycol Soc 79:401-407. http://dx.doi.org /10.1016/S0007-1536(82)80033-8

272. Abadeh A, Lew RR. 2013. Mass flow and velocity profiles in Neurospora hyphae: partial plug flow dominates intra-hyphal transport. Microbiology 159:2386-2394. http://dx.doi.org/10.1099/mic.0.071191-0 273. Lew RR, Levina NN, Walker SK, Garrill A. 2004. Turgor regulation in hyphal organisms. Fungal Genet Biol 41:1007-1015. http://dx.doi.org /10.1016/j.fgb.2004.07.007

274. Brody JP, Yager P, Goldstein RE, Austin RH. 1996. Biotechnology at low Reynolds numbers. Biophys J 71:3430-3441. http://dx.doi.org /10.1016/S0006-3495(96)79538-3

275. Steinberg G, Schliwa M. 1996. Characterization of the biophysical and motility properties of kinesin from the fungus Neurospora crassa. J Biol Chem 271:7516-7521. http://dx.doi.org/10.1074/jbc.271.13.7516 276. Ramos-García SL, Roberson RW, Freitag M, Bartnicki-García S, Mouriño-Pérez RR. 2009. Cytoplasmic bulk flow propels nuclei in mature hyphae of Neurospora crassa. Eukaryot Cell 8:1880-1890. http://dx.doi .org/10.1128/EC.00062-09

277. Xiang X, Plamann M. 2003. Cytoskeleton and motor proteins in filamentous fungi. Curr Opin Microbiol 6:628-633. http://dx.doi.org $\underline{\text { /10.1016/j.mib.2003.10.009 }}$

278. Steinberg G. 2000. The cellular roles of molecular motors in fungi. Trends Microbiol 8:162-168. http://dx.doi.org/10.1016/S0966-842X(00) $\underline{01720-0}$

279. Bleichrodt RJ, Hulsman M, Wösten HA, Reinders MJ. 2015. Switching from a unicellular to multicellular organization in an Aspergillus niger hypha. MBio 6:e00111-15. http://dx.doi.org/10.1128/mBio $.00111-15$

280. Meijer WH, Gidijala L, Fekken S, Kiel JA, van den Berg MA, Lascaris R, Bovenberg RA, van der Klei IJ. 2010. Peroxisomes are required for efficient penicillin biosynthesis in Penicillium chrysogenum. Appl Environ Microbiol 76:5702-5709. http://dx.doi.org/10.1128/AEM.02327-09

281. Pieuchot L, Lai J, Loh RA, Leong FY, Chiam KH, Stajich J, Jedd G. 2015. Cellular subcompartments through cytoplasmic streaming. Dev Cell 34:410-420. http://dx.doi.org/10.1016/j.devcel.2015.07.017

282. Bleichrodt RJ, Vinck A, Read ND, Wösten HA. 2015. Selective transport between heterogeneous hyphal compartments via the plasma membrane lining septal walls of Aspergillus niger. Fungal Genet Biol 82:193-200. http://dx.doi.org/10.1016/j.fgb.2015.06.010

283. Reynaga-Peña CG, Bartnicki-Garcia S. 1997. Apical branching in a temperature sensitive mutant of Aspergillus niger. Fungal Genet Biol 22:153-167. http://dx.doi.org/10.1006/fgbi.1997.1003

284. Reynaga-Peña CG, Bartnicki-García S. 2005. Cytoplasmic contractions in growing fungal hyphae and their morphogenetic consequences. Arch Microbiol 183:292-300. http://dx.doi.org/10.1007/s00203-005-0771-z

285. Forment JV, Flipphi M, Ramón D, Ventura L, Maccabe AP. 2006. Identification of the mstE gene encoding a glucose-inducible, low affinity glucose transporter in Aspergillus nidulans. J Biol Chem 281:8339-8346. http://dx.doi.org/10.1074/jbc.M508198200

286. Gow NAR, Gooday GW, Newsam RJ, Gull K. 1980. Ultrastructure of the septum in Candida albicans. Curr Microbiol 4:357-359. http://dx .doi.org/10.1007/BF02605377

287. Trinci AP, Collinge AJ. 1973. Structure and plugging of septa of wild type and spreading colonial mutants of Neurospora crassa. Arch Mikrobiol 91:355-364. http://dx.doi.org/10.1007/BF00425054

288. Freitag M, Hickey PC, Raju NB, Selker EU, Read ND. 2004. GFP as a tool to analyze the organization, dynamics and function of nuclei and microtubules in Neurospora crassa. Fungal Genet Biol 41:897-910. http://dx.doi.org/10.1016/j.fgb.2004.06.008
289. Markham P. 1994. Occlusions of septal pores in filamentous fungi. Mycol Res 98:1089-1106. http://dx.doi.org/10.1016/S0953-7562(09) 80195-0

290. Aylmore RC, Wakley GE, Todd NK. 1984. Septal sealing in the basidiomycete Coriolus versicolor. Microbiology 130:2975-2982. http://dx.doi.org/10.1099/00221287-130-11-2975

291. van Peer AF, Müller WH, Boekhout T, Lugones LG, Wösten HA. 2009. Cytoplasmic continuity revisited: closure of septa of the filamentous fungus Schizophyllum commune in response to environmental conditions. PLoS One 4:e5977. http://dx.doi.org/10.1371/journal.pone.0005977

292. Wilsenach R, Kessel M. 1965. On the function and structure of the septal pore of Polyporus rugulosus. J Gen Microbiol 40:397-400. http://dx.doi.org/10.1099/00221287-40-3-397

293. Giesy RM, Day PR. 1965. The septal pores of Coprinus lagopus in relation to nuclear migration. Am J Bot 52:287-293. http://dx.doi.org /10.2307/2439942

294. van Driel KG, van Peer AF, Grijpstra J, Wösten HA, Verkleij AJ, Müller WH, Boekhout T. 2008. Septal pore cap protein SPC18, isolated from the basidiomycetous fungus Rhizoctonia solani, also resides in pore plugs. Eukaryot Cell 7:1865-1873. http://dx.doi.org/10.1128/EC.00125 $-08$

295. van Peer AF, Wang F, van Driel KG, de Jong JF, van Donselaar EG, Müller WH, Boekhout T, Lugones LG, Wösten HA. 2010. The septal pore cap is an organelle that functions in vegetative growth and mushroom formation of the wood-rot fungus Schizophyllum commune. Environ Microbiol 12:833-844. http://dx.doi.org/10.1111/j.1462-2920.2009.02122.x

296. Engh I, Würtz C, Witzel-Schlömp K, Zhang HY, Hoff B, Nowrousian M, Rottensteiner H, Kück U. 2007. The WW domain protein PRO40 is required for fungal fertility and associates with Woronin bodies. Eukaryot Cell 6:831-843. http://dx.doi.org/10.1128/EC.00269-06

297. Fleissner A, Glass NL. 2007. SO, a protein involved in hyphal fusion in Neurospora crassa, localizes to septal plugs. Eukaryot Cell 6:84-94. http://dx.doi.org/10.1128/EC.00268-06

298. Maruyama J, Escaño CS, Kitamoto K. 2010. AoSO protein accumulates at the septal pore in response to various stresses in the filamentous fungus Aspergillus oryzae. Biochem Biophys Res Commun 391: 868-873. http://dx.doi.org/10.1016/j.bbrc.2009.11.154

299. Tsukasaki W, Saeki K, Katayama T, Maruyama J, Kitamoto K. 2016. Molecular dissection of SO (SOFT) protein in stress-induced aggregation and cell-to-cell interactive functions in filamentous fungal multicellularity. Fungal Biol 120:775-782. http://dx.doi.org/10.1016/j.funbio .2016 .02 .001

300. Fleissner A, Sarkar S, Jacobson DJ, Roca MG, Read ND, Glass NL. 2005. The so locus is required for vegetative cell fusion and postfertilization events in Neurospora crassa. Eukaryot Cell 4:920-930. http:// dx.doi.org/10.1128/EC.4.5.920-930.2005

301. Maruyama J, Juvvadi PR, Ishi K, Kitamoto K. 2005. Threedimensional image analysis of plugging at the septal pore by Woronin body during hypotonic shock inducing hyphal tip bursting in the filamentous fungus Aspergillus oryzae. Biochem Biophys Res Commun 331: 1081-1088. http://dx.doi.org/10.1016/j.bbrc.2005.03.233

302. Shen KF, Osmani AH, Govindaraghavan M, Osmani SA. 2014. Mitotic regulation of fungal cell-to-cell connectivity through septal pores involves the NIMA kinase. Mol Biol Cell 25:763-775. http://dx.doi.org /10.1091/mbc.E13-12-0718

303. Govindaraghavan M, Lad AA, Osmani SA. 2014. The NIMA kinase is required to execute stage-specific mitotic functions after initiation of mitosis. Eukaryot Cell 13:99-109. http://dx.doi.org/10.1128/EC $.00231-13$

304. Lai J, Koh CH, Tjota M, Pieuchot L, Raman V, Chandrababu KB, Yang D, Wong L, Jedd G. 2012. Intrinsically disordered proteins aggregate at fungal cell-to-cell channels and regulate intercellular connectivity. Proc Natl Acad Sci USA 109:15781-15786. http://dx.doi.org/10.1073 Ipnas.1207467109 
305. Buller AHR. 1933 . Researches on Fungi, p 75-167. Longmans and Green. London, United Kingdom.

306. Woronin M. 1865. Zur Entwicklungsgeschichte des Ascobolus pulcherrimus Cr. und einiger Pezizen. Abh Senckenb Nat Gesell 5:333-344. 307. Markham P, Collinge AJ. 1987. Woronin bodies of filamentous fungi. FEMS Microbiol Rev 46:1-11. http://dx.doi.org/10.1111/j.1574 -6968.1987.tb02448.x

308. Beck J, Ebel F. 2013. Characterization of the major Woronin body protein HexA of the human pathogenic mold Aspergillus fumigatus. Int J Med Microbiol 303:90-97. http://dx.doi.org/10.1016/j.ijmm.2012.11.005 309. Momany M, Richardson EA, Van Sickle C, Jedd G. 2002. Mapping Woronin body position in Aspergillus nidulans. Mycologia 94:260-266. http://dx.doi.org/10.2307/3761802

310. Collinge AJ, Markham P. 1985. Woronin bodies rapidly plug septal pores of severed Penicillium chrysogenum hyphae. Exp Mycol 9:80-85. http://dx.doi.org/10.1016/0147-5975(85)90051-9

311. Plamann M. 2009. Cytoplasmic streaming in neurospora: disperse the plug to increase the flow? PLoS Genet 5:e1000526. http://dx.doi.org 110.1371/journal.pgen.1000526

312. Brenner DM, Carroll GC. 1968. Fine-structural correlates of growth in hyphae of Ascodesmis sphaerospora. J Bacteriol 95:658-671.

313. Reichle RE, Alexander JV. 1965. Multiperforate septations, Woronin bodies, and septal plugs in Fusarium. J Cell Biol 24:489-496. http://dx .doi.org/10.1083/jcb.24.3.489

314. Trinci AP, Collinge AJ. 1974. Occlusion of the septal pores of damaged hyphae of Neurospora crassa by hexagonal crystals. Protoplasma 80:57-67. http://dx.doi.org/10.1007/BF01666351

315. Jedd G, Chua NH. 2000. A new self-assembled peroxisomal vesicle required for efficient resealing of the plasma membrane. Nat Cell Biol 2:226-231. http://dx.doi.org/10.1038/35008652

316. Tenney K, Hunt I, Sweigard J, Pounder JI, McClain C, Bowman EJ, Bowman BJ. 2000. Hex-1, a gene unique to filamentous fungi, encodes the major protein of the Woronin body and functions as a plug for septal pores. Fungal Genet Biol 31:205-217. http://dx.doi.org/10.1006/fgbi.2000.1230 317. Asiegbu FO, Choi W, Jeong JS, Dean RA. 2004. Cloning, sequencing and functional analysis of Magnaporthe grisea MVP1 gene, a hex-1 homolog encoding a putative 'woronin body' protein. FEMS Microbiol Lett 230:85-90. http://dx.doi.org/10.1016/S0378-1097(03)00858-9

318. Curach NC, Te’o VS, Gibbs MD, Bergquist PL, Nevalainen KM. 2004. Isolation, characterization and expression of the hex1 gene from Trichoderma reesei. Gene 331:133-140. http://dx.doi.org/10.1016/j.gene .2004 .02 .007

319. Managadze D, Würtz C, Wiese S, Meyer HE, Niehaus G, Erdmann R, Warscheid B, Rottensteiner H. 2010. A proteomic approach towards the identification of the matrix protein content of the two types of microbodies in Neurospora crassa. Proteomics 10:3222-3234. http://dx .doi.org/10.1002/pmic.201000095

320. Yuan P, Jedd G, Kumaran D, Swaminathan S, Shio H, Hewitt D, Chua NH, Swaminathan K. 2003. A HEX-1 crystal lattice required for Woronin body function in Neurospora crassa. Nat Struct Biol 10:264270. http://dx.doi.org/10.1038/nsb910

321. Markham P, Collinge AJ, Head JB, Poole RK. 1987. Is the spatial organization of fungal hyphae maintained and regulated by Woronin bodies?, p 79-99. In Poole RK, Trinci APJ (ed), Spatial Organization in Eukaryotic Microbes. IRL Press, Oxford, United Kingdom.

322. Wergin WP. 1973. Development of Woronin bodies from microbodies in Fusarium oxysporum f.sp. lycopersici. Protoplasma 76:249260. http://dx.doi.org/10.1007/BF01280701

323. Keller GA, Krisans S, Gould SJ, Sommer JM, Wang CC, Schliebs W, Kunau W, Brody S, Subramani S. 1991. Evolutionary conservation of a microbody targeting signal that targets proteins to peroxisomes, glyoxysomes, and glycosomes. J Cell Biol 114:893-904. http://dx.doi.org $\underline{110.1083 / j \mathrm{cb} .114 .5 .893}$
324. Tey WK, North AJ, Reyes JL, Lu YF, Jedd G. 2005. Polarized gene expression determines woronin body formation at the leading edge of the fungal colony. Mol Biol Cell 16:2651-2659. http://dx.doi.org/10.1091 Imbc.E04-10-0937

325. Liu F, Ng SK, Lu Y, Low W, Lai J, Jedd G. 2008. Making two organelles from one: woronin body biogenesis by peroxisomal protein sorting. J Cell Biol 180:325-339. http://dx.doi.org/10.1083/jcb.200705049 326. Beck J, Echtenacher B, Ebel F. 2013. Woronin bodies, their impact on stress resistance and virulence of the pathogenic mould Aspergillus fumigatus and their anchoring at the septal pore of filamentous Ascomycota. Mol Microbiol 89:857-871. http://dx.doi.org/10.1111/mmi .12316

327. Managadze D, Würtz C, Sichting M, Niehaus G, Veenhuis M, Rottensteiner H. 2007. The peroxin PEX14 of Neurospora crassa is essential for the biogenesis of both glyoxysomes and Woronin bodies. Traffic 8:687-701. http://dx.doi.org/10.1111/j.1600-0854.2007.00560.x 328. Escaño CS, Juvvadi PR, Jin FJ, Takahashi T, Koyama Y, Yamashita S, Maruyama J, Kitamoto K. 2009. Disruption of the Aopex11-1 gene involved in peroxisome proliferation leads to impaired Woronin body formation in Aspergillus oryzae. Eukaryot Cell 8:296-305. http://dx.doi .org/10.1128/EC.00197-08

329. Ramos-Pamplona M, Naqvi NI. 2006. Host invasion during riceblast disease requires carnitine-dependent transport of peroxisomal acetylCoA. Mol Microbiol 61:61-75. http://dx.doi.org/10.1111/j.1365-2958 $.2006 .05194 . \mathrm{x}$

330. Berns MW, Aist JR, Wright WH, Liang H. 1992. Optical trapping in animal and fungal cells using a tunable, near-infrared titanium-sapphire laser. Exp Cell Res 198:375-378. http://dx.doi.org/10.1016/0014-4827 (92)90395-O

331. Ng SK, Liu F, Lai J, Low W, Jedd G. 2009. A tether for Woronin body inheritance is associated with evolutionary variation in organelle positioning. PLoS Genet 5:e1000521. http://dx.doi.org/10.1371/journal .pgen.1000521

332. Han P, Jin FJ, Maruyama J, Kitamoto K. 2014. A large nonconserved region of the tethering protein Leashin is involved in regulating the position, movement, and function of Woronin bodies in Aspergillus oryzae. Eukaryot Cell 13:866-877. http://dx.doi.org/10.1128/EC.00060-14

333. Labeit D, Watanabe K, Witt C, Fujita H, Wu Y, Lahmers S, Funck T, Labeit S, Granzier H. 2003. Calcium-dependent molecular spring elements in the giant protein titin. Proc Natl Acad Sci USA 100:13716-13721. http://dx.doi.org/10.1073/pnas.2235652100

334. Soundararajan S, Jedd G, Li X, Ramos-Pamploña M, Chua NH, Naqvi NI. 2004. Woronin body function in Magnaporthe grisea is essential for efficient pathogenesis and for survival during nitrogen starvation stress. Plant Cell 16:1564-1574. http://dx.doi.org/10.1105/tpc.020677

335. Collinge AJ, Markham P. 1987. Response of severed Penicillium chrysogenum hyphae following rapid Woronin body plugging of septal pores. FEMS Microbiol Lett 40:165-168. http://dx.doi.org/10.1111 j.1574-6968.1987.tb02018.x

336. Sánchez-León E, Riquelme M. 2015. Live imaging of $\beta$-1,3-glucan synthase FKS-1 in Neurospora crassa hyphae. Fungal Genet Biol 82:104107. http://dx.doi.org/10.1016/j.fgb.2015.07.001

337. Sánchez-León E, Verdín J, Freitag M, Roberson RW, BartnickiGarcia S, Riquelme M. 2011. Traffic of chitin synthase 1 (CHS-1) to the Spitzenkörper and developing septa in hyphae of Neurospora crassa: actin dependence and evidence of distinct microvesicle populations. Eukaryot Cell 10:683-695. http://dx.doi.org/10.1128/EC.00280-10

338. Schuster M, Kilaru S, Guo M, Sommerauer M, Lin C, Steinberg G. 2015. Red fluorescent proteins for imaging Zymoseptoria tritici during invasion of wheat. Fungal Genet Biol 79:132-140. http://dx.doi.org /10.1016/j.fgb.2015.03.025

339. Schuster M, Kilaru S, Latz M, Steinberg G. 2015. Fluorescent markers of the microtubule cytoskeleton in Zymoseptoria tritici. Fungal Genet Biol 79:141-149. http://dx.doi.org/10.1016/i.fgb.2015.03.005 
340. Ma W, Kilaru S, Collins C, Courbot M, Steinberg G. 2015. Libraries for two-hybrid screening of yeast and hyphal growth forms in Zymoseptoria tritici. Fungal Genet Biol 79:94-101. http://dx.doi.org/10.1016 /j.fgb.2015.03.023

341. Guo M, Kilaru S, Schuster M, Steinberg G. 2015. Fluorescent markers for the Spitzenkörper and exocytosis in Zymoseptoria tritici. Fungal Genet Biol 79:158-165. http://dx.doi.org/10.1016/j.fgb.2015.04.014

342. Kilaru S, Ma W, Schuster M, Courbot M, Steinberg G. 2015. Conditional promoters for analysis of essential genes in Zymoseptoria tritici. Fungal Genet Biol 79:166-173. http://dx.doi.org/10.1016/j.fgb.2015.03.024

343. Kilaru S, Schuster M, Studholme D, Soanes D, Lin C, Talbot NJ, Steinberg G. 2015. A codon-optimized green fluorescent protein for live cell imaging in Zymoseptoria tritici. Fungal Genet Biol 79:125-131. http://dx.doi.org/10.1016/j.fgb.2015.03.022
344. Rabe F, Bosch J, Stirnberg A, Guse T, Bauer L, Seitner D, Rabanal FA, Czedik-Eysenberg A, Uhse S, Bindics J, Genenncher B, Navarrete F, Kellner R, Ekker H, Kumlehn J, Vogel JP, Gordon SP, Marcel TC, Münsterkötter M, Walter MC, Sieber CM, Mannhaupt G, Güldener U, Kahmann R, Djamei A. 2016. A complete toolset for the study of Ustilago bromivora and Brachypodium sp. as a fungal-temperate grass pathosystem. eLife 5:e20522. http://dx.doi.org/10.7554/eLife .20522

345. Beck J, Wagener J, Ebel F. 2013. The septal cell wall of filamentous fungi, p 129-142. In Mora-Montes HM (ed), The Fungal Cell Wall. Nova Publishers, New York, NY.

346. Moore RT, Marchant R. 1972. Ultrastructural characterization of the basidiomycete septum of Polyporus biennis. Can J Bot 50:2463-2469. http://dx.doi.org/10.1139/b72-317 